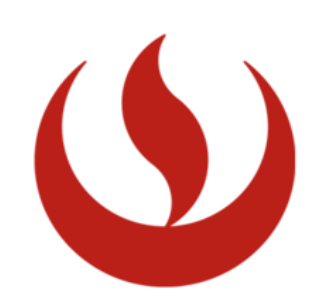

UNIVERSIDAD PERUANA DE CIENCIAS APLICADAS

FACULTAD DE NEGOCIOS

CARRERA DE ADMINISTRACIÓN DE EMPRESAS

\title{
APLICATIVO MOVIL : KALLPA TEXTIL
}

TRABAJO DE INVESTIGACION

Para optar el grado de Bachiller en Administración de Empresas

\author{
AUTOR(ES) : \\ Jayo Ryan, Fiorella Yazmin (0000-0001-8013-4946) \\ Mercado Alvarado, Pedro Luis (0000-0003-4249-956X) \\ Mondragon Vernal, Rodrigo Alejandro (0000-0002-9571-8263) \\ Silva Santisteban Sierra, Giancarlo (0000-0001-9431-1755) \\ ASESOR : \\ Ricardo Enrique Lora Álvarez (0000-0001-6969-8492)
}




\section{RESUMEN}

Nuestro proyecto empresarial, Kallpa Textil, es un aplicativo móvil para la selección y compra de distintas prendas elaboradas por talentosos diseñadores nacionales. Buscamos con esta idea, poder brindarle un impulso a un sector que no ha sido atendido de manera adecuada y otorgarle a la población un espacio virtual donde puedan seleccionar sus prendas desde la comodidad de su casa.

Los usuarios deberán registrarse en nuestra aplicación, al ingresar, podrán seleccionar sus prendas por: marca, precios, tallas, tipo de prenda, etc. Nuestra idea es que mediante pocos clicks, el cliente pueda realizar la compra.

La idea de negocio ha sido validada por diferentes herramientas, entre la que podemos destacar el Experiment Board, donde se confirmó que el $40.43 \%$ de potenciales clientes se encontraban interesados en la idea de negocio.

La inversión total del proyecto es de S/. 39,755 soles (treinta y nueve mil setecientos cincuenta y cinco con 0/100), donde se obtendrá una rentabilidad (TIR) de 42.79\%, un VAN de 31,252.12 (treinta y un mil doscientos cincuenta y dos con 12/100) y el retorno de la inversión en un periodo no mayor a 3 años. Todos estos datos se han obtenido con una tasa de descuento de $13.90 \%$.

Por lo que consideramos que llevar a cabo este proyecto es viable.

Palabras Clave : proyecto, aplicativo móvil, espacio virtual, aplicación, inversión total, idea de negocio, tasa interna de retorno, valor actual neto, retorno de la inversión, tasa de descuento. 


\begin{abstract}
Our business project, Kallpa Textil, is a mobile application for the selection and purchase of different garments made by talented national designers. We seek with this idea, to provide a boost to a sector that has not been adequately addressed and give the population a virtual space where they can select their clothes from the comfort of your home.

Users must register in our application, upon entering, they can select their garments by: brand, prices, sizes, type of garment, etc. Our idea is that with a few clicks, the customer can make the purchase.

The business idea has been validated by different tools, among which we can highlight the Experiment Board, where it was confirmed that $40.43 \%$ of potential customers were interested in the business idea.

The total investment of the project is S/. 39,755 soles (thirty-nine thousand seven hundred fifty-five with 0/100), where a return (IRR) of 42.79\%, a NPV of 31,252.12 (thirty-one thousand two hundred and fifty-two with 12/100) and the return will be obtained of the investment in a period no longer than 3 years. All these data have been obtained with a discount rate of $13.90 \%$.

For what we consider that carrying out this project is viable.
\end{abstract}

Keywords: project, mobile application, virtual space, application, total investment, business idea, internal rate of return, net real value, return on investment, discount rate. 


\section{TABLA DE CONTENIDO}

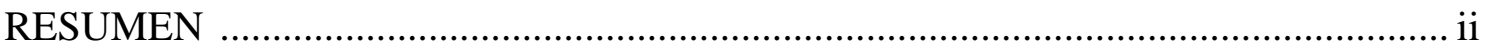

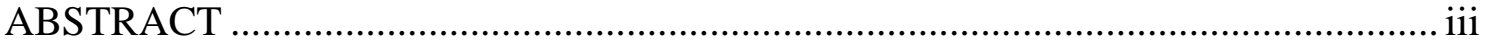

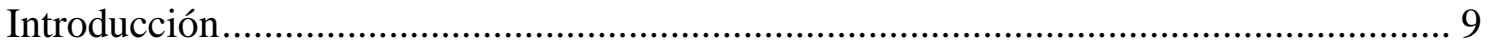

Capítulo 1. Aspectos Generales del Negocio ................................................................. 10

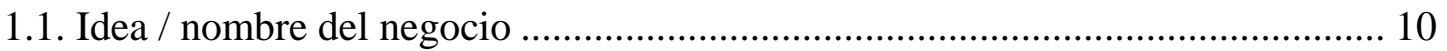

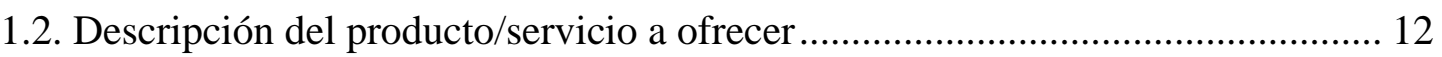

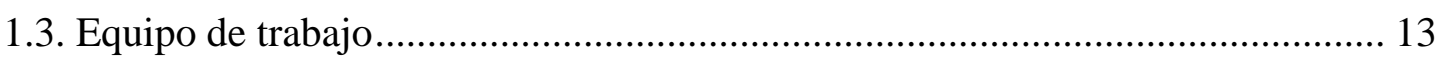

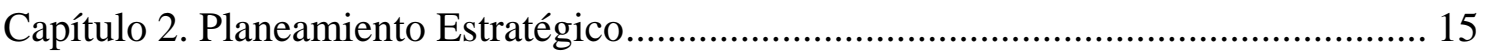

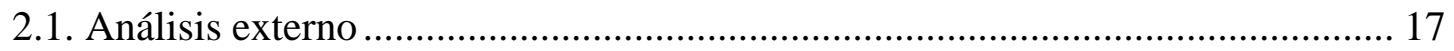

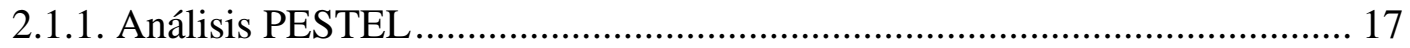

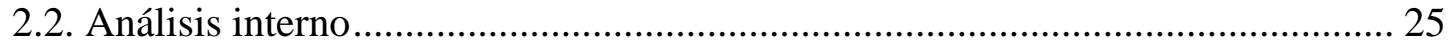

2.2.1. Análisis de las 5 fuerzas de Porter .............................................................. 25

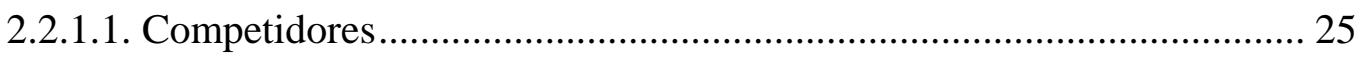

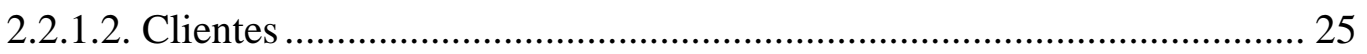

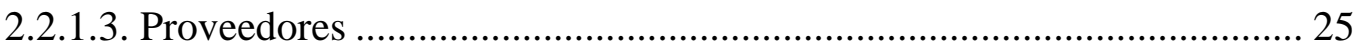

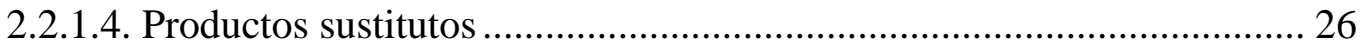

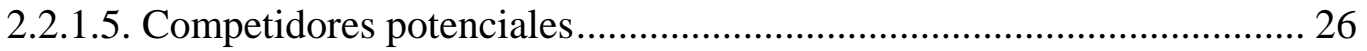

2.2.1.6. Consolidado de Oportunidades y Amenazas ......................................... 27

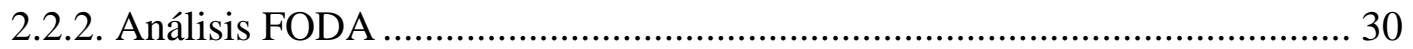

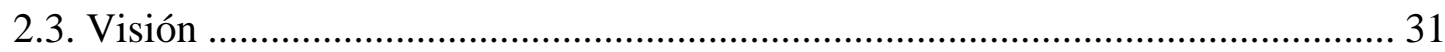

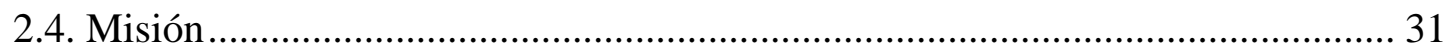

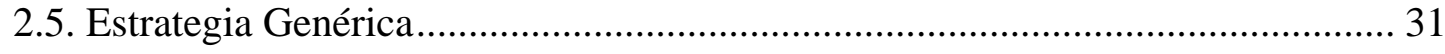

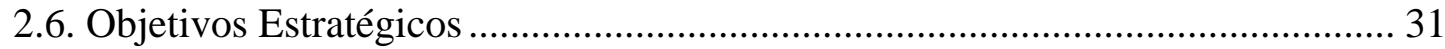

Capítulo 3. Investigación / Validación de mercado........................................................... 33

3.1. Diseño metodológico de la investigación / metodología de validación de hipótesis

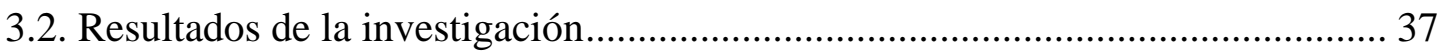

3.3. Resultado, decisión y aprendizaje: perseverar o pivotar. .................................. 40

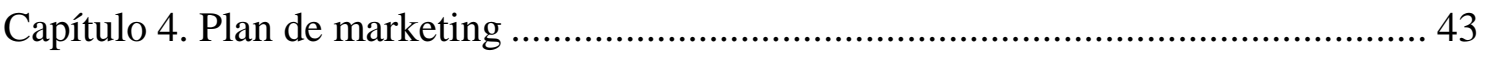

4.1. Planteamiento de objetivos de marketing .......................................................... 43 


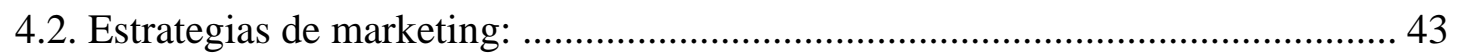

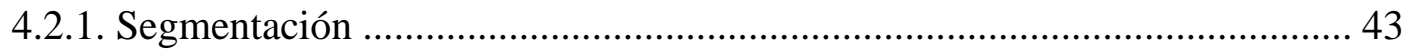

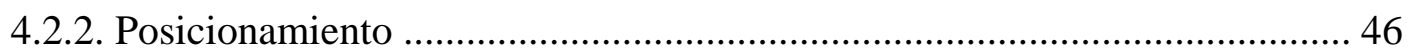

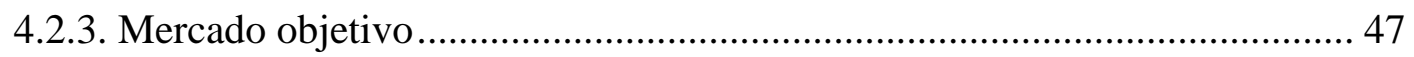

4.2.4. Tamaño de mercado disponible ............................................................. 48

4.2.5. Tamaño de mercado operativo (target) ....................................................... 48

4.2.6. Potencial de crecimiento del mercado ......................................................... 50

4.3. Desarrollo y estrategia del marketing mix ......................................................... 50

4.3.1. Estrategia de producto / servicio ................................................................. 50

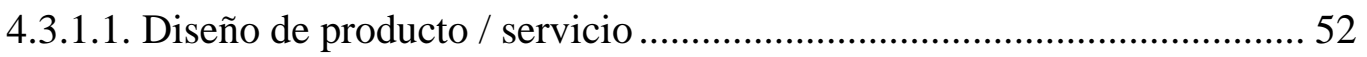

4.3.2. Estrategia de precios (Análisis de costos, precios de mercado) .................... 54

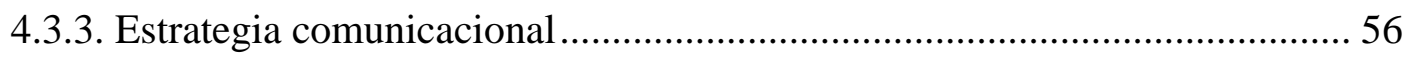

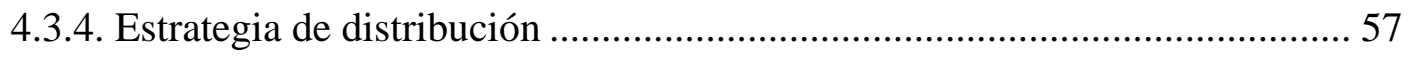

4.4. Plan de Ventas y Proyección de la Demanda ........................................................ 57

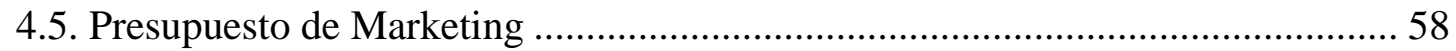

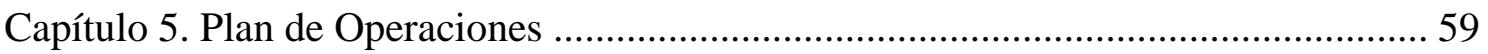

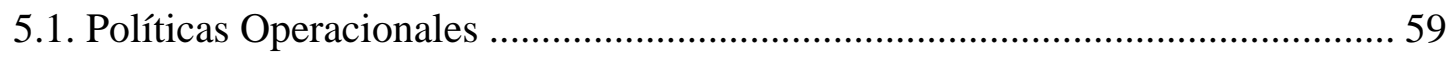

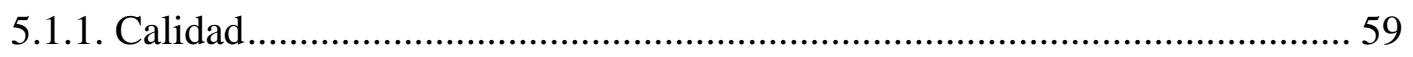

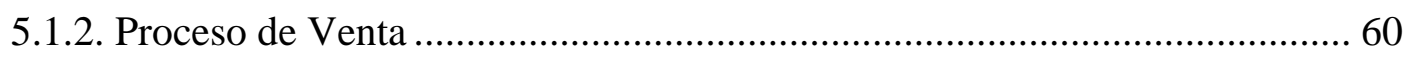

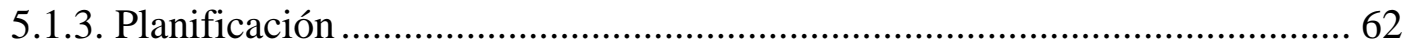

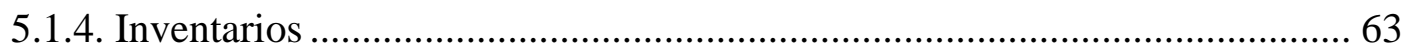

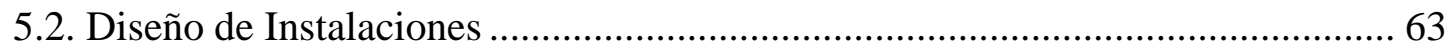

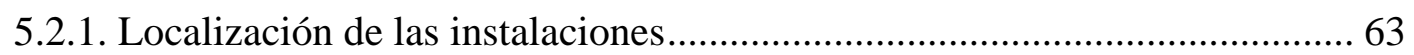

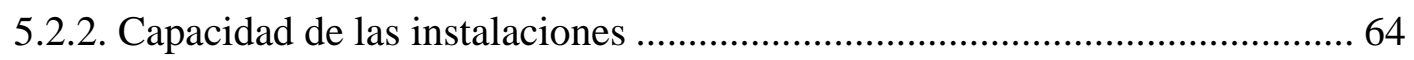

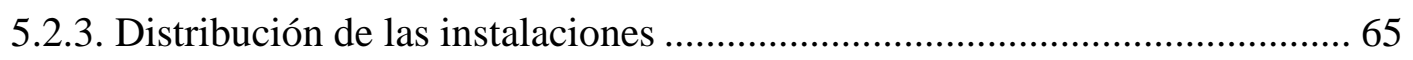

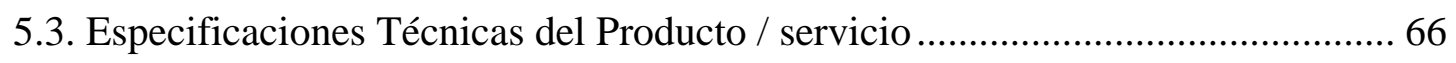

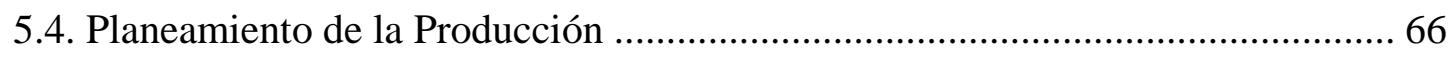

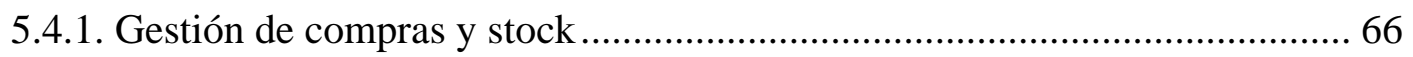

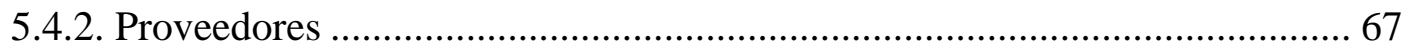

5.4.3. Inversión en activos fijos vinculados al proceso productivo........................ 68

5.4.4. Estructura de costos de producción y gastos operativos .............................. 69

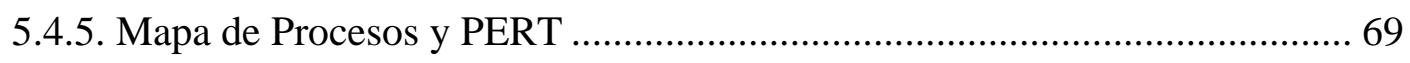

Capítulo 6. Estructura organizacional y recursos humanos........................................ 78

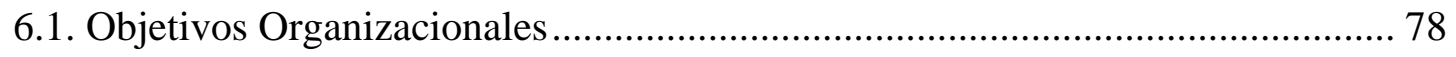




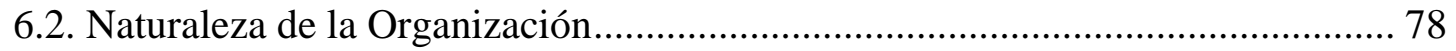

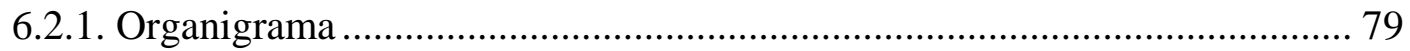

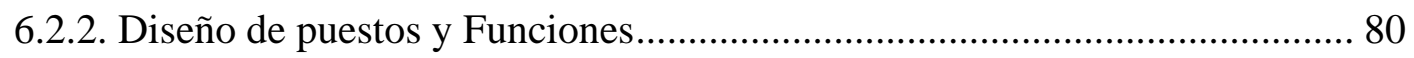

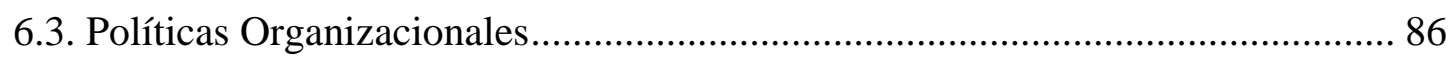

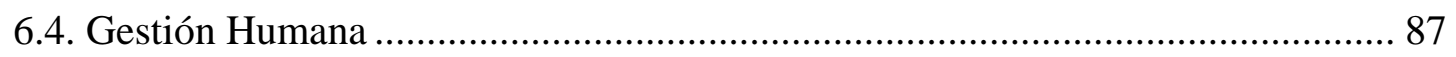

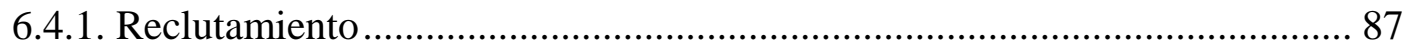

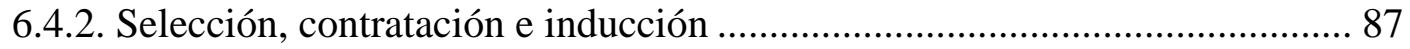

6.4.3. Capacitación, desarrollo y evaluación del desempeño ................................. 88

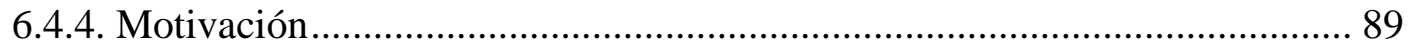

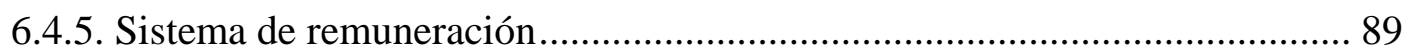

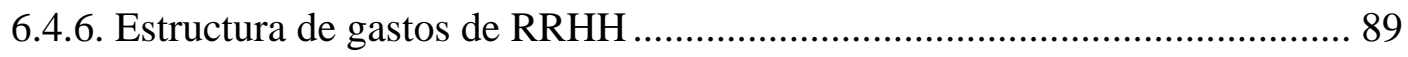

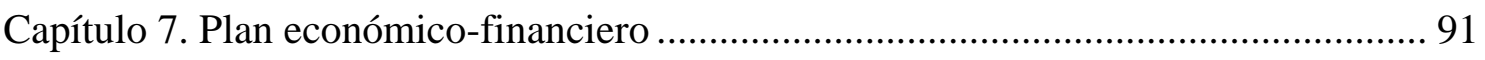

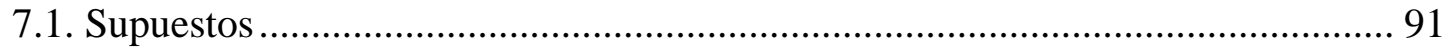

7.2. Inversión en activos (fijos e intangibles) y depreciación .................................... 92

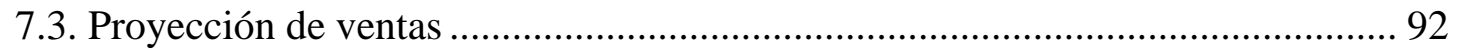

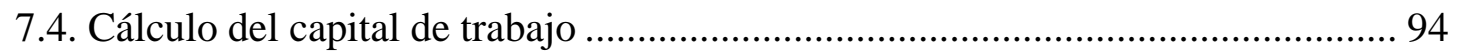

7.5. Estructura de financiamiento: Tradicional y no tradicional ............................... 94

7.6. Estados Financieros (Balance General, Estado de GGPP, Flujo de Caja) ........... 95

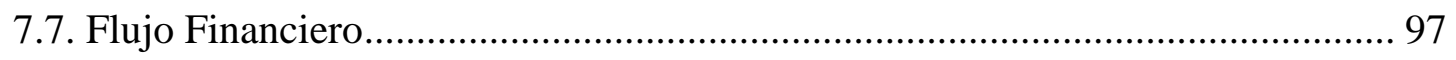

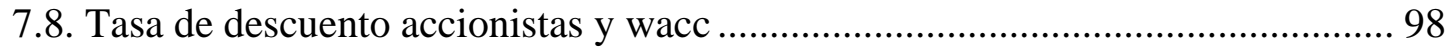

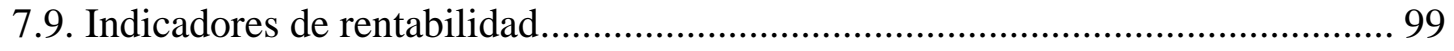

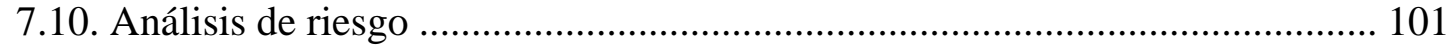

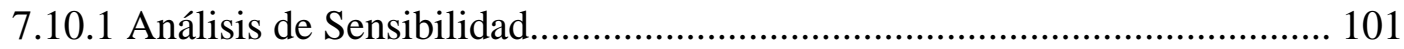

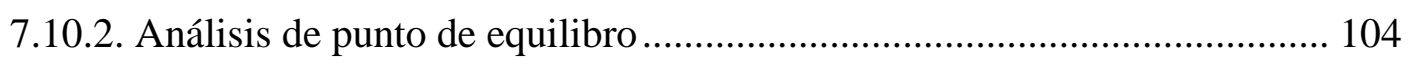

7.10.3. Principales riesgos del proyecto (cualitativos) ...................................... 104

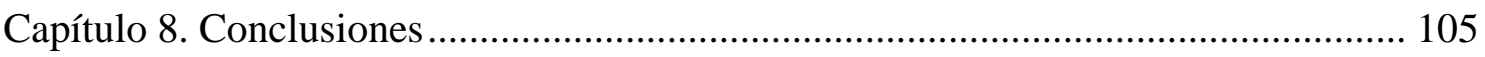

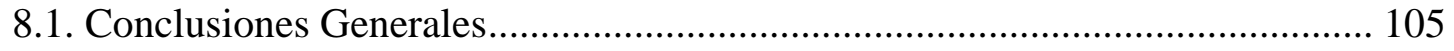

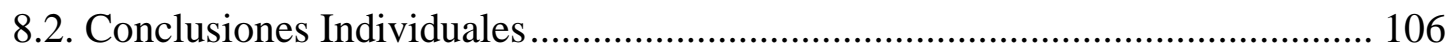

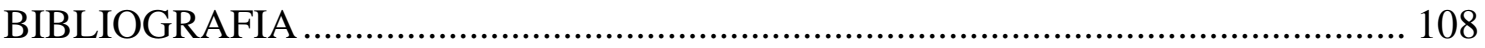




\section{INDICE DE TABLAS}

Tabla 1: Distribucion de los niveles socioeconómicos por Zonas ................................ 19

Tabla 2: Deuda a largo plazo en ME y MN de LATAM.............................................. 20

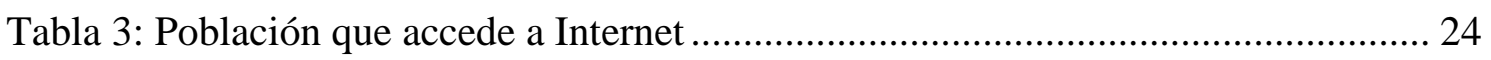

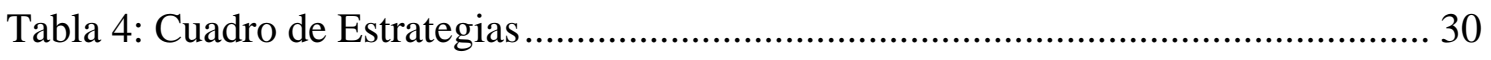

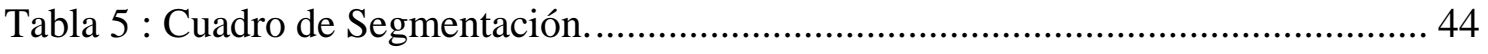

Tabla 6: Cuadro de Segmentación (Cuantitativo) .............................................................. 45

Tabla 7: Cuadro de Segmentación (Cuantitativo) ............................................................. 49

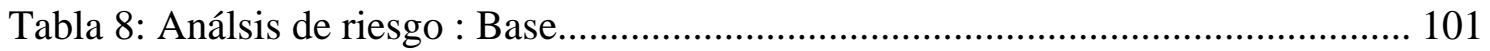

Tabla 9: Análsis de riesgo : Escenario pesimista ........................................................ 102

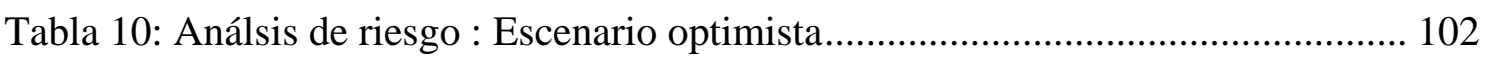

\section{INDICE DE FIGURAS}

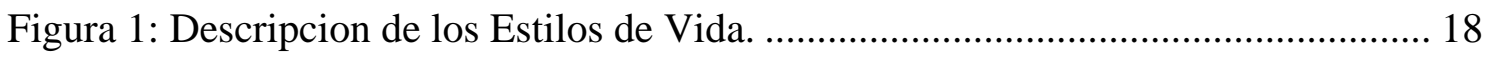

Figura 2: Distribución porcentual de los niveles socioeconómicos del Perú .................. 19

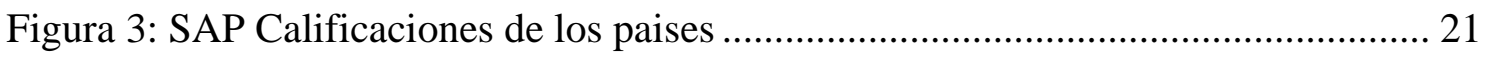

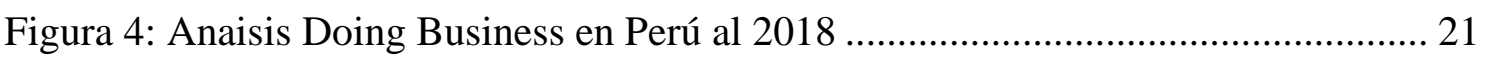

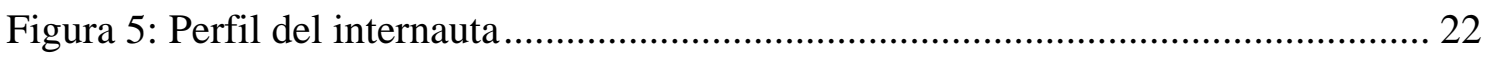

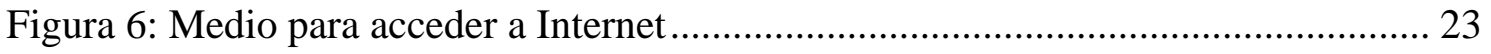

Figura 7: Preferencias de consumo Retail Online ...................................................... 24

Figura 8: Población que accede a Internet.................................................................... 24

Figura 9: Matriz de Analisis y Diagnosticos ...................................................................... 27

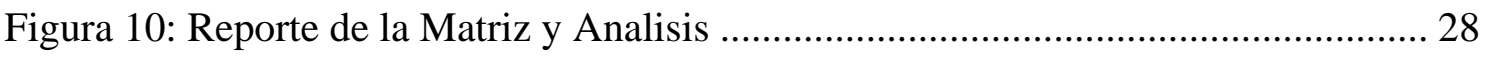

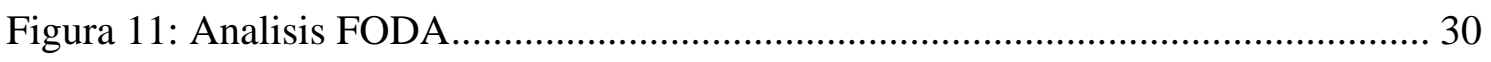

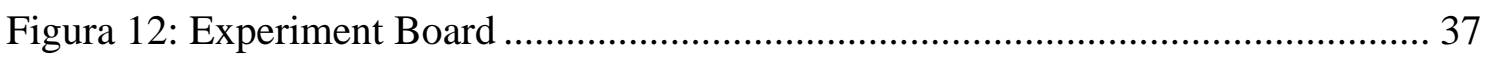

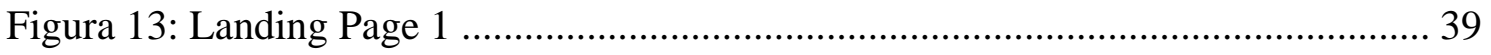

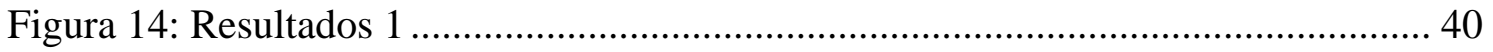

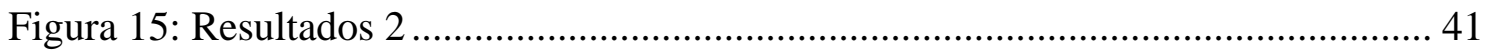

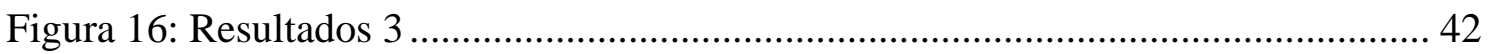

Figura 17: Distribución NSE en Lima Metropolitana ................................................ 45

Figura 18: Distribución NSE en Lima Metropolitana por Zonas .................................. 46

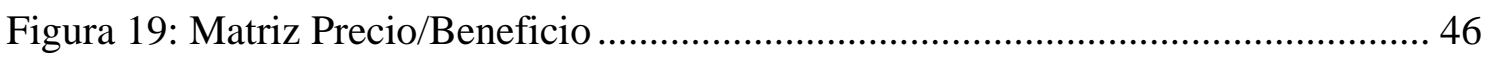

Figura 20. Características del consumidor peruano ….................................................. 47 


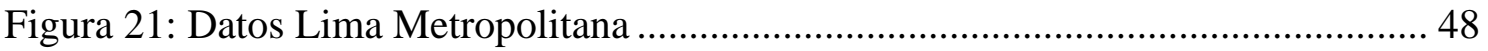

Figura 22: Distribución de habitantes por Distrito ......................................................... 49

Figura 23: Grafica de las cifras de los consumidores via Online ................................ 50

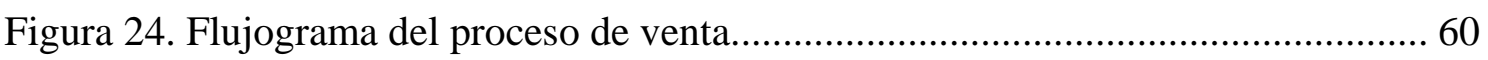

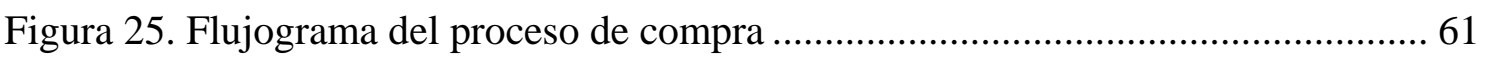

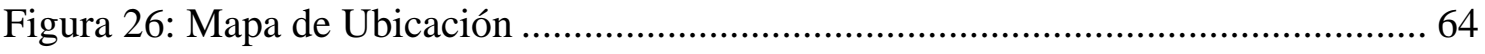

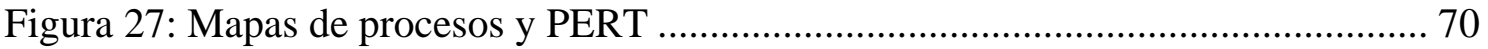




\section{Introducción}

Los negocios por internet y la era digital han impactado en la forma de hacer negocios hoy en dia existen muchas empresas que han migrado, algunas que han dejado de existir, otras que han que se han adaptado y por ultimo las nuevas propuestas.

Entre las formas de hacer negocios mas importantes tenemos las paginas webs y los aplicativos moviles en nuestro caso estamos planteando el uso de estas nuevas tecnologias, siendo mas especificos un aplicativo movil para venta de ropa de diseñadores nacionales, sacando provecho a la era digital y los bajos costes que se necesitan para llevar a cabo un negocio utilizando estos medios.

Por otro lado se tienen varios beneficios comerciales debido a la tendencia que hay actualmente en el mundo en lo que respecta a dispositivos moviles y el uso de la tecnologia en si, entre las mas importantes un canal de venta fuerte, la velocidad para hacer negocios, la forma sencilla de uso, el desollarrollo de la marca y la fidelizacion de clientes.

Consideramos que nuestro proyecto tendra buena acogida lo cual se sustenta con los distinto capitulos desarrollados en este trabajo de investigación, donde se podra encontrar informacion detallada acerca del mismo en todas sus etapas. En lo que respecta a limitaciones consideramos que la informacion acerca de este rubro en nuestro pais no es tan precisa ya que no se implementa mucho lo cual dificulta en cierta forma la recopilacion de informacion. 


\section{Capítulo 1. Aspectos Generales del Negocio}

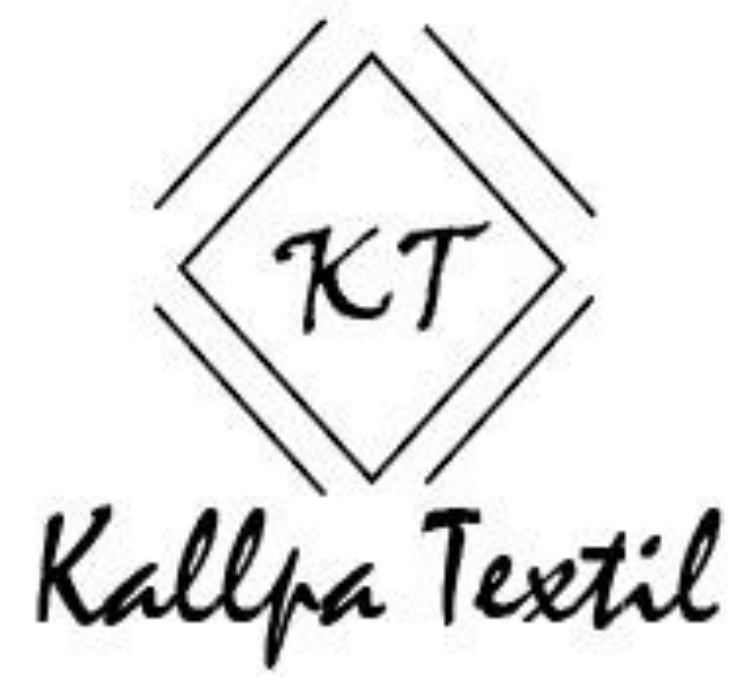

"Lo que construye una marca no es el mensaje, es la experiencia que se vive con ella"

\subsection{Idea / nombre del negocio}

El grupo de investigación, para el sector retail de indumentaria y moda, ha decidido lanzar al mercado un nuevo canal de ventas que afronte los distintos problemas por los que hoy en día atraviesa el sector. Estos problemas son varios, por lo que trataremos de especificar los más importantes en estas líneas, con la intención de plasmar la oportunidad de negocio presentada.

El sector, en su mayoría de empresas que la representan, ha presentado un decrecimiento en sus ventas anuales. Por un lado, existe una alta guerra cruzada de precios, ocasionada por el agresivo ingreso de distintas marcas de ropa (fast fashion) y la apertura de diversos centros comerciales, en donde se aperturan nuevas tiendas que ofrecen el mismo producto y que entran a competir con las ya existentes. Por otro lado, existe un tipo de cambio inestable, lo cual encarece el precio de las materias primas para la confección de las prendas y resulta en un incremento en el precio final para el consumidor (Semana Económica: 2016). 
Además de los problemas mencionados líneas arriba, se presentan otros inconvenientes que el sector debe afrontar. Estos problemas son los contratos que las empresas suscriben por el local en donde se encuentran ubicados. El precio de los arrendamientos para comercializar las prendas, en muchas ocasiones, supera el 30\% de las ventas totales, lo cual hace que la rentabilidad del negocio disminuya considerablemente (Semana Económica: 2016).

Asimismo, existen locales comerciales cuyo precio está en moneda extranjera (dólares americanos), por lo que el costo de alquiler está sujeto al tipo de cambio y genera un impacto mayor al rendimiento esperado por la organización ${ }^{1}$.

Todos estos factores mencionados, el alto costo del alquiler del local, la agresiva competencia que sigue ingresando con el transcurso de los años y un tipo de cambio inestable que encarece la elaboración del producto final, ocasionan que las empresas posicionadas disminuyan sus gastos en mejorar su productividad para generar mayores márgenes y se ha reflejado una disminución en la publicidad que le ofrecen al consumidor final, lo que afecta directamente al volumen de ventas esperado.

Frente a ello, un factor que encontró el grupo para generar la oportunidad de negocio fue un incremento significativo en el consumo online en el país. La Cámara Peruana de Comercio Electrónico indica que las ventas por internet alcanzaron los US\$ 2800 millones en el año 2016, lo que representa un incremento de casi $200 \%$ durante los 2 periodos anteriores (Gestión: 2017a).

Asimismo, según Ipsos Perú, el comercio e-commerce crecerá 11\% en el 2017 y 16\% para el 2018 y que, del total de consumidores digitales, el 57\% realiza las compras desde un Smartphone ${ }^{2}$.

El estudio también determinó que las categorías o bienes más adquiridos por aplicaciones o páginas webs son moda, calzado y ropa, con un $58 \%$ del total de compradores en línea ${ }^{3}$. Esta misma opinión la comparte en su tesis de posgrado, la autora María Mercedes Díaz Estela, quien afirma que existe una predisposición por adoptar en los clientes la modalidad online:

Según la investigación de mercados, a los clientes les gustaría recibir en su hogar las prendas de vestir y/o accesorios que compren a través de un sitio web, ya que ahorra dinero; está en la comodidad de su residencia, evita desplazarse, así mismo

\footnotetext{
${ }^{1}$ Cfr. Semana Económica: 2016.

${ }^{2}$ Cfr. Gestión: 2017a.

${ }^{3}$ Cfr. Gestión: 2017a.
} 
evita el caos vehicular de nuestra ciudad. A más de la mitad de las personas que se encuestaron (58\%) también les gustaría poder comprar por medio de un sitio web los artículos que ofreceremos (Díaz: 2016, p. 57).

Con base en la información encontrada, se visualiza que el sector está atravesando un momento complicado debido a los altos gastos que se necesitan para ofrecer el producto al público, la poca inversión que se realiza en publicidad y la volatilidad del dólar, lo cual encarece el precio de la confección de las prendas.

Por ello, y aprovechando las tendencias que marcan al perfil del consumidor nacional, se está presentando una nueva alternativa al sector, en donde los gastos invertidos en alquileres de locales con precios muy elevados se puedan realizar a otras tareas que han sido desatendidas y que son necesarias para el impulso de la industria nacional. Entonces, la propuesta que planteamos es utilizar el recurso de las ventas en línea mediante la creación de una app, con la intención de que los clientes encuentren diversidad en prendas de vestir creadas por diseñadores peruanos, variedad de estilos, así como también en diferentes tallas, cuyos stocks estarían siempre actualizándose. De esta forma, se abaratarían costos de alquiler, y se podría enfatizar en publicidad

\subsection{Descripción del producto/servicio a ofrecer}

Kallpa Textil es una página web y aplicación móvil que funciona como cualquier plataforma de compras online. En ella se comercializarán distintas variedades de prendas fabricadas por diseñadores nacionales, dando así un impulso a un sector golpeado por la entrada de productos elaborados en distintas partes del mundo a un costo muy por debajo de los que tiene la industria.

Se ofrecerá un amplio catálogo de marcas y prendas para que el cliente con solo unos cuantos clicks, tenga la posibilidad de adquirir sus productos desde la comodidad de su casa, trabajo o cualquier lugar en donde se encuentre.

La empresa realiza diversas actividades para el funcionamiento del negocio, en primer lugar, necesita una buena plataforma virtual en donde los clientes puedan visualizar, escoger y comprar los productos; para ello, se elaborará una página web y una aplicación dinámica en donde el cliente disfrute de buscar y seleccionar sus productos de una manera simple y ágil; la página ofrecerá comodidad a los clientes al recibir distintos modos de pago por los productos adquiridos. 
Otro punto importante que se realizará es la coordinación con los distintos proveedores (diseñadores de moda) para comercializar sus productos por medio de nuestro canal de ventas, llegando a acuerdos donde las prendas que nos brindan se comercializarán únicamente por nuestro canal y a un precio que considere el margen de ganancia de nuestra organización.

Para la entrega de los productos trabajaremos con distintos courier que lleven el producto al lugar seleccionado por el cliente, la velocidad de la entrega de estos productos es indispensable en la aceptación del cliente hacia nuestro negocio, ya que una de las principales quejas de los usuarios que compran por internet es la demora de entrega de los productos comprados.

Asimismo, otro de las actividades que realizará la organización es el entallamiento de las prendas a la medida de nuestros clientes. Este es un servicio más personalizado que busca que nuestro cliente se sienta seguro de comprar las prendas que crean conveniente. Al trabajar directamente con los diseñadores de moda, podemos coordinar con ellos para la elaboración de prendas a pedido del cliente.

Por último y no menos importante, la empresa tiene como pilar brindar un servicio de postventa de calidad, consultando con el cliente la calidad de la prenda, dando consejos sobre la tela que acaba de adquirir, etc. De esta manera, mantendremos una comunicación constante con nuestros clientes y ganaremos su confianza para que pueda seguir comprando por medio de nuestro canal.

\subsection{Equipo de trabajo}

\section{Rodrigo Alejandro Mondragón Vernal}

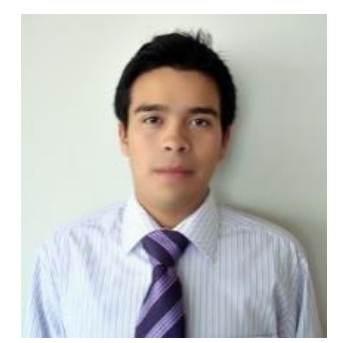

Tiene 26 años de edad, es egresado de la carrera de Administración con especialidad en Finanzas Corporativas en el instituto San Ignacio de Loyola; asimismo, cuenta con más de 5 años de experiencia en el sector banca.

Será responsable de la administración financiera de la empresa, aprobando proyectos que sean rentables para los accionistas y con menor riesgo por su ejecución.

En la actualidad, se encuentra estudiando el último ciclo de la carrera de Administración de Banca y Finanzas en la Universidad Peruana de Ciencias Aplicadas (UPC). 


\section{Fiorella Yazmin Jayo Ryan}

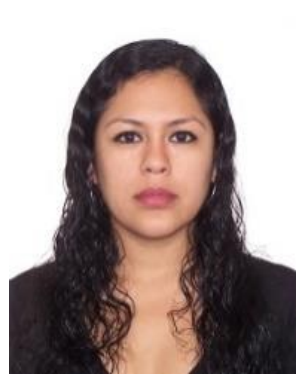

Técnica egresada del Instituto SISE en la carrera de Contabilidad y finanzas, con más de 8 años de experiencia como analista contable. Seré responsable de la jefatura del área de contabilidad, una de las principales funciones a mi cargo será la formulación e interpretación de los estados financieros, y de la declaración mensual a la administración tributaria (SUNAT). De esta manera será de gran ayuda a los accionistas para la toma de decisiones y mejora de la empresa.

Actualmente curso 9no ciclo de la carrera de Contabilidad en la universidad Peruana de Ciencias Aplicadas (UPC)

\section{Giancarlo Silva Santisteban Sierra}

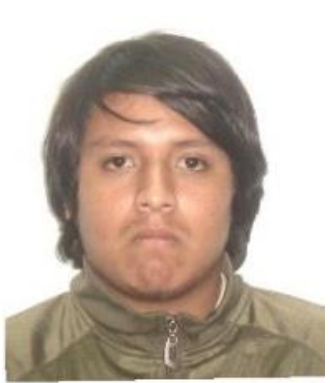

Cuenta con 27 años de edad. Estudiante de administración de empresas en la Universidad Peruana de Ciencias Aplicada. Gerente de administración en la cevicheria "Los tres mariscos".

Será responsable de la administración de las operaciones de la empresa, tomando en cuenta los procesos que se realicen en esta.

\section{Pedro Luis Mercado Alvarado}

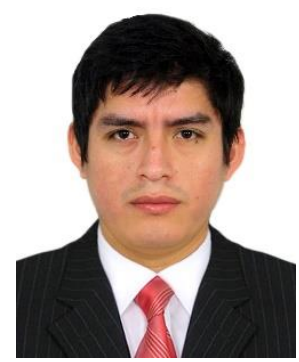

Cuenta con 29 años de edad. Estudiante de administración de empresas en la Universidad Peruana de Ciencias Aplicadas. Cuenta con experiencia en el área de logística de empresas relacionadas al área de computación.

Será responsable del área de logística de la empresa. 
Capítulo 2. Planeamiento Estratégico

Business Model Canvas - Modelo de Negocio.

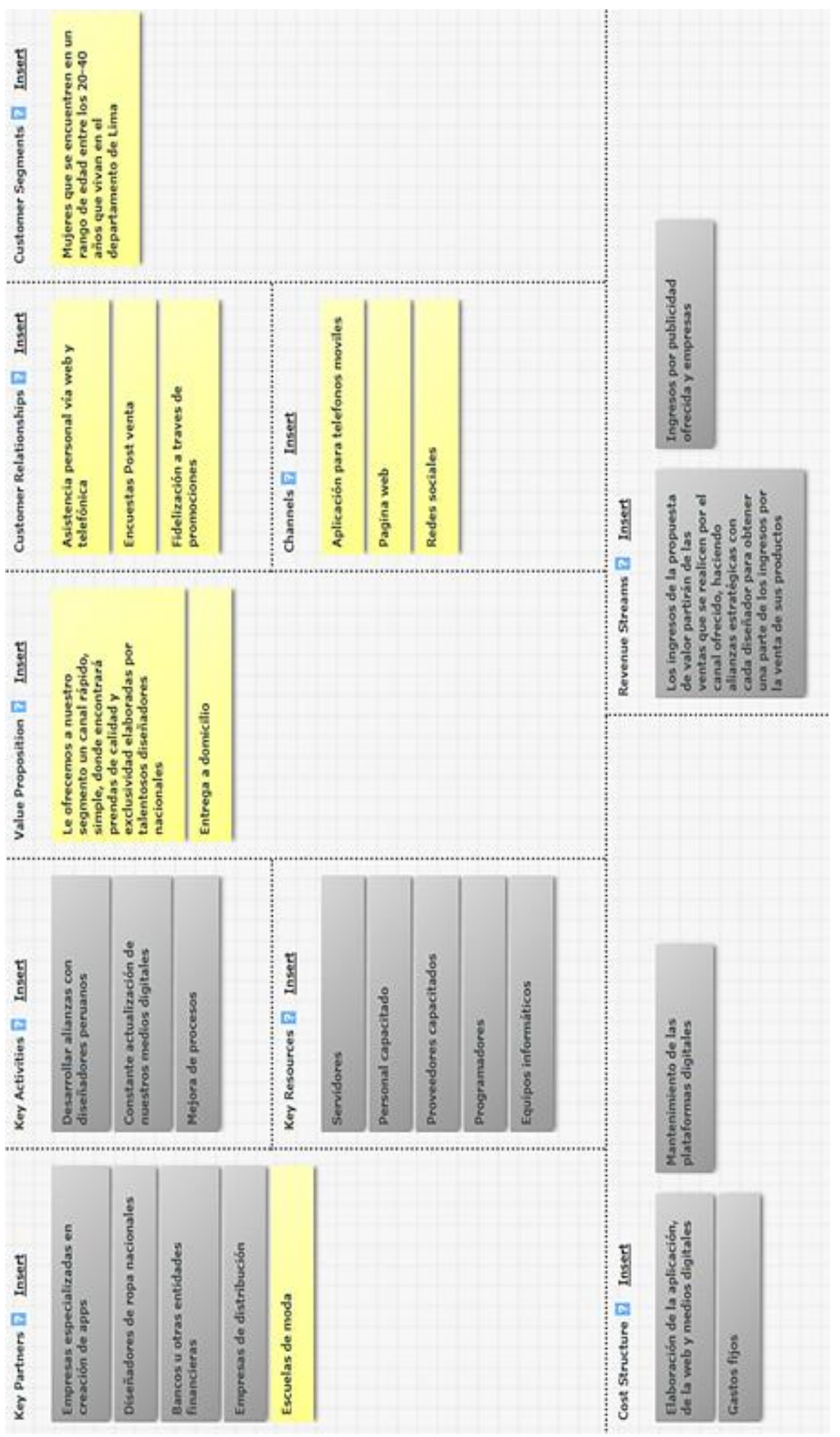


- Aliados Clave: Los aliados claves de nuestro negocio corresponden a las empresas que nos darán la posibilidad de cumplir con la propuesta de valor ofrecida a nuestro segmento.

En este caso, contamos con empresas que se encarguen de la creación y mantenimiento de nuestras aplicaciones digitales; diseñadores nacionales, quienes nos darán un catálogo de productos y de dónde vendrá parte de los ingresos de la organización; bancos u otras entidades financieras que nos brinden soporte económico para futuras operaciones internas o falta de liquidez; empresas de distribución para llevar el producto hasta el consumidor final.

- Actividades Clave: Estas actividades corresponden a la obtención de nuevas alianzas con diseñadores; contar con una web y aplicación dinámica y atractiva, en donde los riesgos sean reducidos por medio de una adecuada gestión; cumplir con los acuerdos de nuestras plataformas de pago (VISA, MASTERCARD, etc.) y proveedores (distribución).

- Recursos Clave: Es importante contar con capital para el negocio, contar con buenas plataformas tecnológicas (app y web) que almacene información (bases de datos), contar con personal y proveedores capacitados en la administración, entrega y servicio postventa del producto.

- Propuesta de Valor: Le ofrecemos a nuestro segmento un canal rápido, simple, donde encontrará prendas de calidad elaboradas por talentosos diseñadores nacionales.

- Relación con el Cliente: Para interactuar con nuestros clientes, le ofrecemos una plataforma virtual y una aplicación en donde el cliente tenga la libertad de interactuar y buscar de manera amigable los productos que desee adquirir.

- Canales: Para llevarle al segmento seleccionado nuestra propuesta de valor, utilizaremos empresas que se dediquen a la distribución de productos. 
- Segmentos de Clientes: Nuestra propuesta de valor está dirigida hacia mujeres que se encuentren en un rango de edad entre los 20-40 años que vivan en el departamento de Lima.

- Estructura de Costes: El costo de elaborar nuestra propuesta de valor está dividido en varios recursos.

- Tenemos el costo por la elaboración de la aplicación y la web, asimismo, tenemos un costo por darle mantenimiento a estas plataformas tecnológicas.

Asimismo, tenemos costos de personal: sueldos administrativos y capacitaciones

Estructura de Ingresos: Los ingresos de la propuesta de valor partirán de las ventas que se realicen por el canal ofrecido, haciendo alianzas estratégicas con cada diseñador para obtener una parte de los ingresos por la venta de sus productos.

Asimismo, se utilizarán distintos medios de pagos para facilidad del cliente, hoy en día es importante contar con distintos medios de pagos como tarjetas de crédito, depósitos a cuenta, PayPal, etc.

\subsection{Análisis externo}

\subsubsection{Análisis PESTEL}

Entorno político-legal:

Hoy en día existen varios beneficios que proporciona el Estado a las micro y pequeñas empresas, brindándoles facilidades para su creación y formalización, creando políticas que impulsan el emprendimiento y la mejora de estas organizaciones empresariales. Ayuda a estas personas naturales o jurídicas a tener un negocio propio de esta manera se puedan formalizar y pagar un menor tributo, claro que deben cumplir con ciertos requisitos: no debe superar las 1700 UIT en ventas. Adicional al beneficio antes mencionado desde el $1^{\circ}$ de marzo del 2017 entró en vigencia el sistema del IGV JUSTO, el cual permitirá postergar el pago de IGV hasta por 3 meses, si es que las ventas fueron a crédito, de esta manera el microempresario no tendría que pagar impuestos al momento 
de la declaración mensual, quitándole liquidez, pues le dan plazo para cancelar el tributo hasta 3 meses pasado la declaración mensual. Por otro lado, el primero de abril para las pequeñas, medianas y grandes empresas, fue aprobado el aumento del sueldo mínimo a los trabajadores hasta la cantidad de 930 nuevos soles, lo cual dificulta el acceso a empresas pequeñas. Así mismo, el primero de mayo para las microempresas según la publicación del día 22 de marzo del 2018 del diario El Peruano.

\begin{tabular}{|l|l|}
\hline \multicolumn{1}{|c|}{ Oportunidades } & \multicolumn{1}{c|}{ Amenazas } \\
\hline $\begin{array}{l}\text { O1. Planes de acción por parte del } \\
\text { gobierno para impulsar el sector }\end{array}$ & A1. Estancamiento del gasto publico \\
\hline $\begin{array}{l}\text { O2. Apertura de nuevos tratados } \\
\text { comerciales }\end{array}$ & $\begin{array}{l}\text { A2. Incremento de la inseguridad } \\
\text { ciudadana }\end{array}$ \\
\hline & $\begin{array}{l}\text { A3. Casos de corrupción por las } \\
\text { autoridades } \\
\text { A4. Aumento de sueldo mínimo }\end{array}$ \\
\hline
\end{tabular}

Entorno social-cultural:

Hoy en día se pueden distinguir distintos tipos de consumidores con diferentes estilos de vida para cada uno. Por ejemplo, dentro de los estilos de vida tenemos a los sofisticados, progresistas, modernas, formales, conservadoras y austeros que representan $10 \%, 18 \%$, $28 \%, 20 \%, 14 \%, 10 \%$ respectivamente.

De los estilos de vida indicados, los que más resaltan son los progresistas, modernos y los formales, cada uno con características distintas.

Los progresistas son personas pujantes, que trabajan duro, y en su mayoría son independientes. Suelen ser un perfil que busca un rendimiento en sus compras.

Las modernas son mujeres trabajadoras que muestran un gran interés en la moda y las tendencias del momento. Para ellas, el trabajo es indispensable ya que es su fuente de progreso.

Los Formales son hombres que buscan seguir con su status quo; adversos al riesgo y muy tradicionales.

Figura 1: Descripcion de los Estilos de Vida.

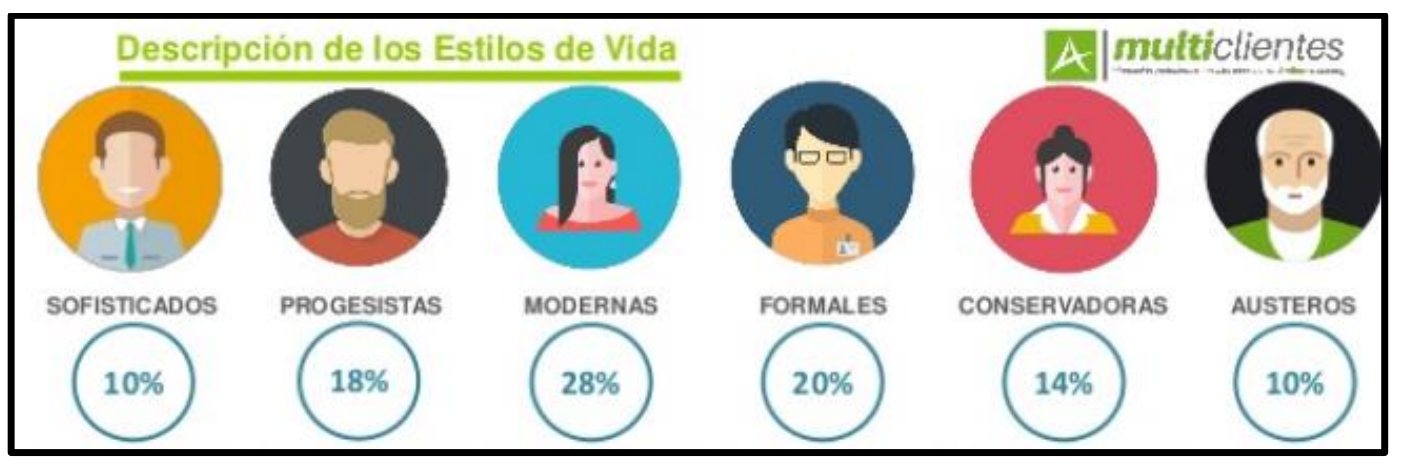


A continuación, se presenta un cuadro con los datos de los niveles socio-económicos de nuestra capital.

Figura 2: Distribución porcentual de los niveles socioeconómicos del Perú

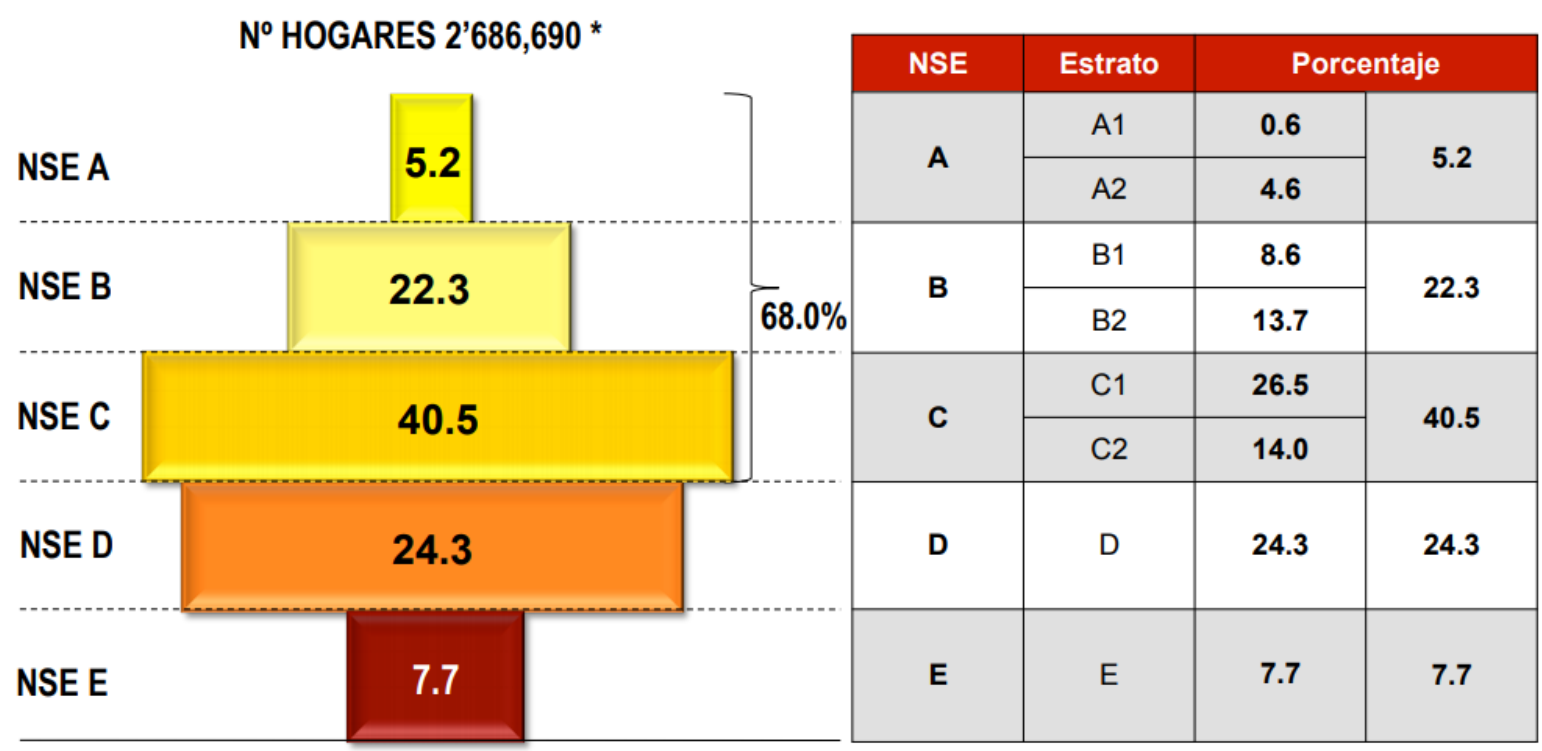

Fuente : http://www.apeim.com.pe/wp-content/themes/apeim/docs/nse/APEIM-NSE2016.pdf

Tabla 1: Distribucion de los niveles socioeconómicos por Zonas

\begin{tabular}{|l|c|c|c|c|c|c|}
\hline \multirow{2}{*}{ Zona } & & \multicolumn{4}{c|}{ Niveles Socioeconómicos } \\
\cline { 2 - 7 } & TOTAL & NSE A & NSE B & NSE C & NSE D & NSE E \\
\hline Total & 100 & 5.2 & 22.3 & 40.5 & 24.3 & 7.7 \\
\hline Zona 1 (Puente Piedra, Comas, Carabayllo) & 100 & 1.0 & 10.7 & 44.3 & 31.5 & 12.5 \\
\hline Zona 2 (Independencia, Los Olivos, San Martín de Porras) & 100 & 1.9 & 23.1 & 51.5 & 21.0 & 2.5 \\
\hline Zona 3 (San Juan de Lurigancho) & 100 & 0.0 & 18.7 & 41.7 & 27.9 & 11.7 \\
\hline Zona 4 (Cercado, Rimac, Breña, La Victoria) & 100 & 3.8 & 26.7 & 45.0 & 19.9 & 4.6 \\
\hline Zona 5 (Ate, Chaclacayo, Lurigancho, Santa Anita, San Luis, El & 100 & 2.0 & 12.1 & 40.6 & 36.3 & 8.9 \\
\hline Agustino) & 100 & 13.6 & 58.0 & 22.4 & 5.2 & 0.7 \\
\hline Zona 6 (Jesús Maria, Lince, Pueblo Libre, Magdalena, San Miguel) & 100 & 34.6 & 45.2 & 14.0 & 5.0 & 1.2 \\
\hline Zona 7 (Miraflores, San Isidro, San Borja, Surco, La Molina) & 100 & 4.2 & 27.8 & 43.3 & 20.1 & 4.6 \\
\hline Zona 8 (Surquillo, Barranco, Chorrillos, San Juan de Miraflores) & 100 & 0.0 & 6.1 & 42.7 & 38.7 & 12.5 \\
\hline Zona 9 (Villa El Salvador, Villa María del Triunfo, Lurin, Pachacamac) & 100.7 & 12.5 \\
\hline Zona 10 (Callao, Bellavista, La Perla, La Punta, Carmen de la Legua, & 100 & 1.4 & 18.5 & 43.8 & 23.7 & 24.5 \\
\hline Ventanilla) & 100 & 0.0 & 8.2 & 42.9 & 24.5 & 24.5 \\
\hline Otros & & &
\end{tabular}

Fuente : http://www.apeim.com.pe/wp-content/themes/apeim/docs/nse/APEIM-NSE2016.pdf 


\begin{tabular}{|l|l|}
\hline Oportunidades & Amenazas \\
\hline $\begin{array}{l}\text { O1. Perfil del consumidor favorable al } \\
\text { negocio. }\end{array}$ & A1. Cambio constante de las tendencias de moda. \\
\hline $\begin{array}{l}\text { O2. Lima es el departamento con más } \\
\text { población. }\end{array}$ & $\begin{array}{l}\text { A2. Tendencia al ahorro por parte de los } \\
\text { consumidores. }\end{array}$ \\
\hline $\begin{array}{l}\text { O3. El consumidor gusta de comprar } \\
\text { ropa. }\end{array}$ & \begin{tabular}{l}
\hline \\
\hline
\end{tabular}
\end{tabular}

\section{Entorno Económico:}

En la actualidad, las principales calificadoras de riesgo a nivel internacional nos han dado una ponderación favorable lo que se transmite en confianza y estabilidad para el país. Por ejemplo, para la agencia calificadora Moody's tenemos una calificación para nuestra deuda a largo plazo en moneda extranjera y local de A3, lo cual sin bien es cierto nos vuelve susceptibles ante cambios económicos, no deja de ser atractivo para las inversiones.

Tabla 2: Deuda a largo plazo en ME y MN de LATAM

Deuda a Largo Plazo en Moneda Extranjera

\begin{tabular}{|l|l|l|l|l|l|}
\hline ARGENTINA & Moody's & S\&P & Fitch & DBRS & NICE \\
\hline BOLIVIA & $\mathrm{Ba} 3$ & $\mathrm{~B}+$ & $\mathrm{B}$ & $\mathrm{B}$ & $\mathrm{B}$ \\
\hline BRASIL & $\mathrm{Ba} 2$ & $\mathrm{BB}-$ & $\mathrm{BB}-$ & - & - \\
\hline CHILE & $\mathrm{Aa} 3$ & $\mathrm{~A}+$ & $\mathrm{A}$ & $\mathrm{D}$ isc. & - \\
\hline COLOMBIA & $\mathrm{Baa} 2$ & $\mathrm{BBB}-$ & $\mathrm{BBB}$ & $\mathrm{BBB}$ & - \\
\hline COSTA RICA & $\mathrm{Ba} 2$ & $\mathrm{BB}-$ & $\mathrm{BB}$ & - & - \\
\hline ECUADOR & $\mathrm{B} 3$ & $\mathrm{~B}-$ & $\mathrm{B}$ & - & - \\
\hline EL SALVADOR & $\mathrm{B} 3$ & $\mathrm{CCC}+$ & $\mathrm{B}-$ & - & - \\
\hline MÉXICO & $\mathrm{A} 3$ & $\mathrm{BBB}+$ & $\mathrm{BBB}+$ & $\mathrm{BBB}(\mathrm{H})$ & $\mathrm{BBB}+$ \\
\hline PANAMÁ & $\mathrm{Baa} 2$ & $\mathrm{BBB}$ & $\mathrm{BBB}$ & - & - \\
\hline PARAGUAY & $\mathrm{Ba} 1$ & $\mathrm{BB}$ & $\mathrm{BB}$ & - & - \\
\hline PERÚ & $\mathrm{A} 3$ & $\mathrm{BBB}+$ & $\mathrm{BBB}+$ & $\mathrm{DisC}$. & $\mathrm{BBB}+$ \\
\hline URUGUAY & $\mathrm{Baa} 2$ & $\mathrm{BBB}$ & $\mathrm{BBB}-$ & $\mathrm{BBB}(\mathrm{L})$ & - \\
\hline VENEZUELA & $\mathrm{Caa} 3$ & $\mathrm{SD}$ & $\mathrm{RD}$ & - & - \\
\hline
\end{tabular}

Deuda a Largo Plazo en Moneda Local

\begin{tabular}{|l|l|l|l|l|l|}
\hline & Moody's & S\&P & Fitch & DBRS & NICE \\
\hline ARGENTINA & $\mathrm{B} 2$ & $\mathrm{~B}+$ & $\mathrm{B}$ & $\mathrm{B}(\mathrm{H})$ & $\mathrm{B}+$ \\
\hline BOLIVIA & $\mathrm{Ba} 3$ & $\mathrm{BB}$ & $\mathrm{BB}-$ & - & - \\
\hline BRASIL & $\mathrm{Ba} 2$ & $\mathrm{BB}-$ & $\mathrm{BB}-$ & $\mathrm{BB}$ & $\mathrm{BB}+$ \\
\hline CHILE & $\mathrm{A} 33$ & $\mathrm{AA}-$ & $\mathrm{A}+$ & $\mathrm{Disc}$ & - \\
\hline COLOMBIA & $\mathrm{Baa} 2$ & $\mathrm{BBB}$ & $\mathrm{BBB}$ & $\mathrm{BBB}$ & - \\
\hline COSTA RICA & $\mathrm{Ba} 2$ & $\mathrm{BB}-$ & $\mathrm{BB}$ & - & - \\
\hline ECUADOR & - & $\mathrm{B}-$ & - & - & - \\
\hline EL SALVADOR & - & $\mathrm{CCC}+$ & $\mathrm{B}-$ & - & - \\
\hline MÉXICO & $\mathrm{A} 3$ & $\mathrm{~A}-$ & $\mathrm{BBB}+$ & $\mathrm{BBB}(\mathrm{H})$ & $\mathrm{A}-$ \\
\hline PANAMÁ & - & $\mathrm{BBB}$ & $\mathrm{BBB}$ & - & - \\
\hline PARAGUAY & $\mathrm{Ba} 1$ & $\mathrm{BB}$ & $\mathrm{BB}$ & - & - \\
\hline PERÚ & $\mathrm{A} 3$ & $\mathrm{~A}-$ & $\mathrm{A}-$ & $\mathrm{Disc}$ & $\mathrm{A}-$ \\
\hline URUGUAY & $\mathrm{Baa} 2$ & $\mathrm{BBB}$ & $\mathrm{BBB}-$ & $\mathrm{BBB}(\mathrm{L})$ & - \\
\hline VENEZUELA & $\mathrm{Caa} 3$ & $\mathrm{CCC}-$ & $\mathrm{CC}$ & - & - \\
\hline
\end{tabular}

Fuente: https://www.mef.gob.pe/es/principales-calificaciones-de-riesgo-soberano 
Figura 3: SAP Calificaciones de los paises

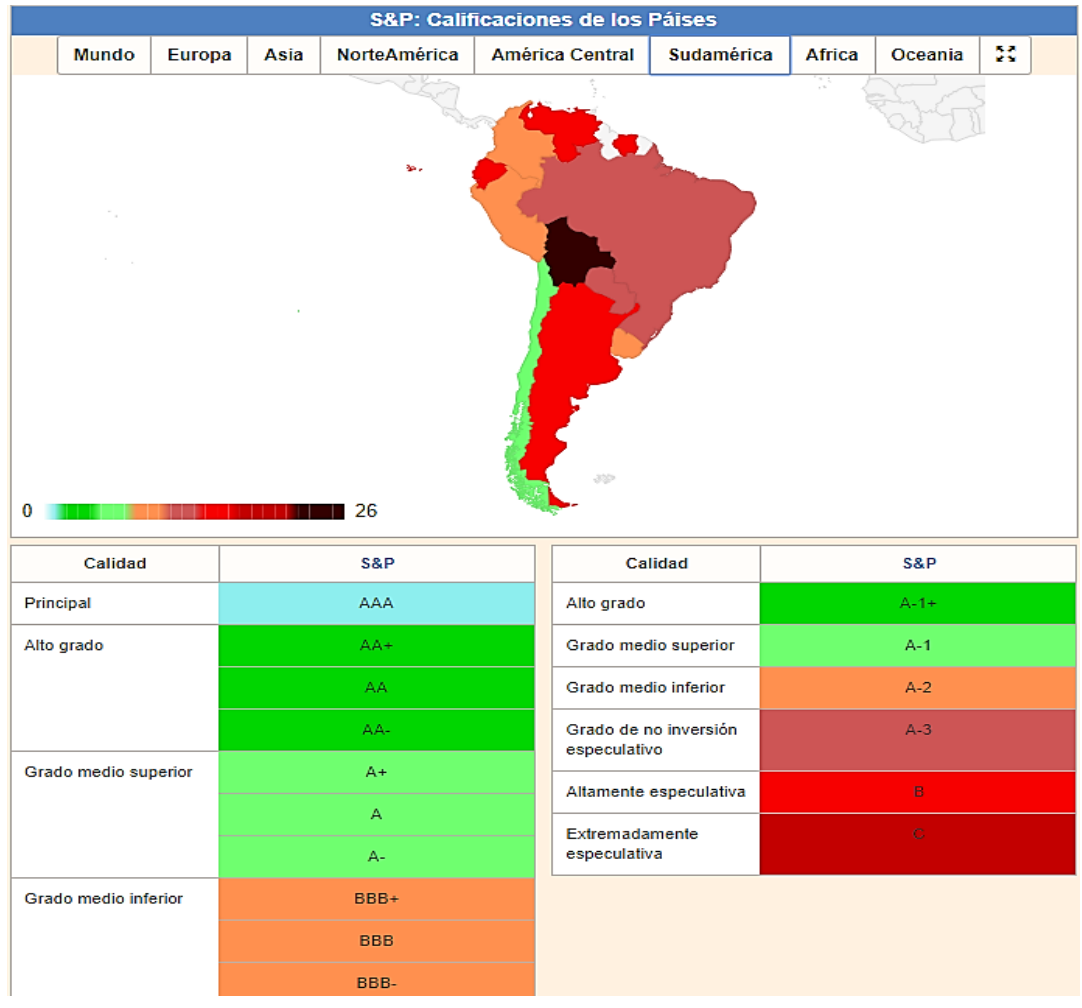

Fuente: https://www.datosmacro.com/ratings/standardandpoors

Por otra parte, resaltar que el 31 de octubre del 2017 el Banco Mundial publicó el ranking de Doing Bussines 2018, el cual mide la facilidad para realizar negocios e inversiones y el Perú se encuentra en el puesto 58.

A continuación, se resaltan los puntos más importantes a considerar para la medición del ranking.

Figura 4: Anaisis Doing Business en Perú al 2018

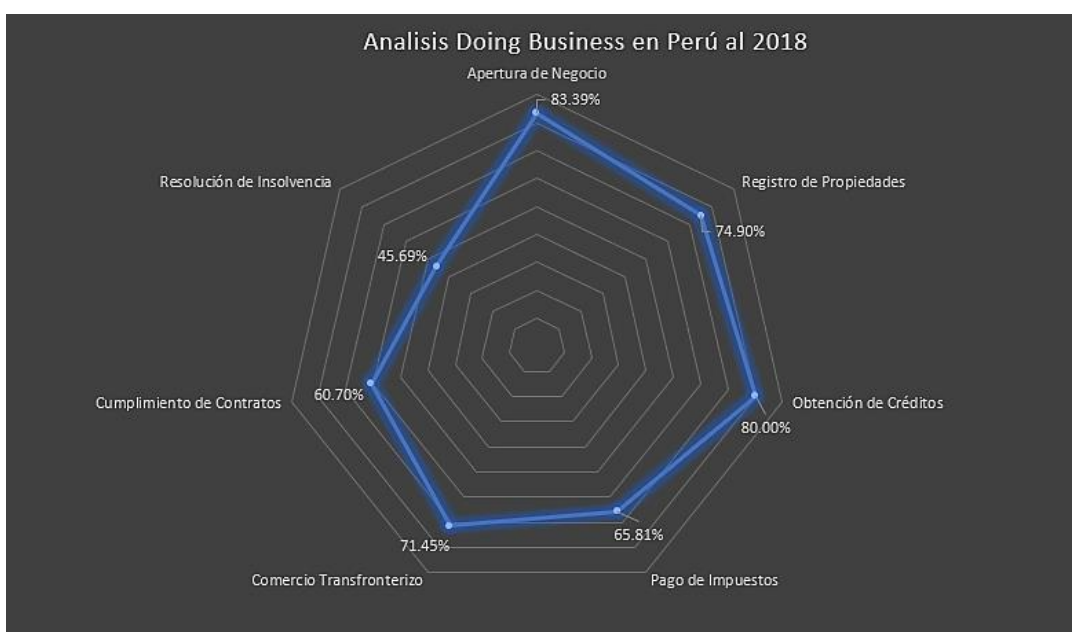

Fuente: http://espanol.doingbusiness.org/data/exploreeconomies/peru. Elaboracion Propia. 
Otro factor importante que considerar es que la economía nacional registro un incremento de $3.8 \%$ en el año 2016. Asimismo, el consumo privado creció aproximadamente $4.1 \%$ y el gasto por parte del gobierno aumento en $2.3 \%$. Con estos resultados el Perú cuenta con 89 meses consecutivos de crecimiento. El Perú mantiene el liderazgo de crecimiento en la región con casi $4 \%$.

\begin{tabular}{|l|l|}
\hline Oportunidades & Amenazas \\
\hline $\begin{array}{l}\text { O1. Mayor poder adquisitivo de los } \\
\text { consumidores }\end{array}$ & $\begin{array}{l}\text { A1. Dificultad para conseguir créditos a las } \\
\text { PYMES }\end{array}$ \\
\hline O2. Inflación Estable & $\begin{array}{l}\text { A2. Estancamiento del crecimiento por casos de } \\
\text { corrupción }\end{array}$ \\
\hline O3. País atractivo para las inversiones & \\
\hline
\end{tabular}

\section{Entorno Demográfico:}

El número de internautas ha crecido considerablemente en el Perú en los últimos años siendo más de 11,7 millones de internautas en el 2014.

Figura 5: Perfil del internauta

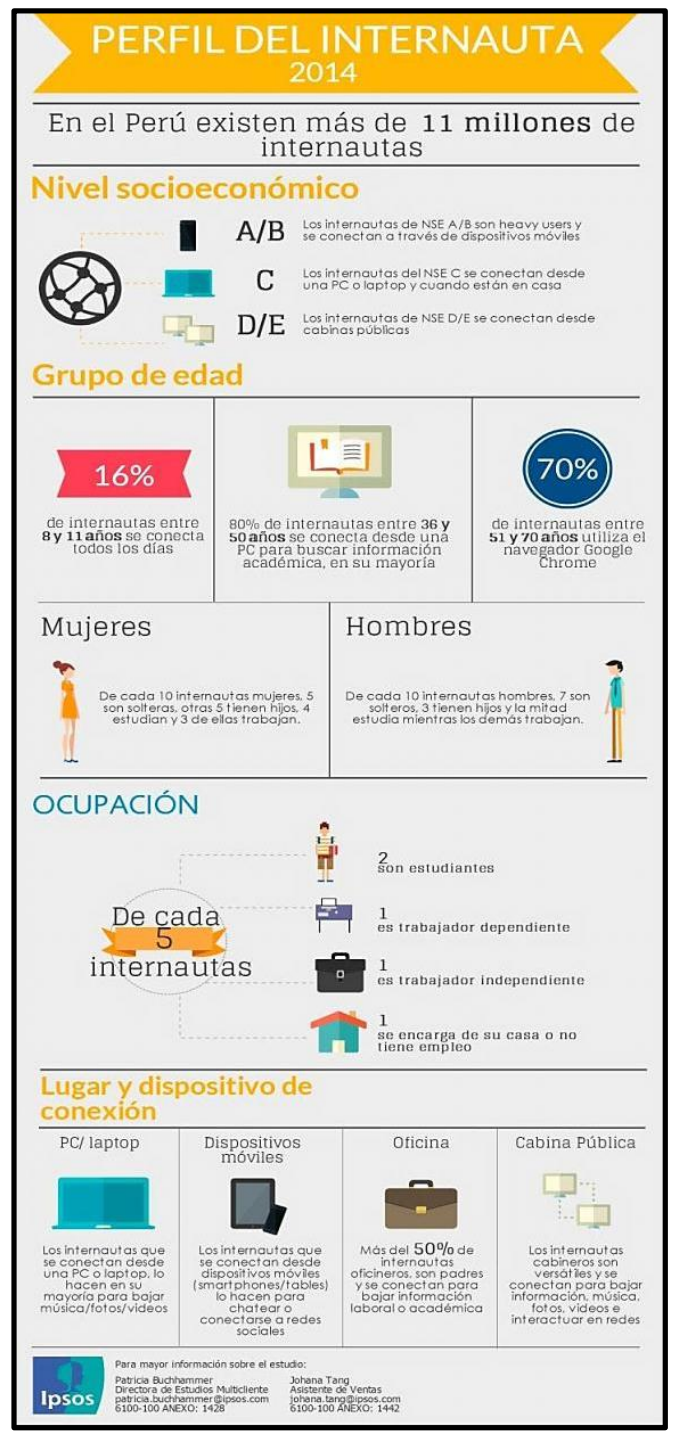


Según informe sobre las compras online en el Perú hecha en 2015 por GFK (Compañía de investigación de mercado), el mayor porcentaje de compras a través de online es la adquisición de ropa con un $26 \%$

\section{Entorno Tecnológico:}

El Perú es un país que no tiene como enfoque el desarrollo de tecnologías para comercializarlas en el mercado local o internacional, sino más bien, es un país que importa tecnología de países que cuentan con un alto nivel de especialización.

Hoy en día muchas empresas del sector textil importan maquinaria de distintas partes del mundo con el fin de mejorar la productividad y rentabilidades del negocio; asimismo, se busca constantemente nuevos acuerdos para adquirir nuevas tecnologías que mejoren y hagan más competitivo al fabricante nacional.

Asimismo, se ha podido comprobar que las redes sociales han incrementado las ventas y reducido los costos en la promoción que utilizan las organizaciones con el fin de llegar al segmento seleccionado.

Junto al aumento en el porcentaje de peruanos que usan internet, los acuerdos para adquirir lo mejor en tecnología para la industria textil, las redes sociales han pasado a tener un rol protagonista en la manera en cómo se da la comunicación entre empresa y cliente.

Figura 6: Medio para acceder a Internet

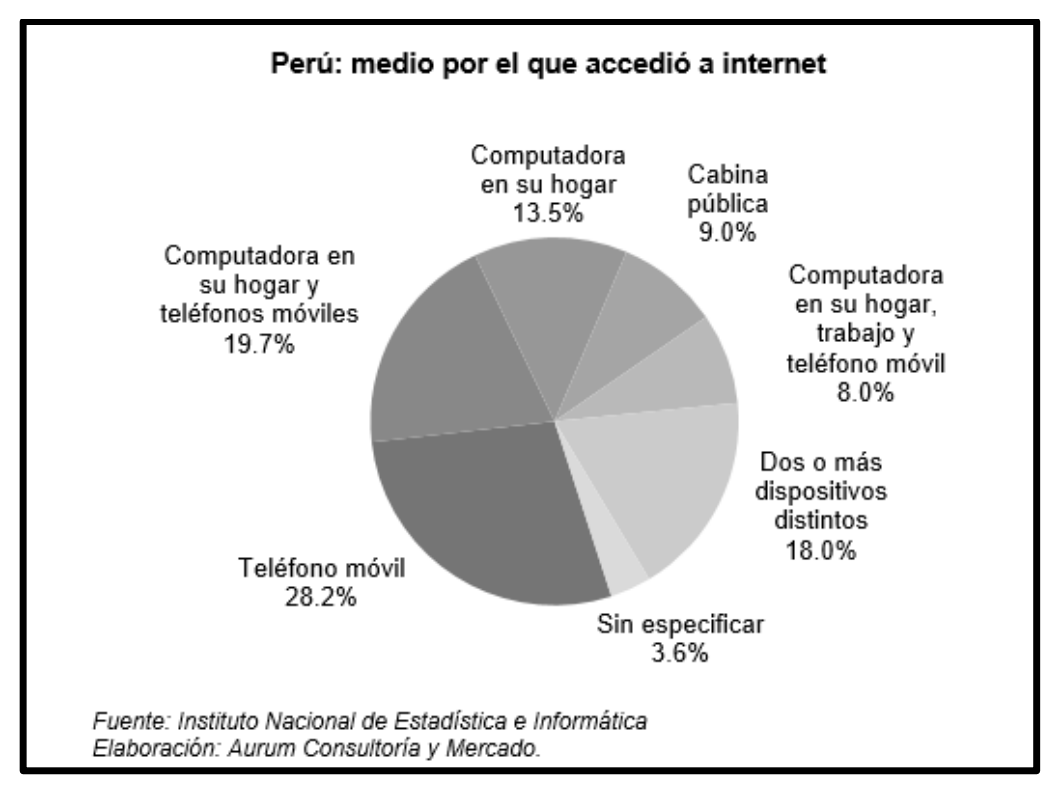


Figura 7: Preferencias de consumo Retail Online

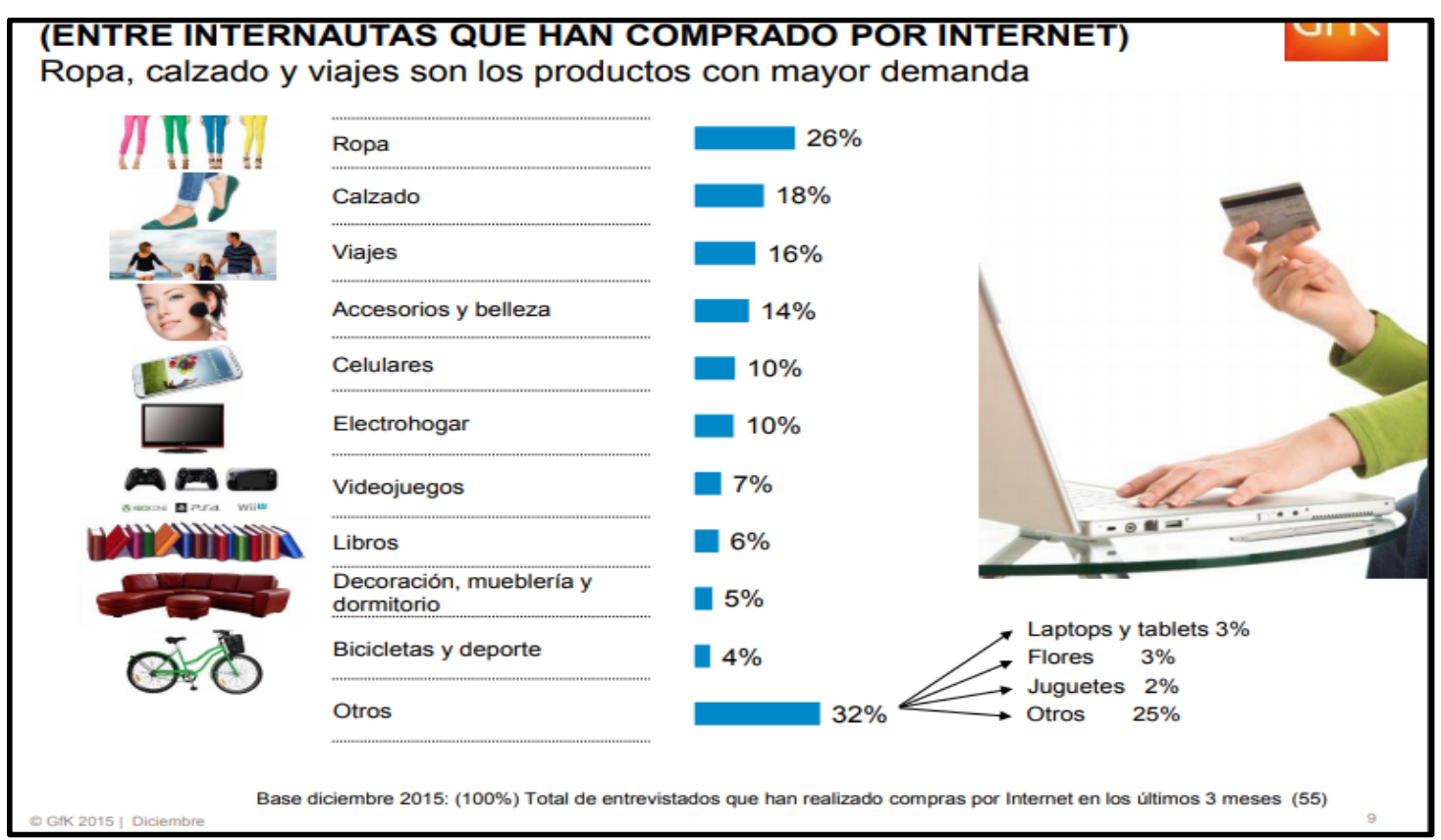

Tabla 3: Población que accede a Internet

\begin{tabular}{|c|c|c|c|c|c|c|c|c|c|}
\hline \multicolumn{10}{|c|}{ Poblacion que accede a Internet } \\
\hline Grupos de Edad / Año & 2012 & Var \% & 2013 & Var $\%$ & 2014 & Var \% & 2015 & Var $\%$ & 2016 \\
\hline Lima Metropolitana & 57.0 & $2.37 \%$ & 58.3 & $2.87 \%$ & 60.0 & $-1.01 \%$ & 59.4 & $8.38 \%$ & 64.4 \\
\hline 6-16 ẫos & 73.2 & $1.44 \%$ & 74.2 & $0.14 \%$ & 74.3 & $-5.18 \%$ & 70.5 & $4.27 \%$ & 73.5 \\
\hline $17-24$ años & 84.2 & $1.65 \%$ & 85.6 & $-0.24 \%$ & 85.4 & $-2.27 \%$ & 83.5 & $7.55 \%$ & 89.8 \\
\hline 25 y más años & $\begin{array}{l}44.4 \\
\end{array}$ & $3.43 \%$ & \begin{tabular}{c|c|}
45.9 \\
\end{tabular} & $5.97 \%$ & \begin{tabular}{l|l}
48.6 \\
\end{tabular} & $2.24 \%$ & \begin{tabular}{c|c|}
49.7 \\
\end{tabular} & $10.81 \%$ & 55.1 \\
\hline
\end{tabular}

Fuente: Elaboracion Propia

Figura 8: Población que accede a Internet

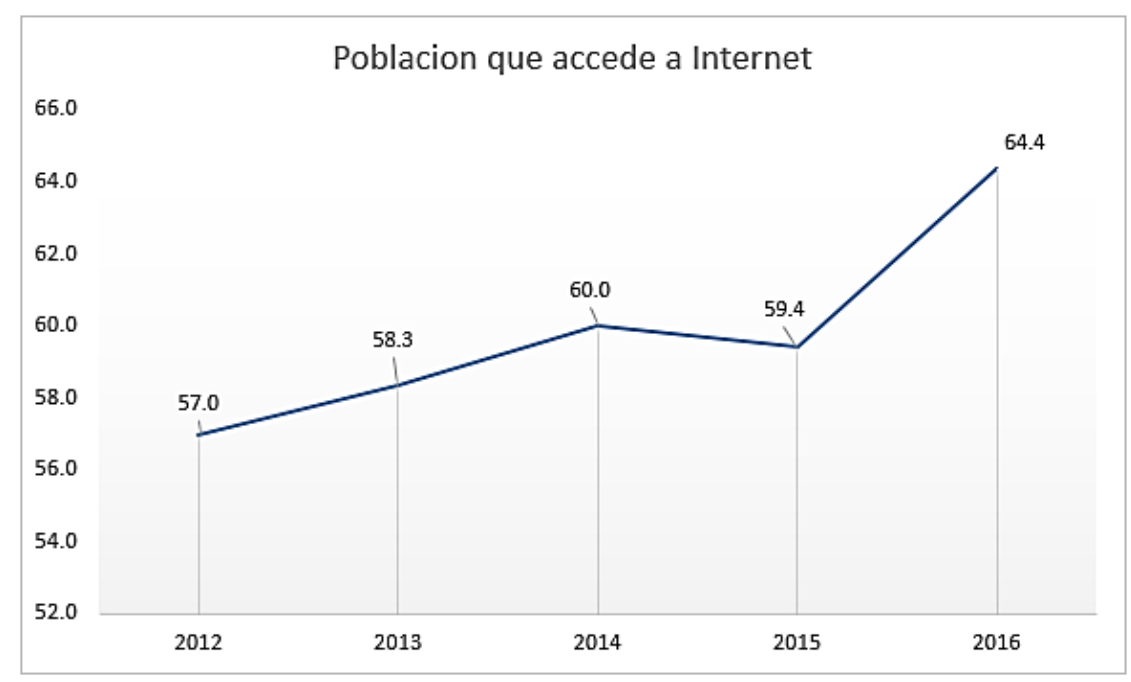

Fuente: Elaboracion Propia 


\begin{tabular}{|l|l|}
\hline Oportunidades & Amenazas \\
\hline $\begin{array}{l}\text { O1. Acuerdos comerciales para la } \\
\text { adquisición de nueva maquinaria }\end{array}$ & $\begin{array}{l}\text { A1. Costos de la maquinaria inaccesibles para el } \\
\text { empresario peruano }\end{array}$ \\
\hline $\begin{array}{l}\text { O2. Incremento en la tasa de hogares con } \\
\text { acceso a Internet }\end{array}$ & $\begin{array}{l}\text { A2. Desconfianza del consumidor a adquirir } \\
\text { prendas vía online }\end{array}$ \\
\hline $\begin{array}{l}\text { O3. Incremento en el comportamiento } \\
\text { del consumidor en utilizar las redes } \\
\text { sociales }\end{array}$ & A3. Robo de información y hackeo \\
\hline
\end{tabular}

\subsection{Análisis interno}

\subsubsection{Análisis de las 5 fuerzas de Porter}

\subsubsection{Competidores}

Según un estudio del Instituto de Estudios Económicos y Sociales, la producción de distintas prendas de fabricación nacional ha disminuido en los últimos años, motivada por un aumento significativo de la importación de textiles más económicos. Esto ha ocasionado que la tienda de prendas de fabricación nacional haya disminuido. La cantidad de competidores es baja.

\begin{tabular}{|c|c|} 
Oportunidades & Amenazas \\
\hline $\begin{array}{c}\text { - Poca competencia en el segmento } \\
\text { del mercado seleccionado. }\end{array}$ & \\
\hline
\end{tabular}

http://www.sni.org.pe/wp-content/uploads/2017/01/Noviembre-2016-Industria-deproductos-textiles.pdf

\subsubsection{Clientes}

En este caso, el poder de negociación de los clientes es alto, debido al hecho de que cuentan con varias opciones a elegir para poder satisfacer sus necesidades con respecto a lo que es vestimenta, como por ejemplo las tiendas mismas, centros comerciales e incluso otras páginas de internet.

\begin{tabular}{|c|c|}
\hline Oportunidades & Amenazas \\
\hline $\begin{array}{c}\text { - Bajo poder de negociacion por parte } \\
\text { de los clientes. }\end{array}$ & \\
\hline
\end{tabular}

\subsubsection{Proveedores}

El Perú en la actualidad ha tenido un desarrollo importante, se ha podido observar un gran aumento en el número de empresas que se apertura día a día, lo cual facilita a la realización del negocio al tener una selección de proveedores destacados. Para el caso de la elaboración de prendas, se ha observado un incremento considerable en los diseñadores 
y productores, que responde a una demanda insatisfecha; sin embargo, estos nuevos fabricantes de prendas no cuentan con una adecuada gestión y no pueden ampliar el mercado para generar mayores ingresos.

El poder de negociación de los proveedores es Medio, ya que una vez que estos sean conocidos en el mercado se pueden ir y aperturar su propio negocio.

\begin{tabular}{|c|c|}
\hline Oportunidades & Amenazas \\
\hline $\begin{array}{c}\text { - Bajo poder de negociacion por parte } \\
\text { de los proveedores. }\end{array}$ & \\
\hline
\end{tabular}

\subsubsection{Productos sustitutos}

En los últimos años se ha visto un incremento en las importaciones de textiles más económicos de distintas partes del mundo. Asimismo, se puede evidenciar en el mercado que marcas con un prestigio internacional ingresan al mercado local a distribuir sus productos.

El mercado de los textiles presenta diversas opciones para todo tipo de consumidor, por lo que es fácil encontrar distintas variedades de diseños, tallas, precios, etc.

\begin{tabular}{|c|c|}
\hline Oportunidades & Amenazas \\
\hline & $\begin{array}{c}\text { - Amplia variedad de productos sustitutos en } \\
\text { el mercado nacional. }\end{array}$ \\
\hline
\end{tabular}

\subsubsection{Competidores potenciales}

En este sector y la modalidad que pretende realizar la organización no cuenta con barreras de entrada fuertes, en realidad, es bastante simple ingresar al mercado debido a que no se necesita una gran cantidad de capital.

\begin{tabular}{|c|c|}
\hline Oportunidades & Amenazas \\
\hline & - Débiles barreras de entrada \\
\hline
\end{tabular}




\subsubsection{Consolidado de Oportunidades y Amenazas}

\begin{tabular}{|c|c|}
\hline Oportunidades & Amenazas \\
\hline $\begin{array}{l}\text { O1. Planes de accion por parte del gobierno para } \\
\text { impulsar el sector. } \\
\text { O2. Apertura de nuevos tratados comerciales } \\
\text { O3. Perfil del consumidor favorable al negocio } \\
\text { O4. Lima es el departamento con más población. } \\
\text { O5. El consumidor gusta de comprar ropa. } \\
\text { O6. Mayor poder adquisitivo de los consumidores } \\
\text { O7. Inflación Estable. } \\
\text { O8. País atractivo para las inversiones. } \\
\text { O9. Acuerdos comerciales para la adquisición de nueva } \\
\text { maquinaria. } \\
\text { O10. Incremento en la tasa de hogares con acceso a } \\
\text { Internet. } \\
\text { O11. Incremento en el comportamiento del } \\
\text { consumidor en utilizar las redes sociales. } \\
\text { O12. Poca competencia en el segmento del mercado } \\
\text { seleccionado. } \\
\text { O13. Bajo poder de negociación por parte de los } \\
\text { clientes. } \\
\text { O14. Bajo poder de negociación por parte de los } \\
\text { proveedores. }\end{array}$ & $\begin{array}{l}\text { A1. Estancamiento del gasto público } \\
\text { A2. Incremento de la inseguridad ciudadana. } \\
\text { A3. Casos de corrupción por las autoridades. } \\
\text { A4. Cambio constante en las tendencias de moda. } \\
\text { A5. Tendencia al ahorro por parte de los consumidores. } \\
\text { A6. Dificultad para conseguir creditos en las PYMES. } \\
\text { A7. Estancamiento del crecimiento por casos de corrupción. } \\
\text { A8. Costos de la maquinaria inaccesibles para el empresario } \\
\text { peruano. } \\
\text { A9. Desconfianza del consumidor a adquirir prendas vía } \\
\text { online. } \\
\text { A10. Robo de información y hackeo. } \\
\text { A11. Amplia variedad de productos sustitutos. }\end{array}$ \\
\hline
\end{tabular}

Figura 9: Matriz de Analisis y Diagnosticos 


\section{MATRIZ DE ANÁLISIS Y DIAGNÓSTICO EXTERNO (MADE)}

\begin{tabular}{|c|c|c|c|c|c|c|c|c|c|c|c|c|c|}
\hline \multirow{2}{*}{\multicolumn{2}{|c|}{$\begin{array}{l}\text { E. Especifico: } \\
\text { Organización: }\end{array}$}} & 5 Fuerzas de M. Porter & \multicolumn{8}{|c|}{ Indicador de Diagnóstico Externo: } & 0.13 & & \multirow{2}{*}{\begin{tabular}{|c|}
$100.00 \%$ \\
26 \\
\end{tabular}} \\
\hline & & \multicolumn{2}{|l|}{ Hallpa Textil SAC. } & \multicolumn{3}{|c|}{ LAS 4 P'S MKT } & \multicolumn{4}{|c|}{ EVAL. FACTORES } & \multicolumn{2}{|c|}{ Tot. Factores: } & \\
\hline n & Tipo_Entorn & Variable & Factor & & & & & $\mathrm{N}$ & 0 & \begin{tabular}{|l|l|}
$\mathrm{P}$ & $\mathrm{N}$ \\
\end{tabular} & $W$ & Valor & Total \\
\hline 1 & E. General & Políico & $\begin{array}{l}\text { Planes de accion por parte del gobierno para } \\
\text { impulsar el sector. }\end{array}$ & & $x$ & & & & & $x$ & $0.32 \%$ & 2 & 0.0065 \\
\hline 2 & E. General & Polifico & Apertura de nuevos tratados comerciales & & $x$ & $\mathrm{x}$ & & & & $x$ & $0.32 \%$ & 2 & 0.0065 \\
\hline 3 & E. General & Social & Perfil del consumidor favorable al negocio & $x$ & & $\mathrm{x}$ & & & & $\mathrm{x}$ & $3.90 \%$ & 1 & 0.0390 \\
\hline 4 & E. General & Demografico & Lima es el departamento con más población. & & $x$ & & & & & $x$ & $3.57 \%$ & 1 & 0.0357 \\
\hline 5 & E. General & Social & El consumidor gusta de comprar ropa. & & & $\mathrm{x}$ & & & & $x$ & $4.22 \%$ & 2 & 0.0844 \\
\hline 6 & E. General & Económico & Mayor poder adquisifivo de los consumidores & $x$ & $x$ & & & & & $x$ & $7.79 \%$ & 2 & 0.1558 \\
\hline 7 & E. General & Económico & Inflación Estable & $\mathrm{x}$ & & & & & & $\mathrm{x}$ & $1.62 \%$ & 1 & 0.0162 \\
\hline 8 & E. General & Económico & Pais atractivo para las inversiones & $x$ & & & & & & $\mathrm{x}$ & $0.65 \%$ & 1 & 0.0065 \\
\hline 9 & E. General & Tecnológico & Acuerdos comerciales para la adquisición de nueva & & $x$ & & & & & $\mathrm{x}$ & $0.32 \%$ & 1 & 0.0032 \\
\hline 10 & E. General & Tecnológico & Incremento en la tasa de hogares con acceso a & $x$ & & $\mathrm{x}$ & & & & $x$ & $5.52 \%$ & 2 & 0.1104 \\
\hline 11 & E. General & Tecnológico & $\begin{array}{l}\text { Incremento en el comportamiento del consumidor en } \\
\text { uflizar las redes sociales. }\end{array}$ & $x$ & & $\mathrm{x}$ & & & & $x$ & $4.87 \%$ & 2 & 0.0974 \\
\hline 12 & E. Especifico & Rivalidad de Compeidores & $\begin{array}{l}\text { Poca competencia en el segmento del mercado } \\
\text { seleccionado. }\end{array}$ & $x$ & $x$ & & & & & $x$ & $4.55 \%$ & 2 & 0.0909 \\
\hline 13 & E. Especifico & Poder de los Clientes & Bajo poder de negociación por parte de los clientes. & $x$ & $x$ & $x$ & & & & $x$ & $6.49 \%$ & 2 & 0.1299 \\
\hline 14 & E. Especifico & Poder de los Proveedores & $\begin{array}{l}\text { Bajo poder de negociación por parte de los } \\
\text { proveedores. }\end{array}$ & $\mathrm{x}$ & $x$ & $\mathrm{x}$ & & & & $x$ & $5.84 \%$ & 2 & 0.1169 \\
\hline 15 & E. General & Polifico & Estancamiento del gasto público & $x$ & & & & $\mathrm{x}$ & & & $0.97 \%$ & -1 & -0.0097 \\
\hline 16 & E. General & Polifico & Incremento de la inseguridad ciudadana. & & 8 & $\mathrm{x}$ & & $\mathrm{x}$ & & & $2.27 \%$ & -1 & -0.0227 \\
\hline 17 & E. General & Polifico & Casos de corrupción por las autoridades. & & $\mathrm{x}$ & & & $x$ & & & $0.65 \%$ & -1 & -0.0065 \\
\hline 18 & E. General & Social & Cambio constante en las tendencias de moda. & $x$ & $x$ & $\mathrm{x}$ & $x$ & & & & $6.82 \%$ & -2 & -0.1364 \\
\hline 19 & E. General & Social & Tendencia al ahorro por parte de los consumidores. & $x$ & $x$ & & & $\mathrm{x}$ & & & $7.79 \%$ & -1 & -0.0779 \\
\hline 20 & E. General & Económico & Dificultad para conseguir creditos en las PYMES. & $\mathrm{x}$ & $\underline{x}$ & & & $\mathrm{x}$ & & & $2.60 \%$ & -1 & -0.0260 \\
\hline 21 & E. General & Económico & $\begin{array}{l}\text { Estancamiento del crecimiento por casos de } \\
\text { corrupción. }\end{array}$ & $\mathrm{x}$ & $\mathrm{x}$ & & & $x$ & & & $0.97 \%$ & -1 & -0.0097 \\
\hline 22 & E. General & Tecnológico & $\begin{array}{l}\text { Costos de la maquinaria inaccesibles para el } \\
\text { empresario peruano. }\end{array}$ & & $\mathrm{x}$ & & & $\mathrm{x}$ & & & $1.62 \%$ & -1 & -0.0162 \\
\hline 23 & E. General & Tecnológico & $\begin{array}{l}\text { Desconfanza del consumidor a adquirir prendas via } \\
\text { online. }\end{array}$ & $x$ & & $x$ & $x$ & & & & $7.47 \%$ & -2 & -0.1494 \\
\hline 24 & E. General & Tecnológico & Robo de información y hackeo. & $\mathrm{x}$ & ) & $\mathrm{x}$ & & $x$ & & & $5.84 \%$ & -1 & -0.0584 \\
\hline 25 & E. Especifico & Productos Susfitutos & Amplia variedad de productos sustitutos. & $x$ & $x$ & & $x$ & & & & $7.14 \%$ & -2 & -0.1429 \\
\hline 26 & E. Especifico & Compeidores Potenciales & Débiles barreras de entrada. & $x$ & & $x$ & $\mathrm{x}$ & & & & $5.84 \%$ & -2 & -0.1169 \\
\hline
\end{tabular}

Figura 10: Reporte de la Matriz y Analisis 


\section{REPORTE FINAL DE LA MATRIZ DE ANÁLISIS Y DIAGNÓSTICO EXTERNO}

\section{INDICADOR DE DIAGNOSTICO EXTERNO: 0.13 \\ OPORTUNIDADES: \\ AMENAZAS: \\ $-0.77$ \\ ENTORNO FAVORABLE}

Los 3 Factores del entorno que más afectan a la Organización

\begin{tabular}{|c|l|c|c|c|}
\hline $\mathbf{N}$ & \multicolumn{1}{|c|}{ Factores Importantes: } & Valor & $\%$ & O/R \\
\hline 1 & Mayor poder adquisitivo de los consumidores & 0.1558 & $17.32 \%$ & OPORTUNIDAD \\
\hline 2 & Desconfanza del consumidor a adquirir prendas via on & -0.1494 & $19.40 \%$ & AMENAZA \\
\hline 3 & Amplia variedad de productos susfitutos. & -0.1429 & $18.55 \%$ & AMENAZA \\
\hline
\end{tabular}

Las 3 Variables del entorno que más afectan a la Organización:

\begin{tabular}{|c|l|c|c|c|}
\hline $\mathbf{N}$ & \multicolumn{1}{|c|}{ Variables Importantes: } & Oportunidad & Riesgo & Valor Final \\
\hline $\mathbf{1}$ & Productos Susfitutos & 0.0000 & -0.14286 & -0.1429 \\
\hline $\mathbf{2}$ & Económico & 0.1786 & -0.03571 & 0.1429 \\
\hline $\mathbf{3}$ & Poder de los Clientes & 0.1786 & -0.03571 & 0.1429 \\
\hline
\end{tabular}

Fecha Actualización: 3 de Abril de 2018

\begin{tabular}{|l|c|}
\hline Muy Positivo & 2 \\
\hline Positivo & 1 \\
\hline Neutro & 0 \\
\hline Negativo & -1 \\
\hline Muy negativo & -2 \\
\hline
\end{tabular}

Indicador

Independencia: $(0,0.7)$

\begin{tabular}{l|l}
\hline Dependencia: & $(0.7,1)$ \\
\hline
\end{tabular}

Efecto del Entorno en las 4 P's del Marketing:

\begin{tabular}{|c|l|c|c|c|c|c|}
\hline $\mathbf{N}$ & Las 4P's & Oportunidad & $\%$ & Riesgo & $\%$ & Valor Final \\
\hline $\mathbf{1}$ & Producto & 0.7630 & $51.20 \%$ & -0.7273 & $48.80 \%$ & 1.4903 \\
\hline $\mathbf{2}$ & Precio & 0.4968 & $54.45 \%$ & -0.4156 & $45.55 \%$ & 0.9123 \\
\hline $\mathbf{3}$ & Plaza & 0.0487 & $17.05 \%$ & -0.2370 & $82.95 \%$ & 0.2857 \\
\hline $\mathbf{4}$ & Promoción & 0.5844 & $54.71 \%$ & -0.4838 & $45.29 \%$ & 1.0682 \\
\hline
\end{tabular}

Distribución del impacto:¿A quien afecta más?

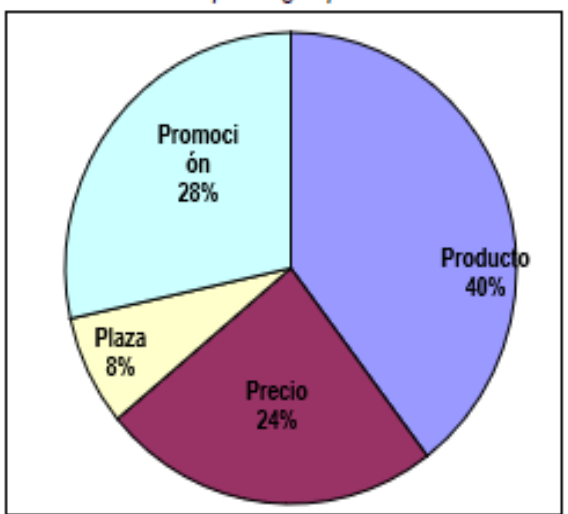

Dependencia e Independencia de las Oportunidades y Amenazas:

\begin{tabular}{|l|c|c|c|l|}
\cline { 2 - 4 } \multicolumn{1}{c|}{} & Total & $\mathbf{2 0 \%}$ Factores & $\mathrm{I}$ & \multicolumn{1}{c|}{} \\
\hline Oportunidades: & 14 & 3 & 0.45 & INDEPENDIENTE \\
\hline Amenazas: & 12 & 3 & 0.56 & INDEPENDIENTE \\
\hline
\end{tabular}

Analisis de Resultados:

Como se puede observar en los resultados de la herramienta administrafva ufilzada, el entorno para realizacion del negocio es favorable. Sin embargo, existen amenazas que deben gesionarse para evitar que el impacto en nuestra organizacion genere grandes perdidas economicas.

Asimismo, podemos observar que ante los posibles escenarios presentados, nuestro producto seria a quien golpearia mas, por lo que nuestras estrategias deben estar enfocadas a mifigar estos riesgos. 


\subsubsection{Análisis FODA}

Figura 11: Analisis FODA

\begin{tabular}{|c|c|c|}
\hline \multirow{8}{*}{ Analisis Foda } & Fortalezas & Debilidades \\
\hline & F1. Gran cantidad de diseñadores brindaran sus productos a través de la & D1. Empresa nueva, no reconocida en el mercado \\
\hline & F2. Excelente atención al cliente & D2. La tendencia de nuevos diseñadores puede no gustarle a los \\
\hline & $\begin{array}{l}\text { F3. Facilidad para que el cliente pueda elegir prendas de diferentes tipos } \\
\text { con las medidas debidamente especificadas }\end{array}$ & \multirow[t]{5}{*}{ D3. Baja de fidelidad de los proveedores } \\
\hline & $\begin{array}{l}\text { F4. Se brindará opción de acomodar los diseños a pedido del cliente } \\
\text { entrevistandose con el diseñador de la prenda }\end{array}$ & \\
\hline & F5. Orientación al cliente & \\
\hline & \begin{tabular}{|l|} 
F6. Servicio postventa \\
\end{tabular} & \\
\hline & F7. Innovacion & \\
\hline Oportunidades & Estrategias F0 & Estrategias D0 \\
\hline 01. Mayor poder adquisitivo de los consumidores & E1. Generar alianzas estratégicas con los proveedores (diseñadores). & $\begin{array}{l}\text { E6. Realizar campañas publicitarias en diferentes medios accesibles } \\
\text { para que la empresa sea reconocida por el público. }\end{array}$ \\
\hline 02. Tendencia alta a comprar ropa & $\begin{array}{l}\text { E2. Realizar campañas virtuales en donde se vean los beneficios que brinda } \\
\text { la empresa para que los clientes sean conscientes de estas. }\end{array}$ & \multirow[t]{3}{*}{$\begin{array}{l}\text { E7. Realizar estudios de mercado donde se pueda ver más claro el gusto } \\
\text { de nuestros clientes para de alguna forma orientar a los diseñadores. }\end{array}$} \\
\hline 03. Incremento en la tasa de hogares con acceso a Internet & \multirow[t]{2}{*}{$\begin{array}{l}\text { E3. Buscar a los diseñadores más destacados de cada uno de los institutos } \\
\text { que se dedican a este rubro. }\end{array}$} & \\
\hline $\begin{array}{l}\text { 04. Incremento en el comportamiento del consumidor en } \\
\text { utilizar las redes sociales }\end{array}$ & & \\
\hline Amenazas & Estrategias FA & Estrategias DA \\
\hline A1. Copia del producto & $\begin{array}{l}\text { E4. Mostrar a los clientes que satisfacen sus necesidades al comprar } \\
\text { nuestras productos. }\end{array}$ & $\begin{array}{l}\text { E8. Realizar contratos con los proveedores para que las prendas que } \\
\text { brinden para la empresa solo puedan ser vendidas mediante la página. }\end{array}$ \\
\hline A2. Desconfianza del cliente & \multirow[t]{2}{*}{$\begin{array}{l}\text { E5. Le daremos la confianza de compra al cliente mediante la opción de que } \\
\text { podrá ir el diseñador a su realizar los ajustes de sus prendas si es que lo } \\
\text { requieren. }\end{array}$} & \multirow[t]{2}{*}{$\begin{array}{l}\text { E9. Fusionar la empresa con empresas grandes que realicen } \\
\text { distribucions mucho más masivas. }\end{array}$} \\
\hline A3. Precios baratos de otras empresas & & \\
\hline
\end{tabular}

\section{$\underline{\text { Resultados }}$}

Como podemos observar en el cuadro anterior, se han planteado diversas estrategias en función de las principales fortalezas, debilidades, oportunidades y amenazas. Cabe resaltar que estas estrategias se realizarán tanto en el corto plazo como en el largo plazo.

Tabla 4: Cuadro de Estrategias

\begin{tabular}{|c|c|c|c|}
\hline Código & Estrategia & Descripción & Alcance \\
\hline E1 & Alianzas Estrategicas & Generar alianzas estratégicas con los proveedores (diseñadores). & Largo Plazo \\
\hline E2 & Crecimiento & $\begin{array}{r}\text { Realizar campañas virtuales en donde se vean los beneficios que brinda la empresa para que } \\
\text { los clientes sean conscientes de estas. }\end{array}$ & Corto Plazo \\
\hline E3 & Diferenciación & Buscar a los diseñadores más destacados de cada uno de los institutos que se dedican a este & rubro. \\
\hline E4 & Diferenciación & Mostrar a los clientes que satisfacen sus necesidades al comprar nuestras productos. & Largo Plazo \\
\hline E5 & Diferenciación & Le daremos la confianza de compra al cliente mediante la opción de que podrá ir el diseñador a & Corto Plazo \\
\hline E6 & Diferenciación & Realizar campañas publicitarias en diferentes medios accesibles para que la empresa sea & reconocida por el público. \\
\hline E7 & Actualización & Realizar estudios de mercado donde se pueda ver más claro el gusto de nuestros clientes para & Mediano Plazo \\
\hline E8 & Alianzas Estrategicas & Realguna forma orientar a los diseñadores. & Mediano Plazo \\
\hline E9 & Alianzas Estrategicas & Fusionar la empresa con empresas grandes que realicen distribucions mucho más masivas. & Largo Plazo \\
\hline
\end{tabular}




\subsection{Visión}

"Ser la empresa líder del mercado en la comercialización de prendas a nivel nacional"

\subsection{Misión}

“Generar bienestar a los consumidores por medio de un canal rápido, atractivo y moderno; en donde encontrarán prendas de alta calidad y elaboradas por talentosos diseñadores a nivel nacional"

\subsection{Estrategia Genérica}

La estrategia genérica planteada por la organización y siguiendo los conceptos de Porter, estará basada en la diferenciación de nuestros productos.

Ofrecemos productos exclusivos, donde no habrá la posibilidad de encontrar un producto similar en el mercado.

Asimismo, el medio por el cual el cliente realizará la compra y obtendrá el producto es poco utilizado en nuestro país.

Consideramos que las fortalezas que posee nuestra empresa nos permitirán adoptar este tipo de estrategia y que los clientes estarán dispuestos a pagar su precio por la calidad, exclusividad y facilidad de compra y entrega del producto.

\subsection{Objetivos Estratégicos}

- Generar alianzas estratégicas con los proveedores (diseñadores).

- Realizar campañas virtuales en donde se vean los beneficios que brinda la empresa para que los clientes sean conscientes de estas.

- Buscar a los diseñadores más destacados de cada uno de los institutos que se dedican a este rubro.

- Le daremos la confianza de compra al cliente mediante la opción de que podrá ir el diseñador a su realizar los ajustes de sus prendas si es que lo requieren.

- Realizar campañas publicitarias en diferentes medios accesibles para que la empresa sea reconocida por el público. 
- Realizar estudios de mercado donde se pueda ver más claro el gusto de nuestros clientes para de alguna forma orientar a los diseñadores.

- Realizar contratos con los proveedores para que las prendas que brinden para la empresa solo puedan ser vendidas mediante la página.

- Fusionar la empresa con empresas grandes que realicen distribucions mucho más masivas. 


\section{Capítulo 3. Investigación / Validación de mercado}

\subsection{Diseño metodológico de la investigación / metodología de validación de hipótesis}

El grupo de investigación, para el sector retail de indumentaria y moda, ha decidido lanzar al mercado un nuevo canal de ventas que afronte los distintos problemas por los que hoy en día atraviesa el sector. Estos problemas son varios, por lo que trataremos de especificar los más importes en estas líneas, con la intención de plasmar la oportunidad de negocio presentada.

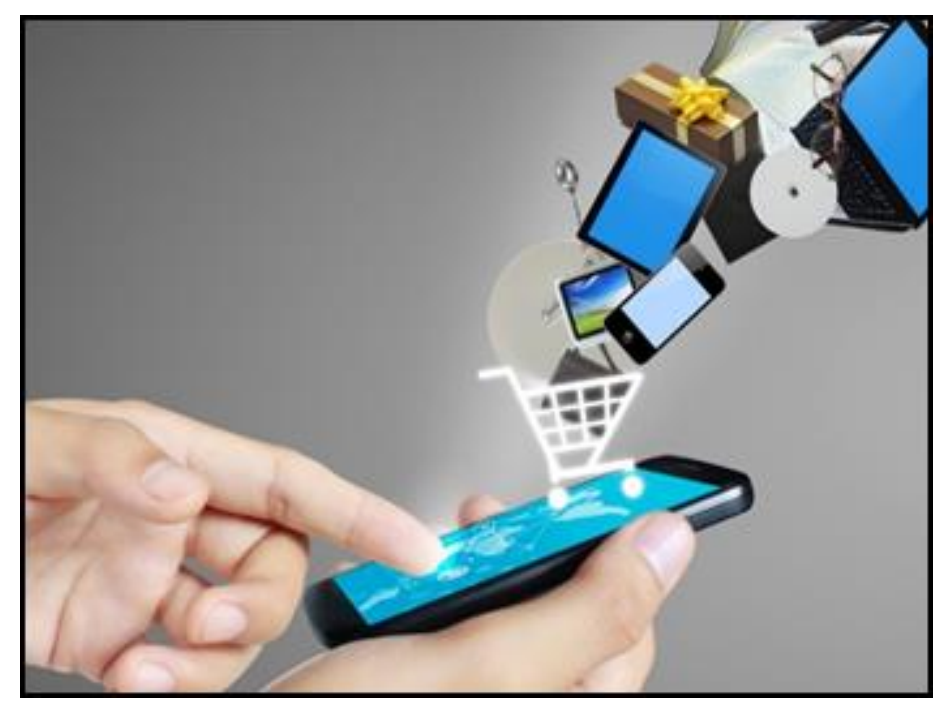

El sector, en su mayoría de empresas que la representan, ha presentado un decrecimiento en sus ventas anuales. Por un lado, existe una alta guerra cruzada de precios, ocasionada por el agresivo ingreso de distintas marcas de ropa (fast fashion) y la apertura de diversos centros comerciales, en donde se apertura nuevas tiendas que ofrecen el mismo producto y que entran a competir con las ya existentes. Por otro lado, existe un tipo de cambio inestable, lo cual encarece el precio de las materias primas para la confección de las prendas y resulta en un incremento en el precio final para el consumidor (Semana Económica: 2016).

Además de los problemas mencionados líneas arriba, se presentan otros inconvenientes que el sector debe afrontar. Estos problemas son los contratos que las empresas suscriben por el local en donde se encuentran ubicados. El precio de los arrendamientos para 
comercializar las prendas, en muchas ocasiones supera el 30\% de las ventas totales, lo cual hace que la rentabilidad del negocio disminuye considerablemente (Semana Económica: 2016).

\section{Hipótesis del cliente}

- Todas aquellas mujeres entre el rango de 20 a 45 años de edad, que sean modernas y estén pendientes de los cambios en las tendencias de moda, que cuenten con un ingreso mensual fijo y estén dispuestas a realizar compras de manera online. Son personas extrovertidas. Asimismo, son mujeres que sientan atracción por las prendas de vestir fabricados por diseñadores nacionales.

Otro punto a tomar como referencia para definir nuestra hipótesis de clientes son las cantidades de horas que las mujeres le dedican a ciertas labores o tareas en su rutina diaria, ya sea dentro o fuera del hogar. Según una encuesta realizada por INEI, donde como resultado se indicó que las mujeres, a diferencia de los hombres, tuvieron una mayor dedicación a ciertos puntos:

- En necesidades personales, las mujeres obtienen 69.26, mientras que los hombres 67.58 , generando una brecha de 1.28 promedio de horas semanales.

- En compras para el hogar, las mujeres obtienen 2.37, mientras que los hombres 2.39 generando una brecha de 0.58 promedio de horas semanales.

En gerencia y organización del hogar, las mujeres obtienen 2.38, mientras que los hombres 1.55 , generando una brecha de 0.43 promedio de horas semanales

\section{Hipótesis del problema}

- No saben dónde encontrar a los diseñadores nacionales.

Cliente indica que no conoce donde poder contactar y comprarle al diseñador nacional. Puede presentar un problema debido a la falta de publicidad por parte de los diseñadores que no dan a conocer sus productos al público a donde están dirigidos.

- Cliente siente que no encuentra variedad de prendas.

Al recurrir a distintos centros comerciales en donde puede adquirir variedad de prendas, no encuentra muchos diseños variados, tallas a su medida o gustos de su preferencia. 
- Siente que elegir ropa de diseños exclusivos le quita tiempo.

Cree que elegir ropa con diseños exclusivos toma más tiempo que al seleccionar prendas tradicionales. El tiempo es importante para este problema.

- No les gusta que otras personas tengan la misma ropa.

Al comparar las distintas prendas en centros comerciales, es posible encontrar en alguna oportunidad a distintas personas utilizando la misma ropa. Esto genera incomodidad en el cliente y al ver en stock gran cantidad de prendas similares, puede desistir de la compra.

\section{Supuesto más riesgoso: supuestos de hipótesis cliente-problema.}

- No conocen donde encontrar variedad en un solo lugar: Muchas no saben dónde encontrar todo en un solo lugar, con diversidad de estilos y tallas.

- No conocen de diseñadores peruanos: muchas conocen poco de los diseñadores y comprar por marca

- Muchas siguen la tendencia de otros países por admiración a alguien, pero no siempre encuentra lo querido.

- Las tiendas se encuentran alejadas de sus domicilios, para muchos tienen que ir hasta molles o al centro de la ciudad para adquirir prendas de su gusto.

\section{Método y criterio de éxito: objetivo mínimo del método de exploración.}

Consideramos que de las 25 mujeres entrevistadas para la etapa de RESULTADO Y DECISIÒN 17 de ellas coincidirá con nuestro supuesto de mayor riesgo el cual es que no saben dónde encontrar variedad.

- Falta de publicidad para los distintos diseñadores nacionales.

En la actualidad, no vemos una publicidad masiva hacia los diseñadores nacionales, la gran mayoría de personas realiza sus compras en los centros comerciales, donde ya existen marcas posicionadas que venden sus productos de forma masiva.

El cliente no cuenta con información de estos ofertantes (diseñadores nacionales)

- La gran cantidad de personas que van a los centros comerciales a comprar ropa origina que las prendas en stock se agoten más rápido. Esto conlleva a que los clientes puedan no encontrar las tallas de su preferencia y abandonen la compra. 
- La poca información que existe en el mercado con respecto a los diseñadores nacionales hace que el proceso de búsqueda y compras de prendas diseñadas por artistas nacionales no sea tomado en cuenta por la cantidad de tiempo que demanda.

- Las marcas que se encuentran posicionadas en los centros comerciales, realizan una producción en masa de sus prendas. Es por ello que en sus establecimientos vamos a encontrar gran cantidad de prendas iguales, y por ello, a numerosas personas utilizando la misma prenda.

\section{Método de Exploración:}

Se ha determinado que el Método y Criterio de Éxito será medido por diversas entrevistas; la muestra seleccionada contará con 22 entrevistas y para aceptar la decisión deberemos tener una aprobación de 14, lo que equivale al $60 \%$ del total de entrevistados.

\section{Guía de Entrevista}

Buen día, mi nombre es....., mi brindas unos minutos de tu tiempo para hacerte unas preguntas sobre tus compras de ropa.

Nombre:

Edad:

En qué distrito vives:

- ¿Qué opinas de la moda?

- ¿Dónde realizas tus compras de ropa?

- ¿Qué consideras al momento de elegir la ropa?

- ¿Qué problemas tienes al momento de elegir tu compra?

- ¿Cuándo te suceden estos problemas buscas como solucionar, o abandonas la compra? ¿De qué manera lo solucionas?

- ¿Cómo sería para ti la compra ideal?

- ¿Cuál es tu experiencia en compras online?

- ¿Qué opinas de los diseñadores peruanos?

Muchas gracias

Que tengas un buen día 


\subsection{Resultados de la investigación}

Figura 12: Experiment Board

\begin{tabular}{|c|c|c|c|c|c|c|c|c|c|}
\hline & & & & (PERIMENT & BOARD & & 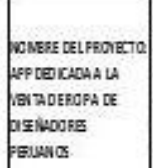 & 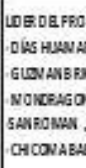 & \\
\hline & & & & DPEPNEAT & 1 & 2 & 3 & 4 & 5 \\
\hline osens thekrz 8 bo & is esertice & & & & & & & & \\
\hline 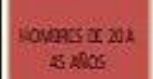 & $\begin{array}{l}\text { GASDCEOASD } \\
\text { ANOSOS EDAC }\end{array}$ & & $\begin{array}{l}\text { sentes of } \\
1212\end{array}$ & पตजा & $\begin{array}{l}\text { MUIEESS DE } 20 \\
\text { A45ANOSOS }\end{array}$ & $\begin{array}{l}\text { MUEEES DE } \boldsymbol{X} \\
\text { A45AYYOS }\end{array}$ & & & \\
\hline 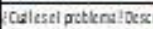 & tylo seste b pryats & & & & & & & & \\
\hline setsiderte & 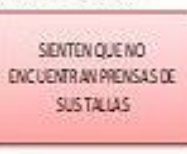 & $\begin{array}{c}\text { CONSOERWQEE BS } \\
\text { COSTOSESTA ALU } \\
\text { MOOA }\end{array}$ & $\begin{array}{l}\text { SETEROUELA } \\
\text { MOCALEQITA } \\
\text { TEMPO }\end{array}$ & Poseswa & $\begin{array}{l}\text { TEYEY } \\
\text { DIROITTD PRAA } \\
\text { CONIRAR } \\
\text { VAREDAD DE } \\
\text { ETILS }\end{array}$ & $\begin{array}{l}\text { TBVEY } \\
\text { DIFOULTAD FAQA } \\
\text { CONTRAR } \\
\text { VAREQAD DE } \\
\text { ETILS }\end{array}$ & & & \\
\hline 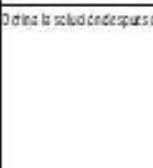 & 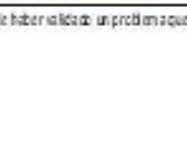 & iplapenarescha & & sauno & $\begin{array}{l}\text { BALPA TEXTL } \\
\text { RESU }\end{array}$ & 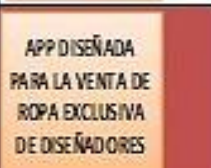 & & & \\
\hline fa us les be ksspiut & 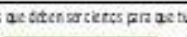 & Atrosetimt & & & & & & & \\
\hline $\begin{array}{l}\text { no conocon oe } \\
\text { Estuos }\end{array}$ & 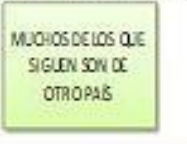 & & 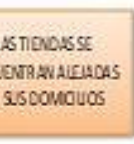 & $\begin{array}{l}\text { SHPUETOCE } \\
\text { NATOS FESTO }\end{array}$ & $\begin{array}{l}\text { NOCONOCBN } \\
\text { DONDE } \\
\text { BXONTRAR } \\
\text { WAREDAD }\end{array}$ & $\begin{array}{l}\text { PHGUEN O QUIERAY } \\
\text { COMRAR ROPADE } \\
\text { OSEKADONES, OESYUS } \\
\text { OE HRBEROECAGADO }\end{array}$ & & & \\
\hline 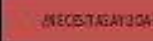 & 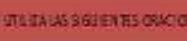 & 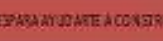 & RT2 बत्कssean: & & & & & & \\
\hline 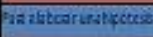 & ac Clens:prebors: & 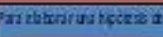 & roblend stuaten & & & & & & \\
\hline $\begin{array}{l}\text { MUESECUENO } \\
\text { CONDCEN } \\
\text { OSEÑSOOESTOR } \\
\text { SATADE } \\
\text { RUSOCDAJ }\end{array}$ & 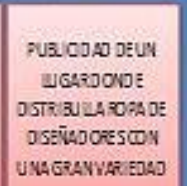 & 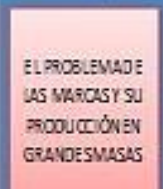 & 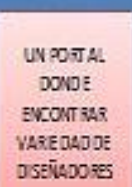 & $\begin{array}{l}\text { NETDOO Y Y CITEPO } \\
\text { IE PESOD }\end{array}$ & $\begin{array}{l}\text { EXPLORACIÓN } \\
15 / 22\end{array}$ & $\begin{array}{l}\text { LANDING PAGE, } \\
\text { FAN PAGE } \\
30 \%\end{array}$ & & & \\
\hline & & & & & & 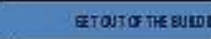 & & & \\
\hline $\begin{array}{r}\text { WUCHAS NUIEAS } \\
\text { CONPGR SUS PR } \\
\text { WUGLRY OPTRN } \\
\text { TE }\end{array}$ & $\begin{array}{l}\text { WOSAEEN DONDE } \\
\text { NaAS EN UY SOLO } \\
\text { OR BUSCAR OTRAS } \\
\text { laLS }\end{array}$ & 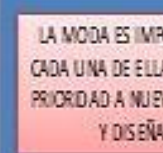 & 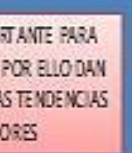 & $\begin{array}{l}\text { Bessu tado } \\
\text { Y } \\
\text { DEcGión }\end{array}$ & $\begin{array}{l}\text { EXPLORACIÓN } \\
15 / 22\end{array}$ & $40 \%$ & & & \\
\hline & & $\begin{array}{r}\text { SE ORCOEPES } \\
\text { BLSUPUEST } \\
\text { OEFI }\end{array}$ & $\begin{array}{l}\text { Eers.con } \\
8360 \\
00\end{array}$ & MPGEIDRAE & Perseverar & $\begin{array}{l}\text { LAS MUIERESESTÁN } \\
\text { INTERESADASEN LA } \\
\text { MODA, VARIEDADY } \\
\text { UTILZARIAN NUESTRA } \\
\text { APP }\end{array}$ & & & \\
\hline
\end{tabular}

\section{Hipótesis de la solución}

En el caso de las empresas de venta ropa online, después de haber realizado las entrevistas y haber analizado las diversas estadísticas online, por medio del Landing Page y Fan Page, observamos que nuestros posibles clientes tienen gran interés en utilizar una herramienta tecnológica -app, la cual nos permita la venta de ropa exclusiva de diseñadores peruanos de alta calidad. 


\section{Supuesto más riesgoso: supuestos de hipótesis problema-solución}

Que las mujeres descarguen nuestra aplicación, ingresen, escojan prendas de diseñadores que sea de su agrado, paguen por la prenda.

\section{Método y criterio de éxito: objetivo mínimo del product pitch}

En el presente trabajo se ha validado nuestra hipótesis / problema de solución utilizando el método de PRE-VENTA, es decir, se ha identificado mujeres que compren ropa exclusiva vía online.

De acuerdo a lo planteado en el Experiment Board; y según la investigación realizada, el criterio mínimo de éxito sobre este proyecto corresponde a un 30\%, esto quiere decir que, de un total de 100 personas, 30 personas o más que tomen contacto con la Landing Page o la Fan Page; y dejen sus respectivos datos se considerará como intención de compra y se habrá de perseverar con el proyecto.

\section{¿Por qué Landing?}

Porque permite dar a conocer nuestro producto, en el caso de nuestro proyecto hay mujeres que se interesan en las prendas de diseñadores, ya que nos dejan sus datos en la plataforma y de esta manera podemos contactarnos por medio de sus correos. Asimismo, hemos utilizado una herramienta el Fan page que nos permitió publicar nuestro anuncio.

\section{¿Para qué Landing?}

Para medir el porcentaje de visitas, es decir obtener el criterio mínimo esperado.

\section{Herramienta de validación: por ejemplo, pantallazos de landing page y métricas.}

Se ha decidido utilizar el lanzamiento de nuestro servicio a manera de una pre-venta, en este caso utilizando una Landing Page, con la cual se recolectará los nombres, apellidos, correos electrónicos y un mensaje con el cual se identificará si la persona que ha ingresado desea comprar; a través de todo esto se medirá el nivel de interés de las personas interesadas en nuestro servicio. En concreto, la Landing Page nos permitirá recabar información de los posibles clientes. http://kallpatextilperu.pagedemo.co/ 
Figura 13: Landing Page 1

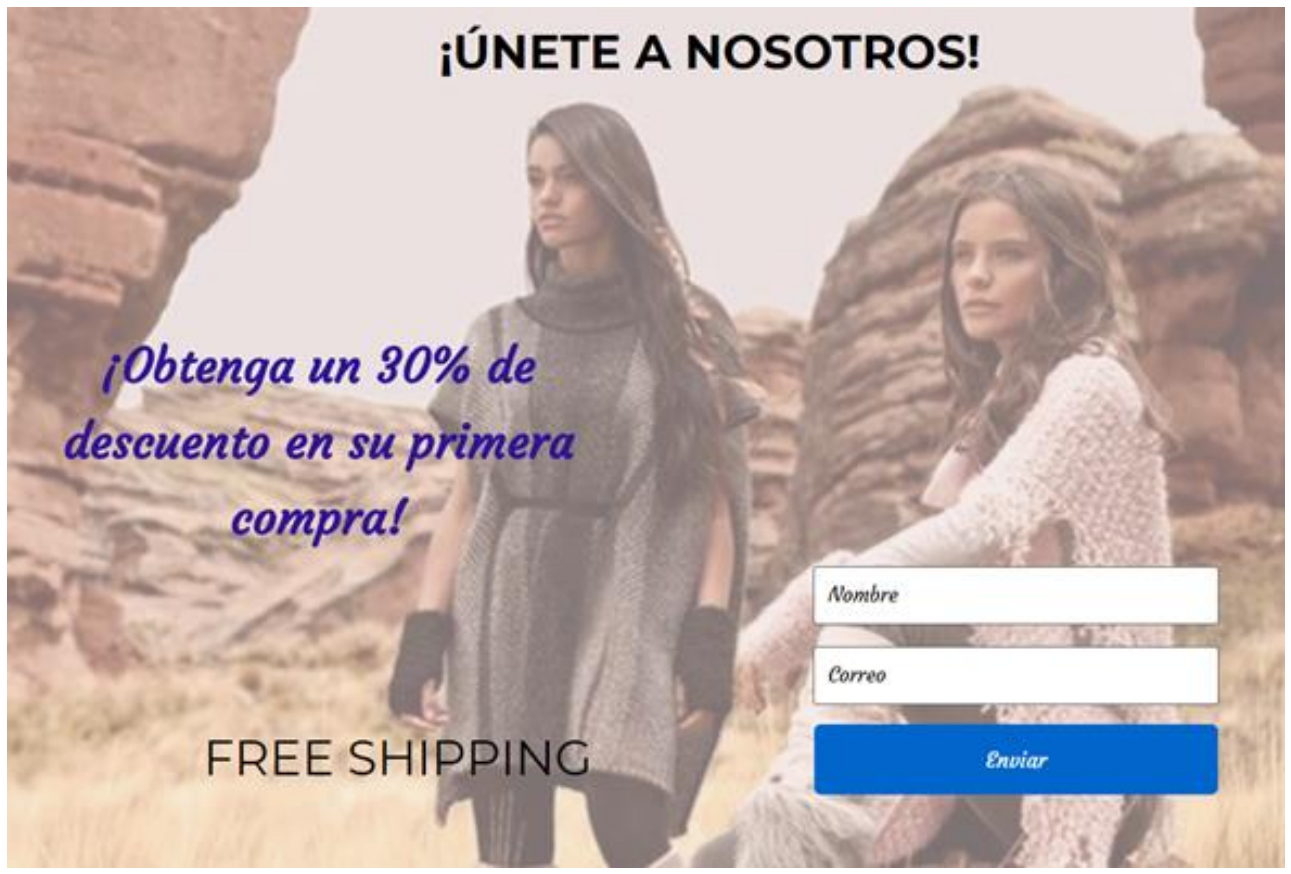

\section{Captación de prospectos: por ejemplo, pantallazos de facebook y métricas.}

- Uso de Instapage

Para validar nuestra idea de negocio se ha utilizado una landing page creada con la ayuda de_www.instapage.com. En el desarrollo de esta landing page se ha tenido en consideración los siguientes criterios:

- Diseño atractivo de un solo bloque.

- Navegación no cargada con muchas animaciones

- Información presentada con un mensaje directo y claro.

- Uso de un lenguaje que va al segmento de mujeres.

- Formulado sencillo que pide información concreta.

- Uso de Facebook

Para validar nuestra idea de negocio también se ha utilizado una fan page que se ha publicado en la red social Facebook (www.facebook.com ), se escogió esta red social por su popularidad entre las mujeres de 20 a 45 años para recabar las estadísticas relacionadas a nuestra idea de negocio.

Página del fan page:

https://m.facebook.com/story.php?story_fbid=152085032298486\&id=14330015984364 0 


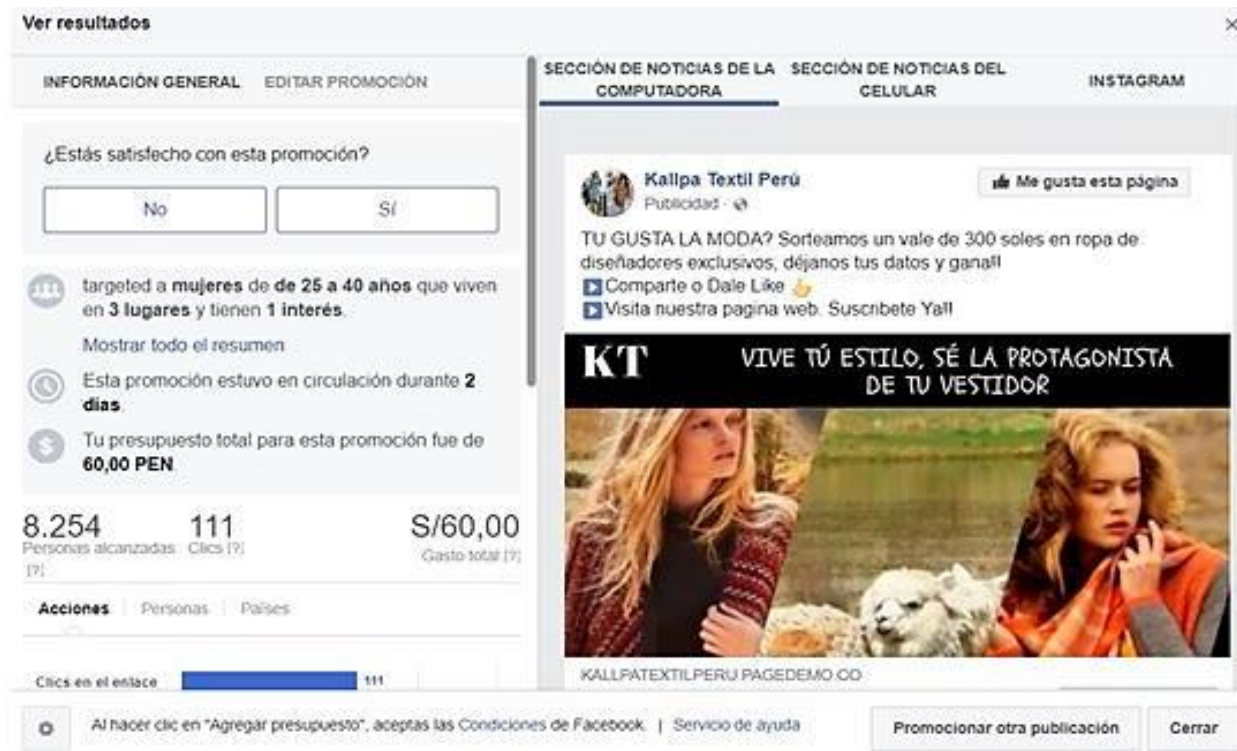

El anuncio fue publicado desde el 25 hasta el 28 de abril, nos dirigimos a las mujeres de 20 entre 45 años, ya que son mujeres que tratan de vestirse a la moda por su estabilidad económica, en los distritos de San Isidro, Miraflores y Lima, nuestro gasto total al publicar el anuncio en la página de Facebook fue de 60 soles, el cual como resultado obtuvimos 8,254 vistas y 111 clic, esta publicación fue muy productivo porque permitió darnos a conocer que cantidad de mujeres visitaron la página y dejaron sus datos en el Landing page.

\subsection{Resultado, decisión y aprendizaje: perseverar o pivotar.}

- Performance del número de conversiones (Entre el 24 y el 27 de abril)

Figura 14: Resultados 1

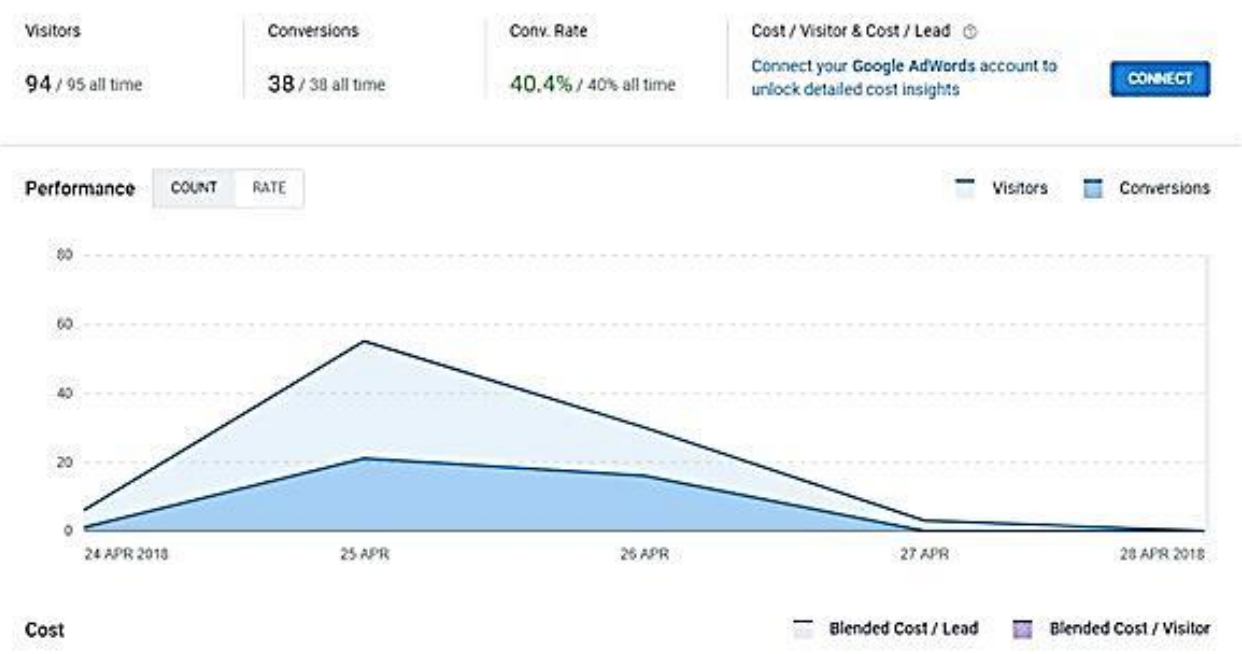


Observamos que 94 personas ingresaron a nuestra Landing Page, sin embargo, dejaron sus datos 38 personas. Se detalla el análisis de dichos datos:

- De las 38 personas que dejaron sus datos y mensajes para que nosotros los contactemos, 30 estaban interesados en comprar ropa de diseñadores peruanos.

- De las 56 personas que dejaron sus datos y mensajes para que nosotros los contactemos, 3 no estaban interesadas en comprar ropa por diseñadores peruanos.

- Performance del ratio de conversiones (Entre el 24 y el 27 de abril)

Figura 15: Resultados 2

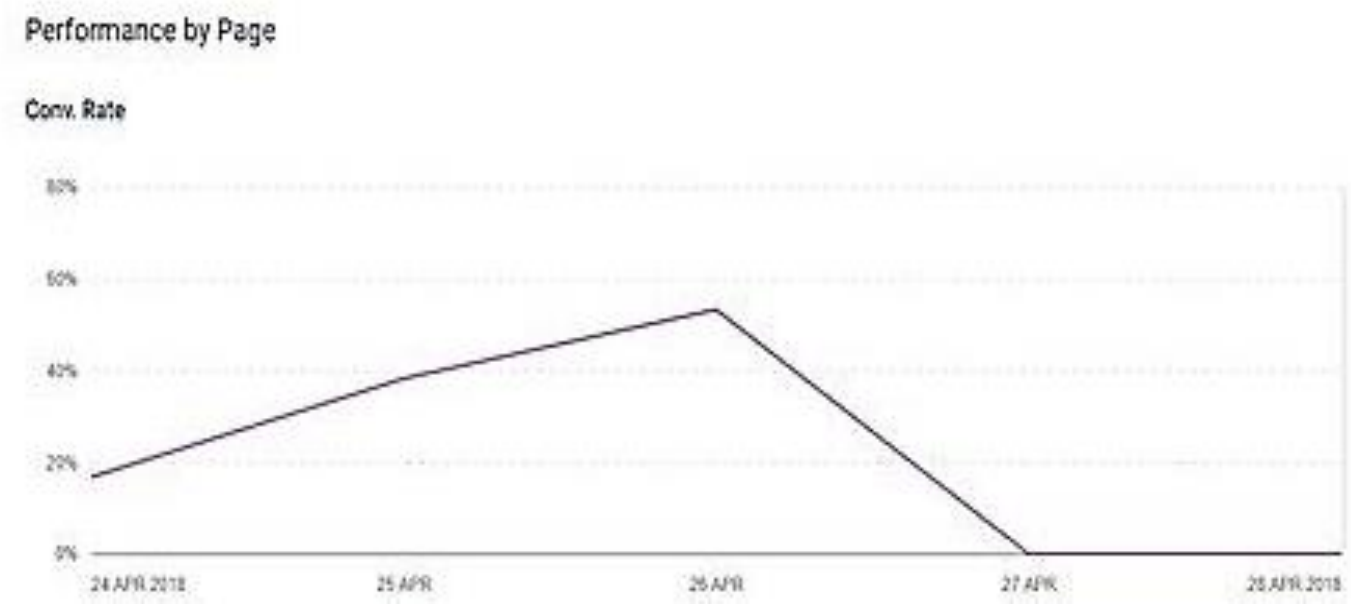

En el caso del análisis realizado a nivel de las estadísticas de la landing page hospedada en Instapage se debe resaltar que el lapso de tiempo en el cual se creó esta página el día miércoles 25/04/18 y el sábado 28/04/18 se contó con modificaciones resaltantes sobre todo en cuanto diseño, estructura y contenido, lo cual comenzó a ser atractivo para cierto público interesado en la moda.

A continuación, se detalla el enlace hacia el producto final: http://kallpatextilperu.pagedemo.co/ 
- Estadísticas Fan Page de Facebook:

Figura 16: Resultados 3

Resumen de la página Úlimos 7 dias *

Resultados del 22 de abril de 2018 at 28 de abrit de 2018

Nota: No se incluyen los datos de hoy. La actividad relativa a las estadisticas se registra seguin la zona horaria del

Pacifico. La actividad relativa a los anuncios se tegistra según la zona horaria de tu cuenta publicitaria.

\section{Acciones en la página \\ 21 de abri -27 de abril

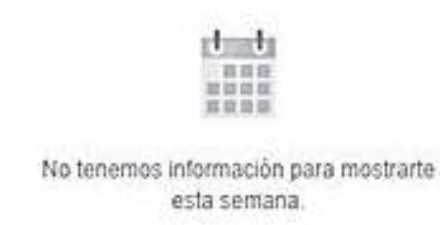

\section{Me gusta de la página}

21 de abril -27 de abnil

18

Ne gusta de la păgina $\wedge .6 \%$

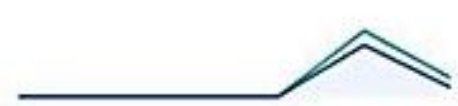

Interaceiones con publicaciones $\quad$ 21 de abri -27 de abrs

\section{0}

Interacciones con publicaciones $\mathbf{\nabla} 57^{2} \%$

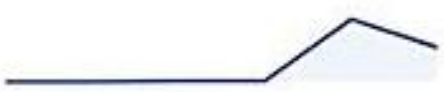

\section{Visitas a la página}

21 de abril-27 de abril

69

Visitas totales a la página $\mathbf{\nabla} 50 \%$

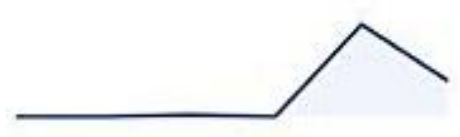

\section{Alcance}

21 de abnl -27 de abril

\subsection{6}

Personas alcanzadas $\mathbf{\nabla} 54 \%$

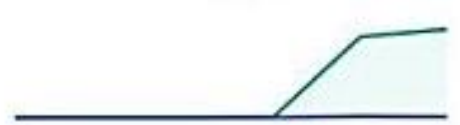

\section{Videos}

21 de abril - 27 de abril

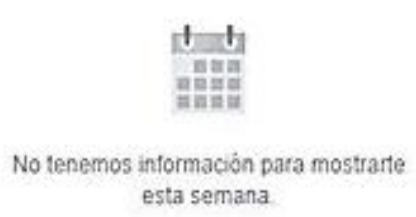

( Vistas previas de la página

21 de abrll -27 de abril

\section{3}

Vistas previas de la página $\mathbf{\nabla} 83 \%$

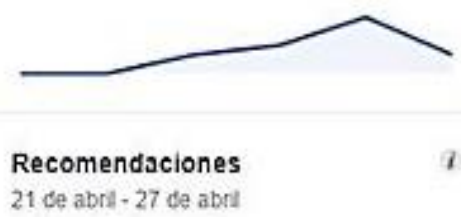

21 de abrl - 27 de abri

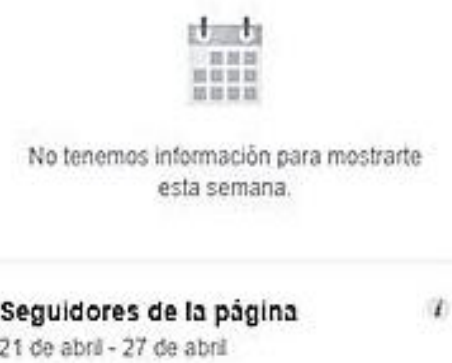

18

Seguidores de la página $\triangle 6 \%$

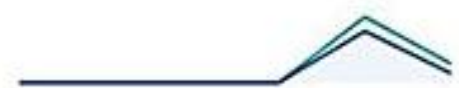

- Las estadísticas expresadas en la fan page de Facebook, podemos notar que la mayoría de personas que han ingresado a esta fan page por el anuncio publicado, quizás por lo que generó el sentido de curiosidad a leer el tema de ropa de diseñadores peruanos. Además, pudimos recibir muchos "Me gusta" y pudimos visualizar que el anuncio fue compartido por muchos usuarios. Debemos recordar que el área de acción de nuestro aviso publicado y pagado es en la ciudad de Lima. 


\section{Capítulo 4. Plan de marketing}

\subsection{Planteamiento de objetivos de marketing}

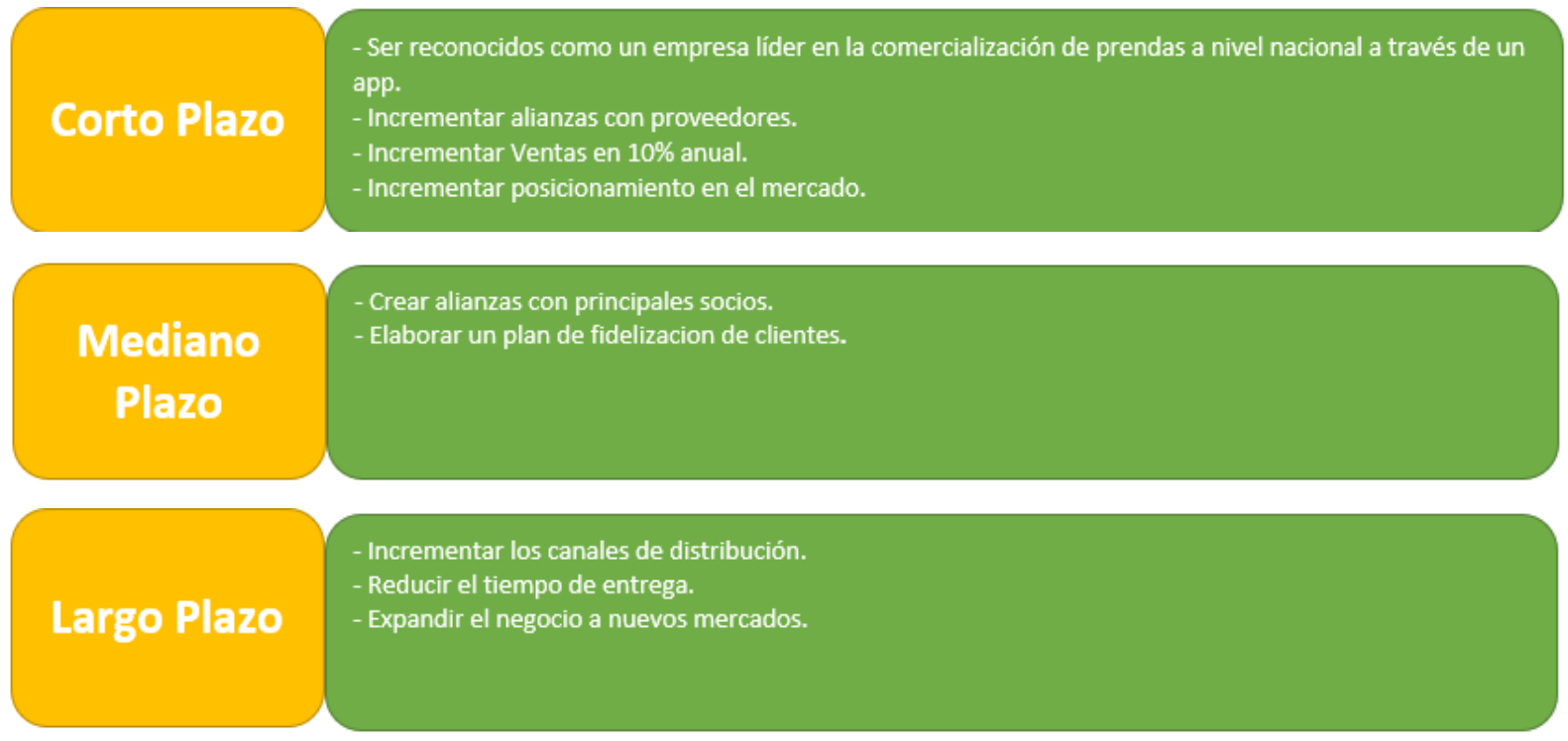

\subsection{Estrategias de marketing:}

Nuestro servicio de venta de prendas a través de una app, es diferenciado con las demás empresas, por el servicio de post venta que ofrecemos. Si el cliente adquiere una prenda de vestir y esta no es de su medida el diseñador les hará los ajustes necesarios. Además de ofrecer prendas exclusivas y de alta calidad.

\subsubsection{Segmentación}

Mujeres entre 25 a 45 años, que vivan en Lima Metropolitana y que cuenten con internet fijo o un smartphone; son mujeres independientes que buscan vestirse a la moda; que no les gusta perder el tiempo al hacer compras, prefieren encontrar variedad de diseños y que no tengan miedo a realizar una compra por internet.

Los sectores económicos a los cuales nos enfocamos son los sectores A y B, por ser un amplio mercado que se requiere satisfacer, se mantiene económicamente estable y que están dispuestos a pagar por un buen producto y servicio de calidad. Asimismo, para segmentar el mercado se utilizarán variables geográficas, demográficas, psicográficas y 
conductuales. El cuadro presentado a continuación muestra cómo se estructurará el mercado.

Tabla 5 : Cuadro de Segmentación.

\begin{tabular}{|c|l|l|}
\hline \multicolumn{2}{|c|}{ Segmentación. } \\
\hline Variable & \multicolumn{1}{|c|}{ Factor } & \multicolumn{1}{c|}{ Descripcion. } \\
\hline \multirow{2}{*}{ Geografica } & Ciudad & Lima Metropolitana \\
\cline { 2 - 3 } & Tamaño & $11,181,000$ habitantes \\
\hline \multirow{3}{*}{ Demografica } & Edad & Desde 20 a 45 años. \\
\cline { 2 - 3 } & Género & Femenino \\
\cline { 2 - 3 } & Nivel SocioEconomico & NSEA a NSE B \\
\hline \multirow{3}{*}{ Psicografica } & Estilo de Vida & Moderna \\
\cline { 2 - 3 } & Personalidad & Compra frecuente por Internet \\
\cline { 2 - 3 } & Búsqueda de Beneficios & Calidad \\
\hline
\end{tabular}

\section{Características Geográficas:}

Nuestro producto será vendido y distribuido en Lima Metropolitana, la cual cuenta con aproximadamente 11’181,000 [KRP3] [RMV4] millones de personas1. Asimismo, más adelante se plantea realizar una expansión a otros departamentos del país.

\section{Características Demográficas:}

Los productos están dirigidos a mujeres que se encuentran en el rango de edad de 20 a 45 años.

Asimismo, este producto estará dirigido a personas que pertenezcan al nivel socioeconómico A hasta el nivel B[KRP5] [RMV6], lo cual representa el 26\% de la población nacional $\left(2^{`} 907,060\right) 2$, debido a que, al ser prendas de carácter exclusivas y diseñadas con materiales de alta calidad, los precios serán más elevados que su competencia. Se espera que como mínimo nuestros clientes tengan un sueldo de S/. 1300.00 a más.

\section{Características Psicográficas:}

Son mujeres con un estilo de vida moderna, representan aproximadamente el $27 \%$ del total de mujeres $\left(1^{\prime} 547,171.01\right) 3$, los cuales presentan un gran interés por las nuevas tendencias tecnológicas, incluyendo los nuevos canales de venta que se ofrecen en el mercado (digital). Estos estilos de vida también son muy sociables, por lo que es posible que, al realizar una interacción con nuestro canal comparta la información con su círculo social. 
Otra característica de este tipo de estilo de vida es que siempre quieren verse bien, están pendientes a detalles de la moda y gustan de comprar prendas y accesorios personales por internet.

Tabla 6: Cuadro de Segmentación (Cuantitativo)

\begin{tabular}{|c|c|}
\hline \multicolumn{2}{|c|}{ Poblacion Segmentada } \\
\hline Datos & $\mathrm{N}^{\circ}$ de Personas \\
\hline Poblacion Total de Lima Metropolitana & $11,181,000$ \\
\hline Mujeres en Lima (51.25\%) & $5,730,263$ \\
\hline Edad de Segmento - 20 a 45 años.(33\%) & $1,890,987$ \\
\hline Nivel Socio Economico $(26 \%)$ & 491,657 \\
\hline Estilo de Vida Moderna (27\%) & 132,747 \\
\hline Uso de Internet en Lima ( $72 \%)$ & 95,578 \\
\hline Mujeres que compran por Internet (56.26\%) & 53,772 \\
\hline Compra de ropa por Internet $(12.83 \%)$ & 6,899 \\
\hline
\end{tabular}

Figura 17: Distribución NSE en Lima Metropolitana

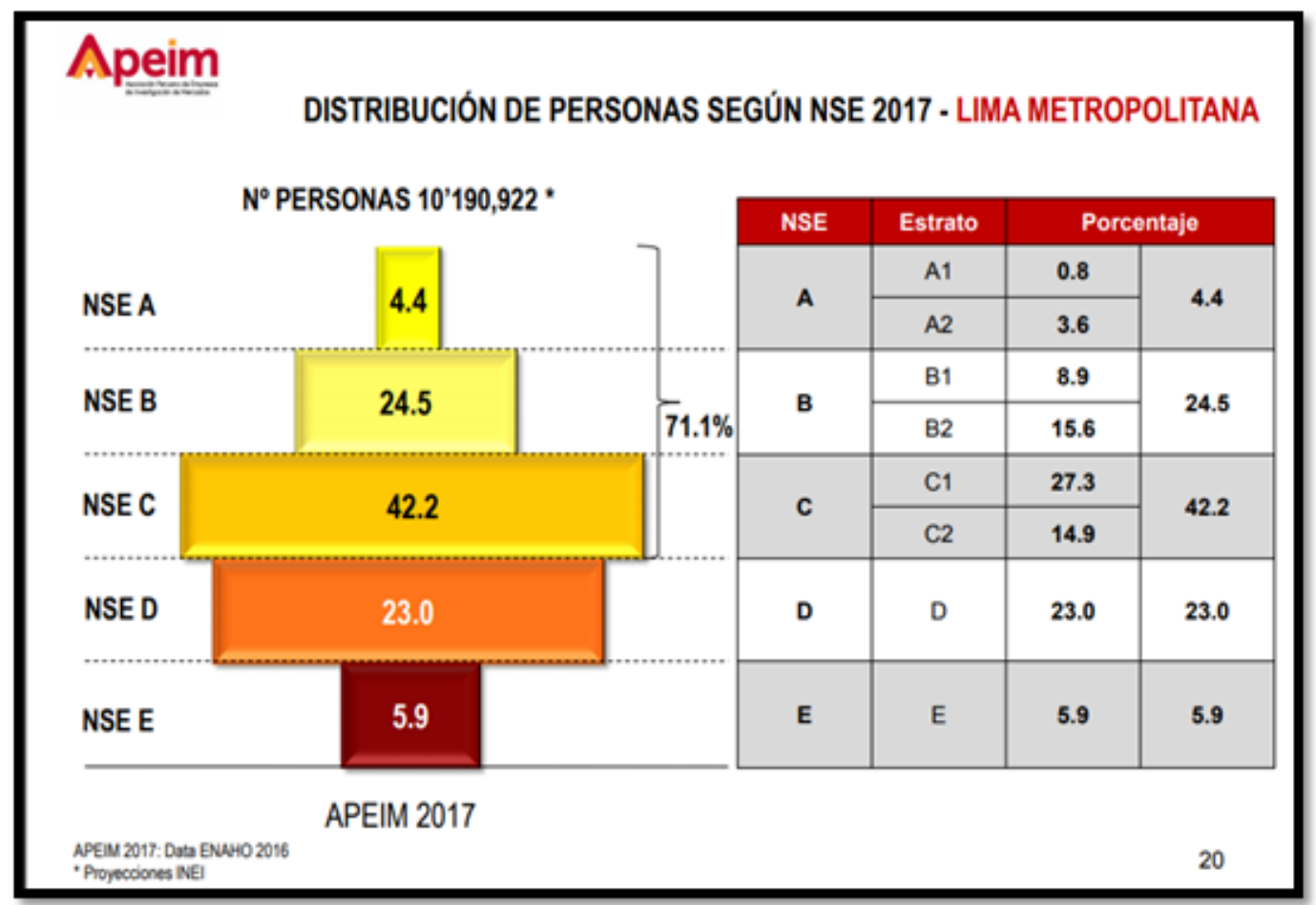


Figura 18: Distribución NSE en Lima Metropolitana por Zonas

\section{Apeim}

(\%) HORIZONTALES

\begin{tabular}{|c|c|c|c|c|c|c|c|c|}
\hline \multirow{2}{*}{ Zona } & \multirow[b]{2}{*}{ TOTAL } & \multicolumn{5}{|c|}{ Niveles Socioeconómicos } & \multirow{2}{*}{ Muestra } & \multirow{2}{*}{ Error $(8)^{\prime}$} \\
\hline & & NSEA & NSE B & NSE C & NSE D & NSE E & & \\
\hline Total & 100 & 5.0 & 24.4 & 41.0 & 23.3 & 6.3 & 4,126 & 1.6 \\
\hline Zona 1 (Puente Piedra, Comas, Carabayllo) & 100 & 0.0 & 13.9 & 44.1 & 31.0 & 11.0 & 310 & 5.5 \\
\hline Zona 2 (Independencia, Los Olivos, San Martin de Porras) & 100 & 2.6 & 26.4 & 51.9 & 18.5 & 0.6 & 352 & 5.3 \\
\hline Zona 3 (San Juan de Lurigancho) & 100 & 1.1 & 14.9 & 42.9 & 31.6 & 9.5 & 275 & 6.1 \\
\hline Zona 4 (Cercado, Rimac, Breña, La Victoria) & 100 & 2.9 & 29.6 & 41.7 & 23.3 & 2.5 & 524 & 4.4 \\
\hline $\begin{array}{l}\text { Zona } 5 \text { (Ate, Chaclacayo, Lurigancho, Santa Anita, San } \\
\text { Luis, El Agustino) }\end{array}$ & 100 & 1.4 & 14.8 & 46.6 & 29.0 & 8.2 & 352 & 5.2 \\
\hline $\begin{array}{l}\text { Zona } 6 \text { (Jesús Maria, Lince, Pueblo Libre, Magdalena, San } \\
\text { Miguel) }\end{array}$ & 100 & 13.5 & 59.7 & 20.3 & 6.2 & 0.3 & 288 & 5.7 \\
\hline $\begin{array}{l}\text { Zona } 7 \text { (Miraflores, San Isidro, San Borja, Surco, La } \\
\text { Molina) }\end{array}$ & 100 & 34.0 & 44.9 & 13.1 & 6.6 & 1.4 & 350 & 5.6 \\
\hline $\begin{array}{l}\text { Zona } 8 \text { (Surquillo, Barranco, Chornillos, San Juan de } \\
\text { Miraflores) }\end{array}$ & 100 & 3.0 & 31.5 & 40.6 & 20.3 & 4.6 & 305 & 5.9 \\
\hline $\begin{array}{l}\text { Zona } 9 \text { (Villa El Salvador, Villa Maria del Triunfo, Lurin, } \\
\text { Pachacamac) }\end{array}$ & 100 & 0.0 & 10.4 & 45.8 & 32.1 & 11.7 & 308 & 5.6 \\
\hline $\begin{array}{l}\text { Zona } 10 \text { (Callao, Bellavista, La Perla, La Punta, Carmen de } \\
\text { la Legua, Ventanilla) }\end{array}$ & 100 & 1.5 & 21.0 & 44.8 & 22.9 & 9.8 & 1015 & 3.1 \\
\hline Otros & 100 & 0.0 & 12.8 & 31.9 & 34.0 & 21.3 & 47 & 14.3 \\
\hline
\end{tabular}

\subsubsection{Posicionamiento}

En los objetivos y segmentación se indicó que los potenciales consumidores de nuestro producto, buscarán la calidad y exclusividad de nuestras prendas por encima de otros atributos que pueda tener el producto. Por ello, se propone seguir una estrategia de posicionamiento de "Más por Más" la cual se grafica en la siguiente Matriz.

Figura 19: Matriz Precio/Beneficio

Precio

Beneficio

\begin{tabular}{|c|c|c|c|}
\hline & Mas & El mismo & Menos \\
\hline Mas & $\begin{array}{l}\text { Mas por } \\
\text { Mas }\end{array}$ & $\begin{array}{l}\text { Mas por lo } \\
\text { mismo }\end{array}$ & $\begin{array}{l}\text { Mas por } \\
\text { Menos }\end{array}$ \\
\hline Lo mismo & & & $\begin{array}{l}\text { Lo mismo } \\
\text { por Menos }\end{array}$ \\
\hline Menos & & & $\begin{array}{l}\text { Menos por } \\
\text { Menos }\end{array}$ \\
\hline
\end{tabular}

La matriz anterior nos indica la posición que tomará la organización en el mercado. Se ofrecerá al mercado prendas de alta calidad con un precio elevado frente a los distintos competidores que operan dentro del mercado. La estrategia planteada sugiere además que debemos innovar constantemente en distintos procesos internos. Inicialmente, sugerimos al cliente que al utilizar productos exclusivos, únicos y de alta calidad, reflejan 
exactamente las características de quien lo compra. Asimismo, se ofrecerá otro tipo de servicios como la comunicación constante con nuestra organización para atender dudas, sugerencias o cualquier interacción que desee tener el cliente a través de llamadas telefónicas, correos, chat, etc. Además, daremos un servicio de ajuste de prendas para personalizar aún más la interacción con el cliente ofreciendo prendas de calidad y fácil canal de compras.

Tener el app de Kallpa textil Perú te ayudará a minimizar el tiempo de compra y realizarlo de una manera fácil y sencilla.

\subsubsection{Mercado objetivo}

\section{Tamaño de mercado}

Según el diario el comercio, el mercado Peruano en el ámbito de la ropa se encuentra en constante crecimiento, ya que las tendencias y gustos de las personas cambia constantemente. Asimismo, nos basaremos en encuestas para poder saber cuál es la preferencia de las personas en cuanto a las tendencias y que ofreceremos en nuestra página. El público que será escogido para este estudio serán todos los ciudadanos de la ciudad de lima y el medio que se utilizará para llegar a estos serán las encuestas por medios virtuales. También se contarán con colaboradores en lugares específicos de la ciudad para que puedan realizar el mismo trabajo.

Figura 20. Características del consumidor peruano

\section{BBVA}

\section{Características del consumidor peruano}

\section{Exigente y racional}

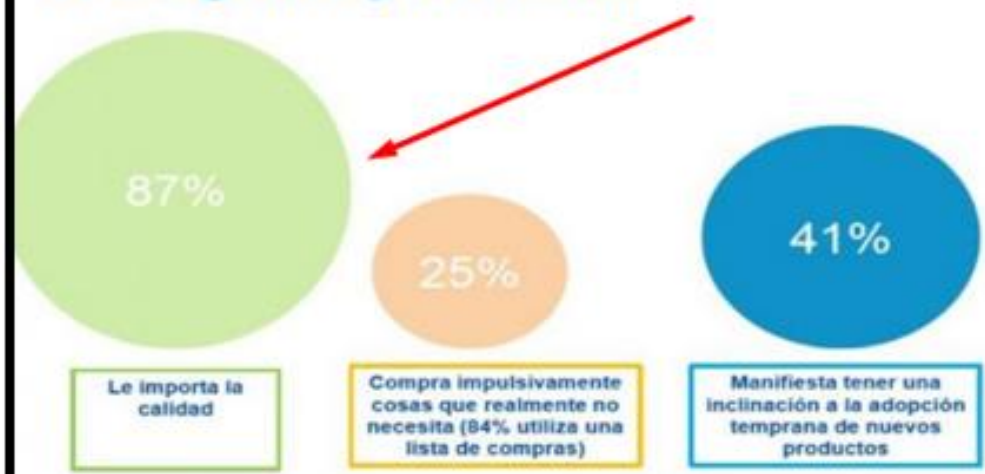

Fuente: Elaborado por BBVA Research Perú 


\subsubsection{Tamaño de mercado disponible}

De acuerdo al nivel socioeconómico A y B que encontramos en Lima Metropolitana el mercado es grande y disperso geográficamente. Al ofrecer un producto de calidad y exclusivo los precios de dichas prendas son altos, como lo mencionamos anteriormente, es por ello que nos enfocaremos en Lima Moderna que comprende algunos de los siguientes distritos: San Miguel, Jesus maria, Pueblo Libre, Magdalena, San Isidro, La Molina, Barranco, San Borja, Surquillo.

Figura 21: Datos Lima Metropolitana

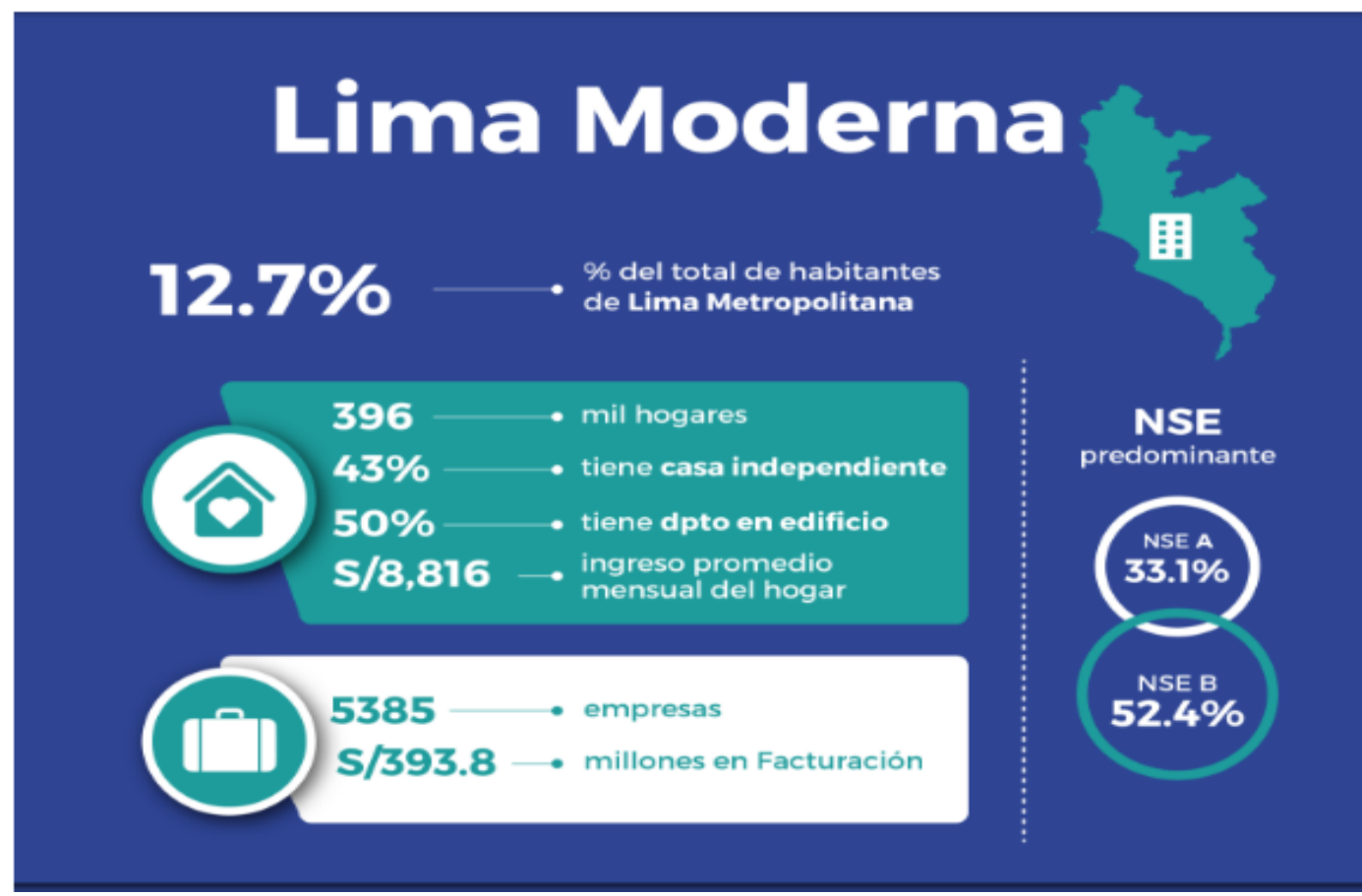

Fuente: Ipsos Perú 2017

\subsubsection{Tamaño de mercado operativo (target)}

Para calcular el tamaño del mercado operativo se ha utilizado a las mujeres de entre 25 y 55 años de edad de la ciudad de Lima que consta de 1890987 personas. Ha sido aplicado el filtro para los sectores A y B de esta población, correspondiente al 26\% del total, luego se utilizó la variable de sus estilos de vida modernos, lo cual corresponde al $27 \%$. Fue utilizado el uso de internet en Lima (72\%), mujeres que compran por internet $(56,26 \%)$ y por último la compra de ropa por internet que es equivalente al $12.83 \%$. Luego de todos los filtros se obtiene un mercado operativo de 6899 personas. 
Tabla 7: Cuadro de Segmentación (Cuantitativo)

\begin{tabular}{|c|c|}
\hline \multicolumn{2}{|c|}{ Poblacion Segmentada } \\
\hline Datos & $\mathbf{N}^{\circ}$ de Personas \\
\hline Poblacion Total de Lima Metropolitana & $11,181,000$ \\
\hline Mujeres en Lima (51.25\%) & $5,730,263$ \\
\hline Edad de Segmento - 20 a 45 años.(33\%) & $1,890,987$ \\
\hline Nivel Socio Economico (26\%) & 491,657 \\
\hline Estilo de Vida Moderna (27\%) & 132,747 \\
\hline Uso de Internet en Lima ( $72 \%)$ & 95,578 \\
\hline Mujeres que compran por Internet ( $56.26 \%)$ & 53,772 \\
\hline Compra de ropa por Internet ( $12.83 \%)$ & 6,899 \\
\hline
\end{tabular}

Figura 22: Distribución de habitantes por Distrito

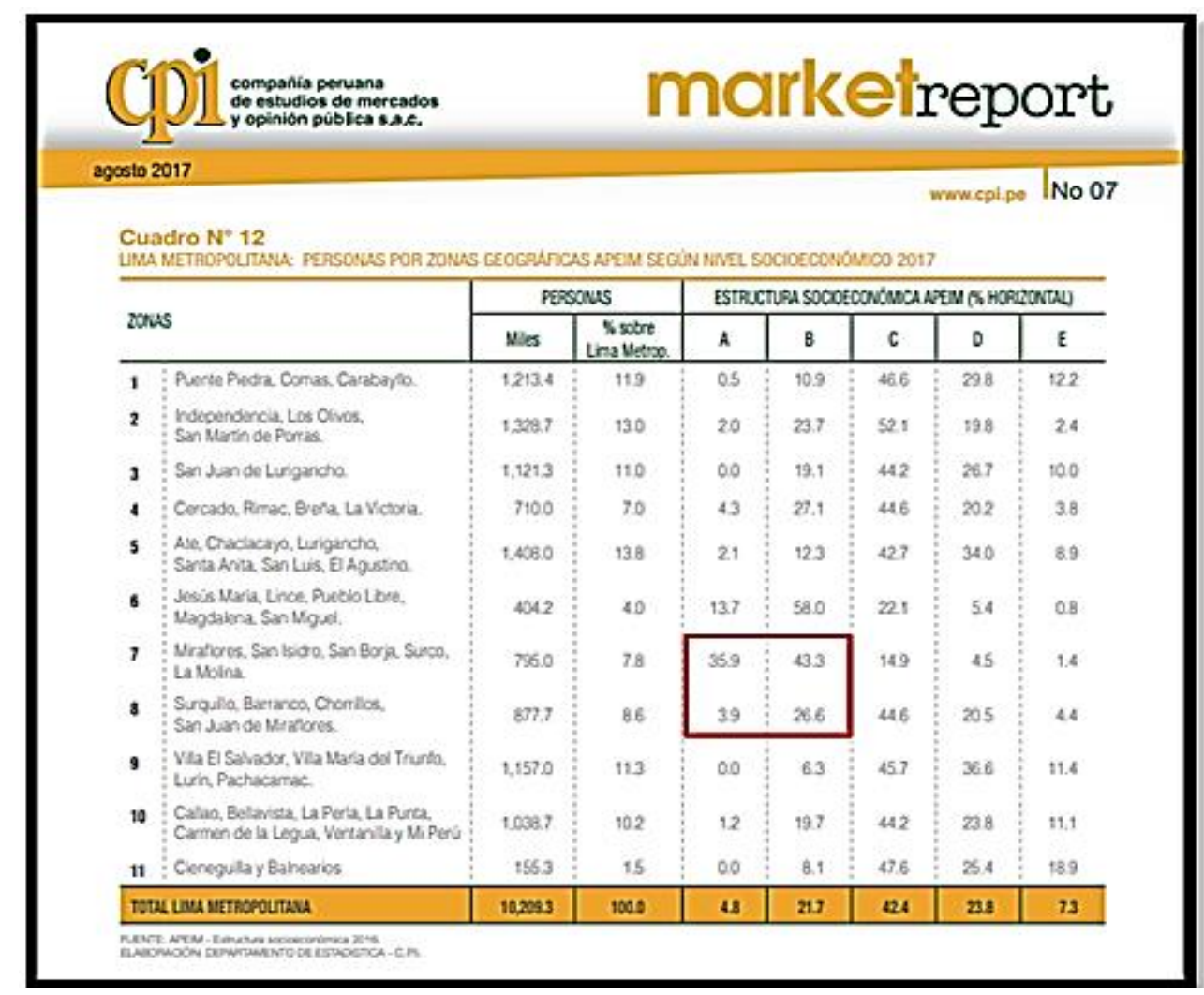

Cuadro $\mathrm{N}^{\circ} 9$

LIMA METROPOLITANA: HOGARES Y POBLACIÓN POR SEXO Y GRUPOS DE EDAD SEGÚN NIVEL SOCIOECONÓMICO 2017 (En miles)

\begin{tabular}{|c|c|c|c|c|c|c|c|c|c|c|c|}
\hline \multirow[b]{2}{*}{ NSE } & \multicolumn{2}{|c|}{ HOGAPES } & \multicolumn{2}{|c|}{ POBLACION } & \multicolumn{7}{|c|}{ POBLACIÓN POR GRUPOS DE EDAD } \\
\hline & Mis & $\%$ & Ms & $\%$ & $\begin{array}{c}00-05 \\
\text { años }\end{array}$ & $\begin{array}{c}06-12 \\
\text { años }\end{array}$ & $\begin{array}{c}\begin{array}{c}13-17 \\
\text { años }\end{array} \\
\end{array}$ & $\begin{array}{c}18 \cdot 24 \\
\text { años }\end{array}$ & $\begin{array}{c}25 \cdot 39 \\
\text { años }\end{array}$ & $\begin{array}{l}40 \cdot 55 \\
\text { anos }\end{array}$ & $\begin{array}{l}56 \cdot+ \\
\text { años }\end{array}$ \\
\hline ABB & 751.5 & 27.5 & $2,698.7$ & 26.5 & 183.8 & 249.1 & 193.6 & 297.7 & 606.8 & 597.2 & 570.5 \\
\hline c & $1,106.8$ & 40.5 & $4,334.7$ & 42.4 & 352.5 & 455.1 & 355.8 & 552.8 & 1061.2 & 876.9 & 680.4 \\
\hline D & 664.0 & 24.3 & $2,430.2$ & 23.8 & 287.0 & 294.6 & 221.0 & 370.6 & 645.8 & 400.5 & 210.7 \\
\hline E & 210.4 & 7.7 & 745.7 & 7.3 & 131.2 & 107.7 & 68.0 & 106.5 & 178.5 & 92.0 & 62.8 \\
\hline $\begin{array}{l}\text { TOTAL LIMA } \\
\text { METROPOLITANA }\end{array}$ & $2,732.7$ & 100.0 & $10,209.3$ & 100.0 & 954.5 & $1,106.5$ & 838.4 & $1,326.6$ & $2,492.3$ & $1,966.6$ & $1,524,4$ \\
\hline
\end{tabular}

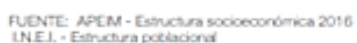

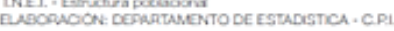




\subsubsection{Potencial de crecimiento del mercado}

El negocio de venta de vestimentas por medio de la web se encuentra por el momento en un constante crecimiento, se puede observar que el uso de plataformas web para realizar compras ha aumentado en la ciudad de Lima. Tomando en cuenta este punto se puede llegar a la conclusión de que la empresa cuenta con un gran potencial de crecimiento.

Se iniciará la venta de estos en la ciudad de Lima para luego poder abarcar todo el mercado peruano.

Figura 23: Grafica de las cifras de los consumidores via Online

\section{CIFRAS: COMPRAS ONLLNE}

CONSUMIDORES ONLINE

3'273.732 USUARIOS PERUANOS COMPRAN EN LINEA

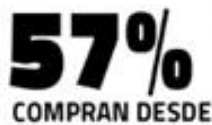

COMPRAN DESDE SU SMARTPHONE.

LOS CONSUMIDORES

PREFIEREN COMPRAR POR:

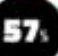

PLATAFOBMAS DE
COMPRA Y VENTA
POP INTEATET

POR INTEANET

Actialmanto 307 rr

Actuaimente, 3.27
de Comex Peru.

Fuente: Ipsos Perú 2017
- 11\% creceria el e-commerce en

todo el Perú este año y un $16 \%$ en

2018, según Ipsos Perú.

- 3.27 milliones de usuarios

peruanos realizan compras online.

- 70\% de los consumidores

reservan sus viajes por Internet.

Los jóvenes entre 18 y 24 años

son los que más usan esta

modalidad.

SEGÚN CANALES DE COMPRA

18 a 24 años

\section{7:}

55 a 64 años

icanal offunes:

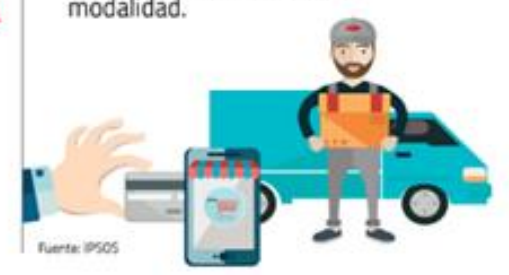

Tnerteses 
A continuación, se muestra el ciclo de vida de Kallpa Textil SAC.

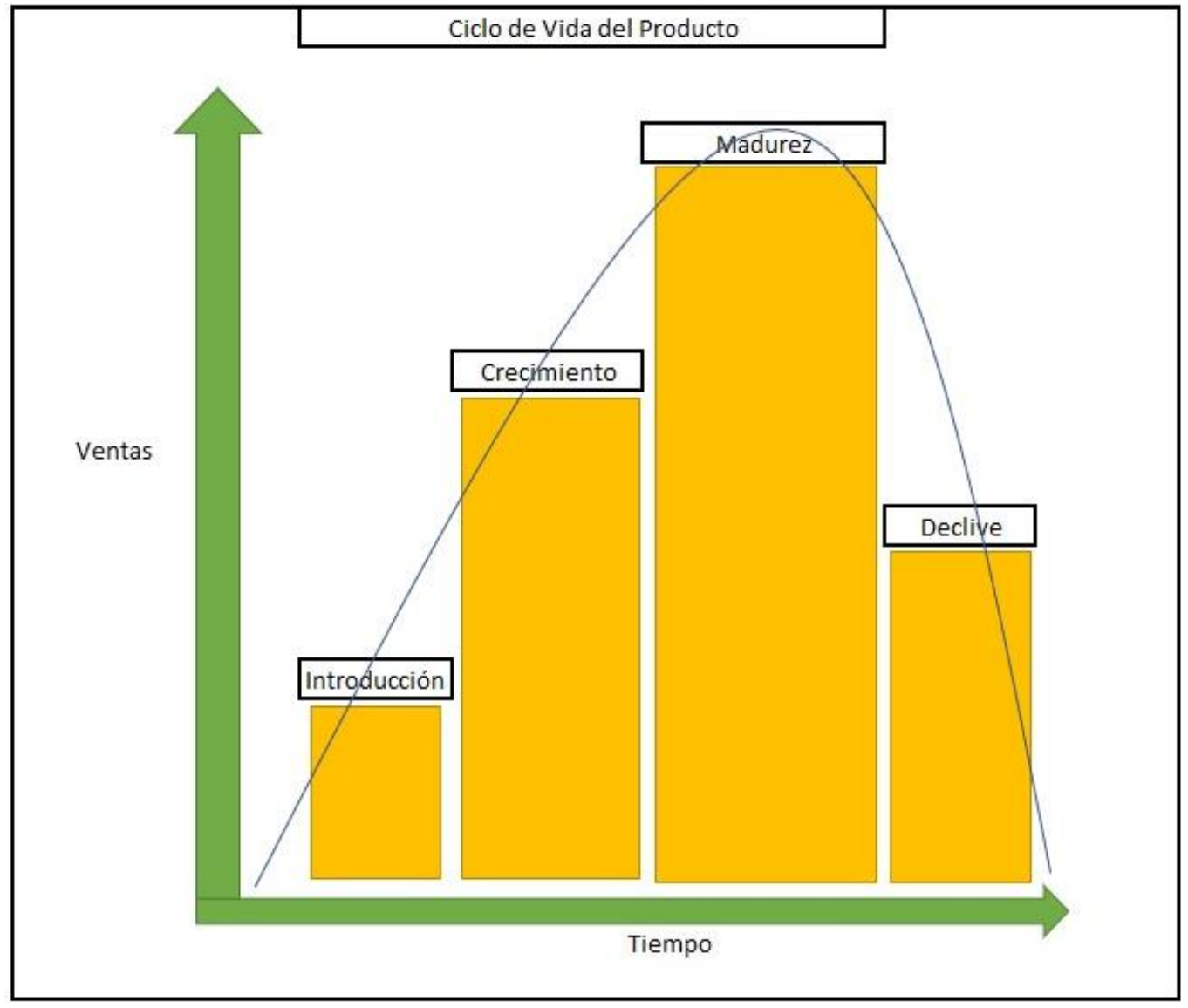

Fuente: Elaboración Propia.

Asimismo, de acuerdo a la matriz de Ansoff, la organización utilizará una estrategia basada en desarrollo de nuevos productos (página web de E-Commerce especializada en venta de prendas de diseñadores nacionales) para satisfacer las nuevas exigencias de un público cada vez más exigente.

\section{PRODUCTOS}

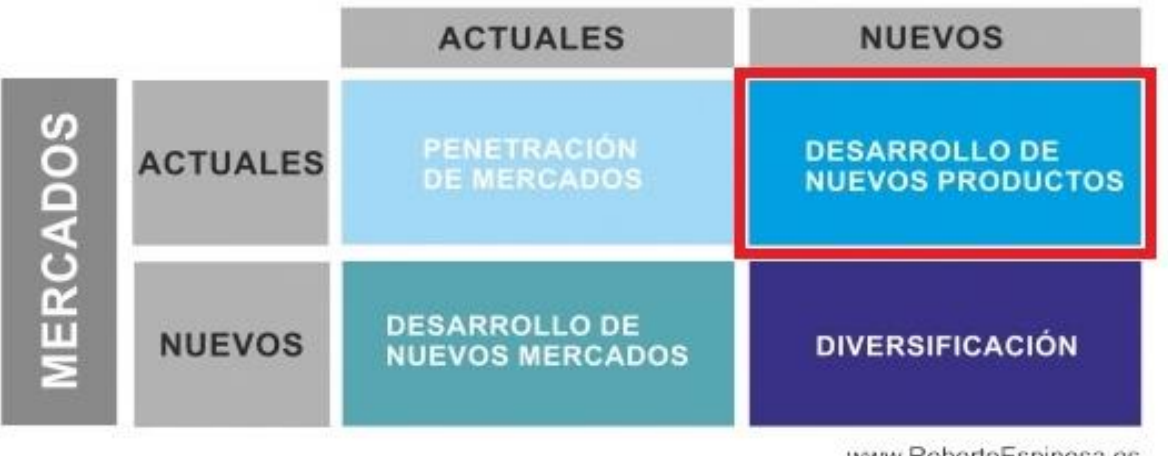

www. RobertoEspinosa es 


\subsubsection{Diseño de producto / servicio}

Para determinar el producto que se pretende desarrollar, se han considerado los distintos niveles de producto que menciona Philip Kotler en su libro de Fundamentos de Marketing. A continuación, se presentará cada uno.

\section{- Producto Básico}

Por definición lo que se va a elaborar es una página web y aplicación en donde los clientes puedan adquirir distintas prendas exclusivas de fabricación nacional. Creamos una página para satisfacer las necesidades de compra de los consumidores.

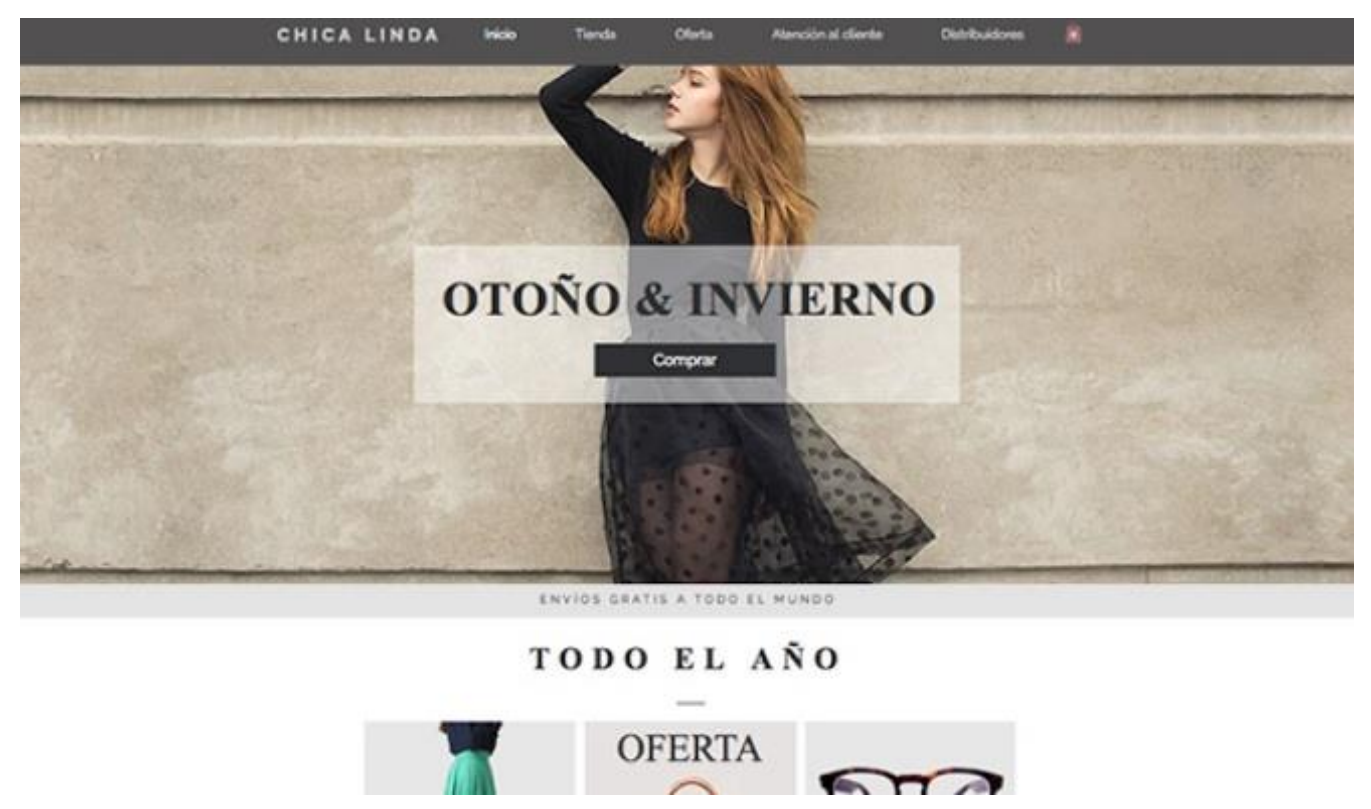

- Producto Real

Se creará una página web dinámica, en donde las personas que ingresen puedan ver un contenido variable. El cliente tendrá la posibilidad de seleccionar la marca, tipo de prenda, modelos, tallas, en general distintas características de la prenda elaborada por el diseñador e ir seleccionando la que le guste para añadirlo a un carrito de compras. Asimismo, tendrá un diseño adecuado para el mercado donde nos estemos enfocando, cuidando los colores e imágenes que acompañarán al diseño de la web. Buscamos que el cliente se sienta cómodo en nuestra página o aplicación para que su experiencia sea agradable y realice compras.

Asimismo, la página web dará la posibilidad de interactuar con el cliente por medio de consultas o sugerencias, de esta manera el cliente podrá comunicarse con nosotros y 
personalizar sus productos a su medida o realizar cualquier consulta que tenga con respecto a la fabricación del producto de su interés.

\begin{tabular}{|l|l|}
\hline \multicolumn{2}{|c|}{ Caracteristicas } \\
\hline Desarrollo & Lenguaje PHP y JAVA. \\
\hline Diseño & Coherente con el mercado y facil manejo al usuario \\
\hline Optimizacion & Palabras claves para un mejor posicionamiento (SEO) \\
\hline Almacen de Informacion & Si, por medio de un hosting. \\
\hline Tipo de Página & Dinámica \\
\hline Acceso & Pública \\
\hline Home & Diseño atractivo con contenido que enganche al usuario \\
\hline Publicidad & Si \\
\hline Interacción & Si \\
\hline Información & Privada \\
\hline Seguridad & Alta \\
\hline
\end{tabular}

- Producto Aumentado

Nuestro producto aumentado pasará a tener alta importancia en la postventa, comunicándonos con el cliente si es que recibió su pedido de forma correcta y a tiempo, si encuentra alguna prenda dañada o si tuvo alguna inquietud durante la compra en nuestra página. Es importante para la organización tener a nuestros clientes contentos y que estos participen en las mejoras que se puedan elaborar dentro de la página web. Esta conversación entre cliente y empresa no solo nos permite mejorar como organización, sino que hacemos participe al cliente del formato de negocio.

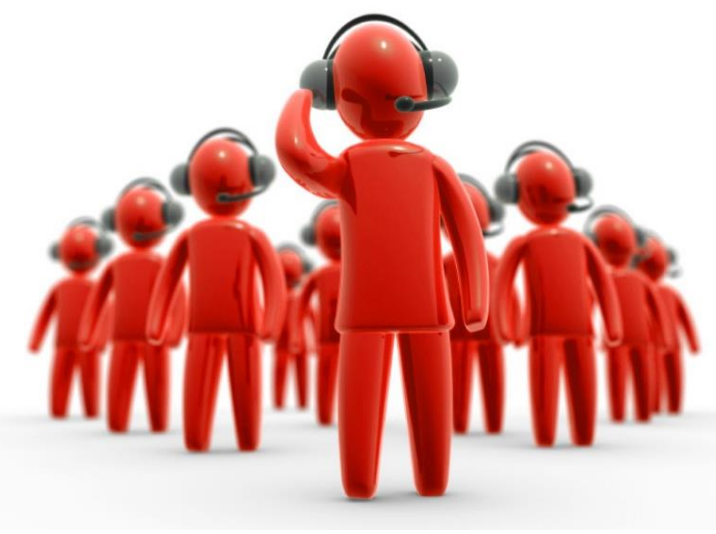

- Marca

La marca a trabajar tiene como denominación Kallpa Textil, la cual hace referencia a una de las lenguas representativas de la historia nacional: el quechua. 
Kallpa significa fuerza y se decidió utilizar este nombre, debido a la poca atención que ha recibido nuestra industria textil, tanto en fabricación como en comercialización de los productos. Con la marca, queremos que el mercado nacional de fabricación de prendas nacionales se expanda y compita a un precio atractivo con distintas marcas de renombre mundial.

La palabra textil, como su propio nombre indica, hace referencia a los productos que vamos a comercializar en nuestra web y aplicación, dando a entender que solamente encontrarás productos relacionados a moda y/o prendas.

En conjunto las 2 palabras seleccionadas para la marca refuerzan la propuesta de valor creada para la organización, dando un impulso a nuestra manufactura textil y a la comercialización de las mismas.

- Logotipo:

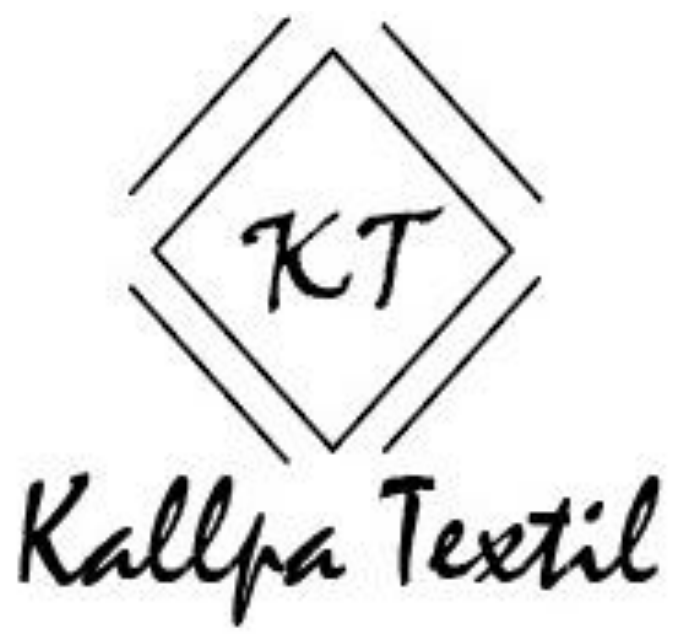

\subsubsection{Estrategia de precios (Análisis de costos, precios de mercado)}

Para poder realizar una adecuada fijación de precios se deben considerar diversos factores. A continuación, presentaremos algunos de ellos:

\section{- Factores Externos}

- Naturaleza del mercado y competencia

El mercado de venta de prendas textiles de fabricación nacional se puede considerar como el de una competencia pura, donde ningún productor o consumidor dispone del poder necesario para fijar precios en el mercado, ya que existen diversos proveedores en la fabricación de prendas y muchos compradores de ropa con diseños atractivos y 
exclusivos. A pesar de esto, existe en el mercado una gran variedad de precios, ello se debe, principalmente a la calidad y procedencia de las prendas fabricadas.

- Naturaleza del consumidor

Según un estudio realizado por, los consumidores del segmento seleccionado están dispuestos a pagar más por un producto de más calidad y que les brinde seguridad; siendo así un segmento que valora más la calidad y/o otros atributos por encima del precio. Otro factor a considerar del consumidor es que gusta que los productos adquiridos lleguen rápido a sus manos. Con frecuencia, los pedidos vía online demoran más de una semana en llegar a destino.

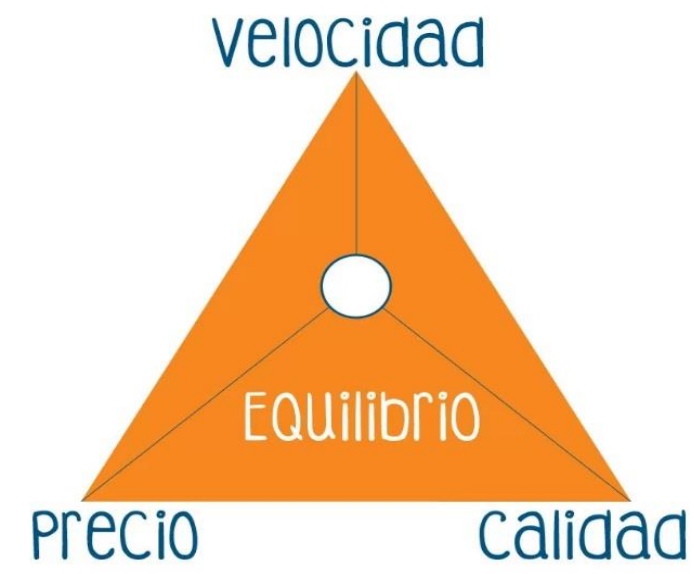

\section{- Factores Internos}

- Costos

El precio también está en función de los costos por la elaboración del producto a ofrecer. Estos comprenden los mantenimientos proyectados para los servidores utilizados y el pago anual por dominio y licencias para operar en el mercado. Asimismo, debe el margen aceptable de ganancia por cada prenda vendida.

\section{Estrategia}

Después de haber analizado el sector y el comportamiento de los consumidores, se puede llegar a la conclusión que la mejor estrategia a utilizar será la de una fijación psicológica de precios.

Esta estrategia implica que todos nuestros clientes asocien de manera emocional el producto con sus atributos. De esta manera estarán dispuestos a pagar más por la 
calidad, seguridad y distintos atributos que se adquiere al comprar una de nuestras prendas.

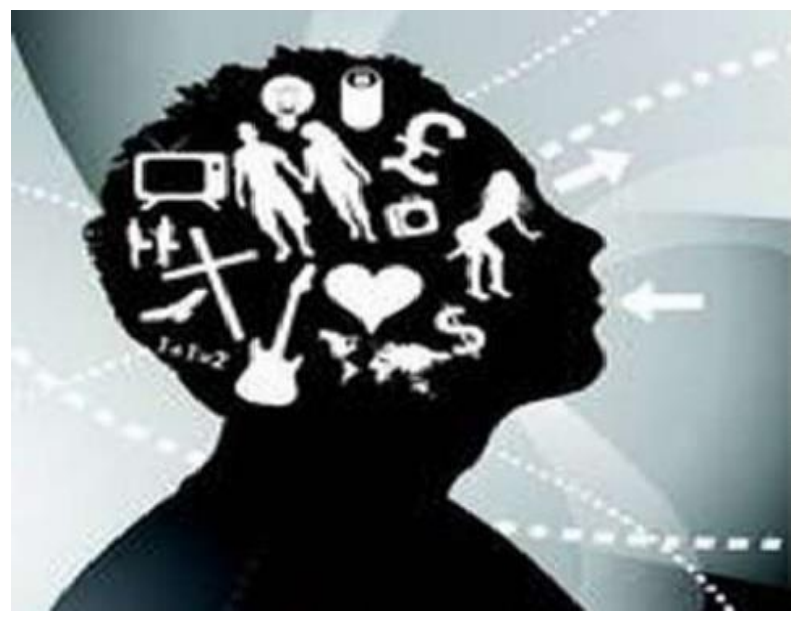

\subsubsection{Estrategia comunicacional}

La comunicación será directa con nuestros usuarios, manteniendo una relación cercana con ellas para así conocer sus gustos y preferencias, ofreciendo un servicio personalizado y de calidad. Manteniendo esta cercanía nos ayudará como empresa a realizar una retroalimentación de modo que nos enteramos de sus necesidades y lo que desean.

La herramienta principal que utilizará Kallpa textil será las redes sociales a través del facebook haremos publicidad para que los clientes conozcan de nuestra app y puedan adquirir las prendas que ofrecemos, estaremos comunicados con ellos a través de chat online, para poder resolver sus dudas y consultas, así como también la comunicación estrecha de postventa, un ejemplo de ello es ofreciéndole el ajuste de sus prendas en el caso no le quede, tendrá la opción de comunicarse con nosotros para poder realizarles el servicio.

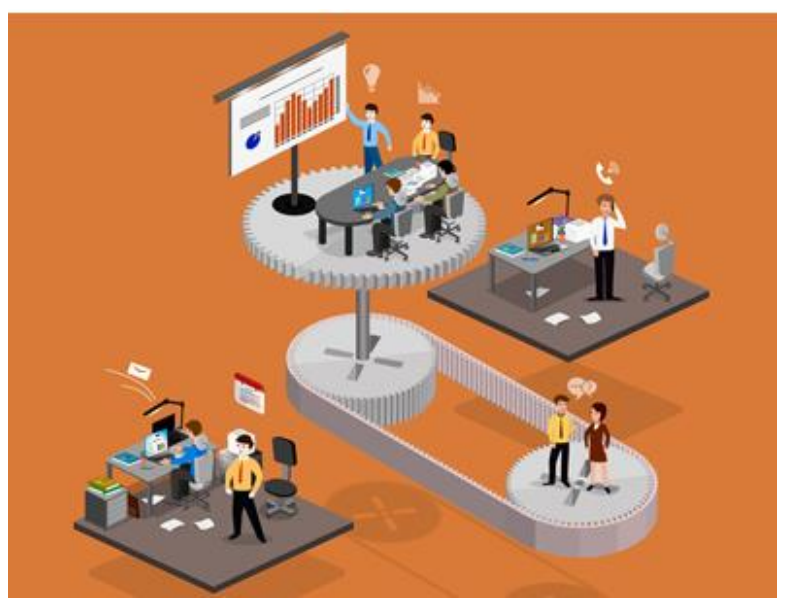




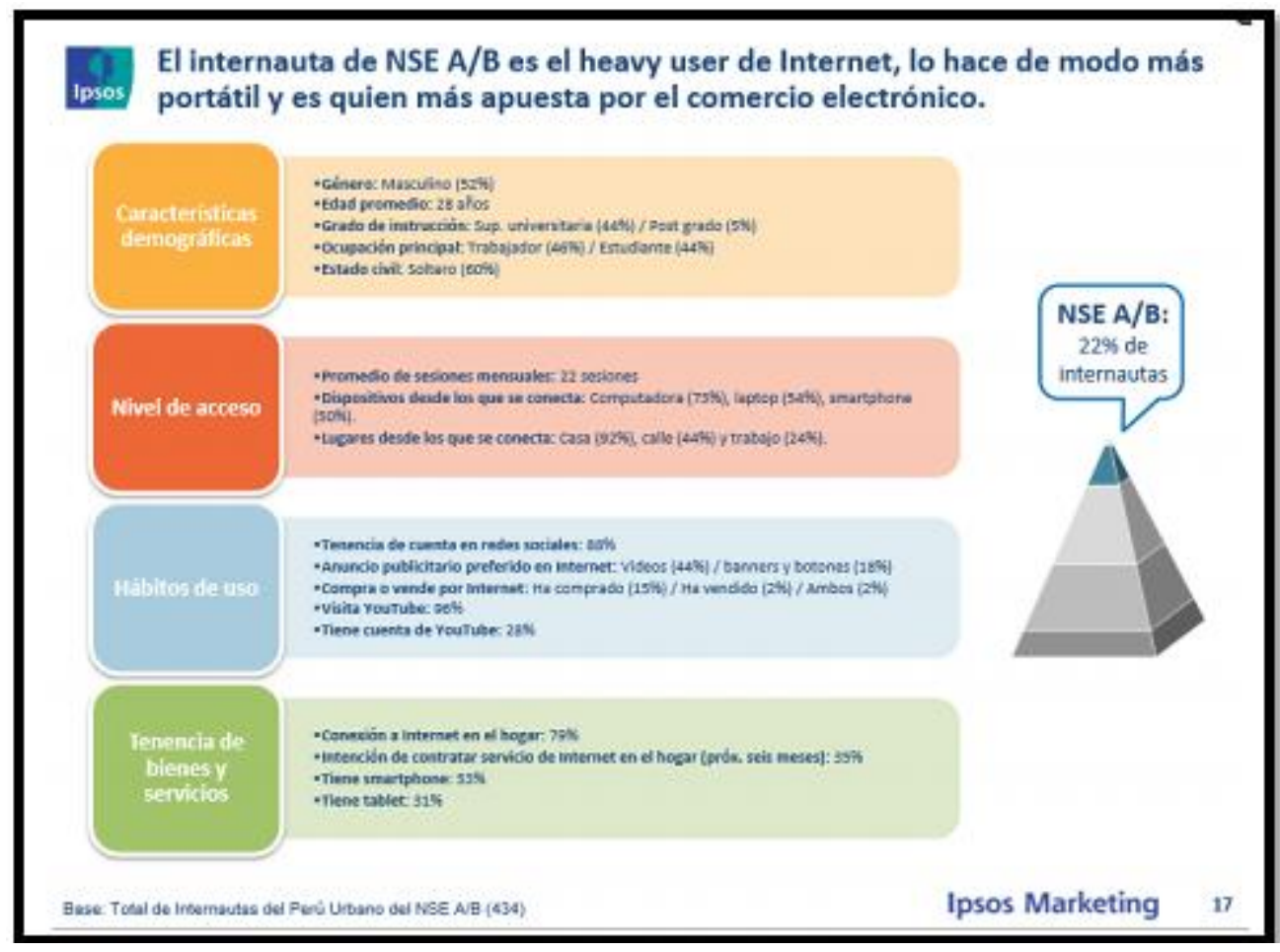

\subsubsection{Estrategia de distribución}

Kallpa textil atenderá directamente al cliente a través de su plataforma virtual (app). Los encargados de entregar nuestras prendas será tercerizado y lo harán por toda la ciudad de Lima Moderna, se desplazará a través de un medio de transporte confiable, de esta manera llegarán las prendas seguras a su destino.

\subsection{Plan de Ventas y Proyección de la Demanda}

\begin{tabular}{|c|c|c|c|c|c|}
\cline { 2 - 6 } \multicolumn{1}{c|}{} & Tipo de Servicio & Q prendas & Frecuencia & QxFrecuencia & Ticket Promedio \\
\hline $100 \%$ & Compra por delivery & 147 & $1 \times$ mes & 147 & 181 \\
\cline { 2 - 6 } & Total Q & 147 & \multicolumn{2}{c}{} \\
\cline { 2 - 6 }
\end{tabular}

\begin{tabular}{|l|r|}
\hline Blusas & 129 \\
\hline Polos & 99 \\
\hline Pantalones & 229 \\
\hline Shorts & 169 \\
\hline Blazers & 279 \\
\hline Ticket promedio (Soles) & 181 \\
\hline
\end{tabular}

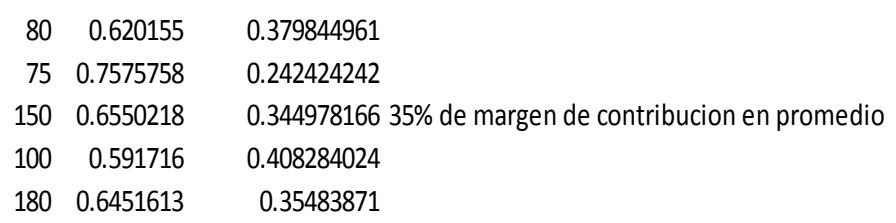

\begin{tabular}{|c|c|c|c|c|c|c|c|c|c|c|c|c|c|}
\hline $\mathrm{P} \times \mathrm{Q}$ & Enero & Febrero & Marzo & Abril & Mayo & Junio & Julio & Agosto & Septiembre & Octubre & Noviembre & Diciembre & Total del primer año \\
\hline Factor de estacionalidad & 1 & 1 & 1 & 1 & 1.4 & 1 & 1.4 & 1 & 1 & 1 & 1 & 1.4 & \\
\hline Compra ado (Soles) & $26,607,00$ & $26,607,00$ & $26,607,00$ & $26,607,00$ & $37,249,8$ & $7,249,8$ & $52,149,72$ & $52,149,72$ & 52,149,72 & $52,149,72$ & $52,199,72$ & 73,009,61 & $514,685,81$ \\
\hline
\end{tabular}


- Se está considerando un factor de estacionalidad de acuerdo a la información recopilada con diseñadores locales, donde se accedió a información interna del rubro considerando que en los meses de mayo, julio y diciembre por las festividades que se celebran en dichos meses (día de la madre, fiestas patrias y navidad).

- El plan de ventas contempla la cantidad adquirida de los clientes mediante nuestra app, se considera la estacionalidad y se llega a un ingreso anual de 514,685.81 soles.

\subsection{Presupuesto de Marketing}

\begin{tabular}{|c|c|c|c|c|c|c|c|c|c|c|c|c|c|}
\hline & Enero & Febrero & Marzo & Abril & Mayo & Junio & Julio & Agosto & Septiembre & Octubre & Noviembre & Diciembre & Total \\
\hline Community manager & $1,050.00$ & $1,050.00$ & $1,050.00$ & $1,050.00$ & $1,050.00$ & $1,050.00$ & $1,050.00$ & $1,050.00$ & $1,050.00$ & $1,050.00$ & $1,050.00$ & $1,050.00$ & $12,600.00$ \\
\hline Publicidad en redes sociales & 350.00 & 350.00 & 350.00 & 350.00 & 350.00 & 350.00 & 350.00 & 350.00 & 350.00 & 350.00 & 350.00 & 350.00 & \begin{tabular}{|l|l|} 
& $4,200.00$ \\
\end{tabular} \\
\hline Crm Online Zoho & 50 & 50 & 50 & 50 & 50 & 50 & 50 & 50 & 50 & 50 & 50 & 50 & 50 \\
\hline Gerente Comcercial (Administrador y/o contador) & $2,500.00$ & $2,500.00$ & $2,500.00$ & $2,500.00$ & $2,500.00$ & $2,500.00$ & $2,500.00$ & $2,500.00$ & $2,500.00$ & $2,500.00$ & $2,500.00$ & $2,500.00$ & $30,000.00$ \\
\hline App & $1,250.00$ & $1,250.00$ & $1,250.00$ & $1,250.00$ & $1,250.00$ & $1,250.00$ & $1,250.00$ & $1,250.00$ & $1,250.00$ & $1,250.00$ & $1,250.00$ & $1,250.00$ & $15,000.00$ \\
\hline
\end{tabular}

Nuestro presupuesto de marketing es de 61,850

Donde el community manager cumplira labores de post venta y manejo de nuestras redes sociales mediante un crm para la mejor gestion de relaciones con nuestros clientes

Dependiendo del crecimiento de la empresa se evaluara contratar mas community manager para cumplir el mismo labor y cumplir nuestros estandares de postventa.

En las alianzas con los diseñadores negociaremos temas de costura adicionales y envío para nuestros clientes y sera neteado en su costo. 


\section{Capítulo 5. Plan de Operaciones}

\subsection{Políticas Operacionales}

\subsubsection{Calidad}

En Kallpa Textil buscamos la satisfacción del cliente a través de nuestro propuesta de valor, que es el servicio de post venta (entalle de prendas si es que al cliente lo necesita), servicio express a una tarifa accesible y atención personalizada.

En el caso que el cliente no esté disponible en el lugar de entrega, deberá contactar con nosotros para que se vuelva a coordinar la entrega, claro que el adicional será asumido por el cliente. En cuanto a la tecnología la mayor inversión se destinará al desarrollo de la plataforma virtual, que está orientada a ser amigable al usuario y enfocada al uso de servicio personalizado y minimizar tiempo a nuestros clientes en escoger las prendas que esté buscando.

La calidad de nuestro servicio será clave para nuestra empresa, por ello se dará servicio de post venta, así como también encuestas a nuestros clientes para que nos ayude a saber sus preferencias y nuevas tendencias que podamos utilizar como retroalimentación para la mejora de nuestra empresa.

\section{Políticas de Ventas y Compra}

El modelo de negocio que se implementara generará ingresos a través de la venta directa de prendas por medio de nuestro canal virtual. Estas ganancias serán destinadas a cancelar nuestra deuda con los proveedores y la otra parte quedará para la empresa.

Las compras de la prendas de ropa serán por medio de un contrato, donde el proveedor nos otorgará una cantidad total de 10 prendas (cantidad sujeta a evaluación), de las cuales, las 3 primeras prendas serán canceladas inmediatamente y a medida que vayan saliendo de stock se pedirán las que faltan.

\section{Tecnología}

La mayor parte de la inversión que se implementara para la realización del negocio es en tecnología, específicamente en la página y aplicación móvil, lo que nos posiciona como una marca de comercialización moderna. Esta tecnología permitirá al cliente conocer los productos que se ofrecen desde cualquier lugar en donde se encuentre; asimismo, 
permitirá realizar la compra, seleccionar un horario específico de entrega que se adecue a su rutina diaria.

Esta plataforma será lo más amigable posible para que el cliente opte por comprar mediante nuestro canal.

\section{$\underline{\text { Seguridad }}$}

En nuestro modelo de negocio es muy importante que los clientes confíen en nosotros, por ello se implementara una política de seguridad de la información con el fin de salvaguardar la información que el cliente nos brinda (nombres, dirección, teléfono, tarjetas de crédito, etc.)

Canal de Asistencia

Para asegurar una óptima comunicación con el cliente y generar una perspectiva favorable con respecto a la calidad de nuestro servicio, se creará un canal de atención de reclamos y/o sugerencias.

\subsubsection{Proceso de Venta}

A continuación, se presenta el flujo de cómo se realizará la venta por medio de nuestro canal virtual. En el flujo presentado se puede visualizar a los participantes y actividades a realizar de cada uno.

Figura 24. Flujograma del proceso de venta

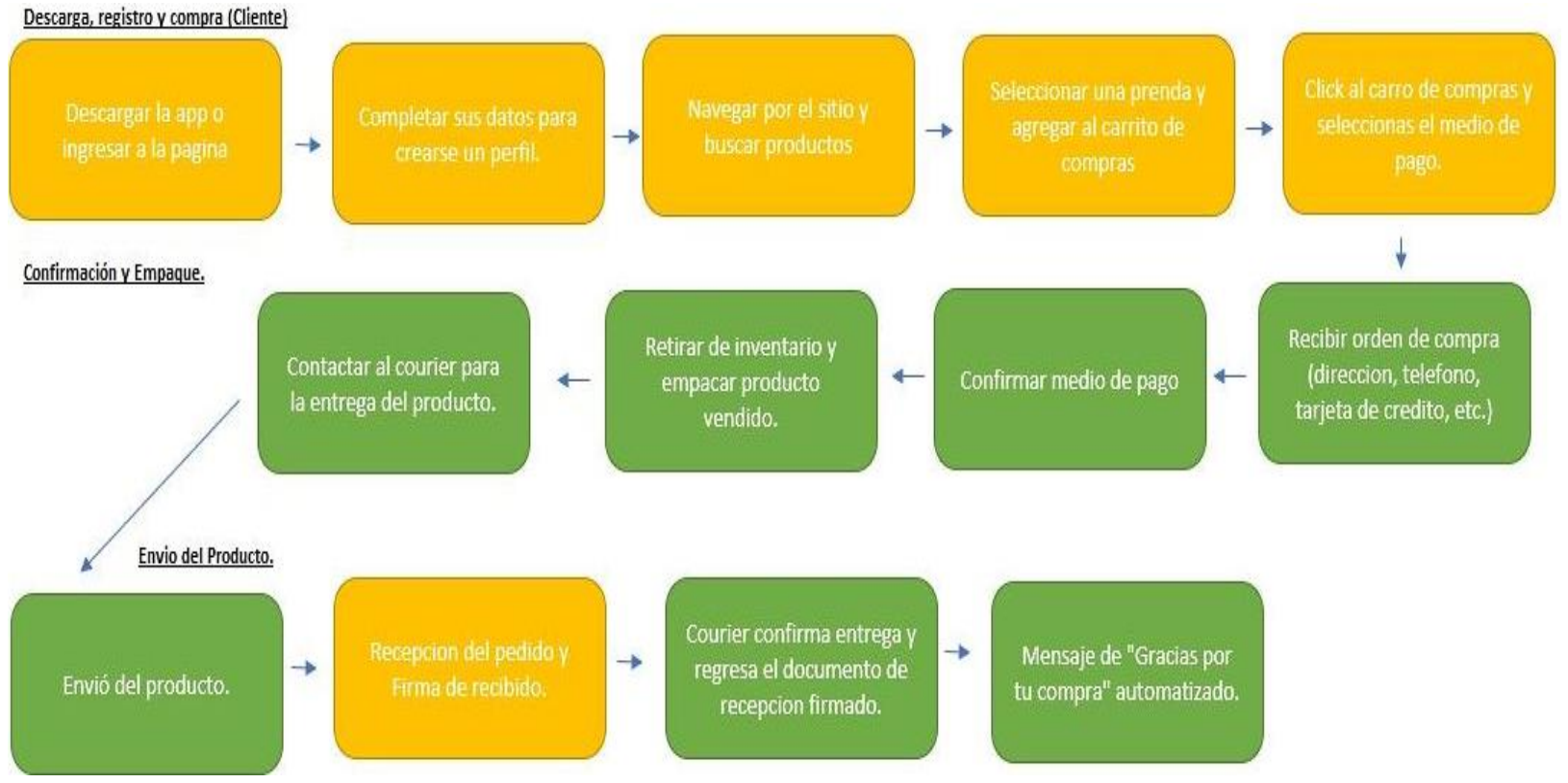

Fuente : Elaboración propia 
Pasos:

1. Descargar la app o ingresar a la página

2. Completar sus datos para crearse un perfil.

3. Navegar por el sitio y buscar productos

4. Seleccionar una prenda y agregar al carrito de compras

5. Click al carro de compras y seleccionas el medio de pago.

6. Recibir orden de compra (dirección, teléfono, tarjeta de crédito, etc.)

7. Confirmar medio de pago

8. Descargar de inventario que tiene el proveedor y empacar producto vendido.

9. Contactar al courier para la entrega del producto.

10. Envió del producto.

11. Recepción del pedido y Firma de recibido.

13. Courier confirma entrega y entrega el documento de recepción firmado.

14. Mensaje de "Gracias por tu compra" automatizado.

\section{Procesos de Compra}

A continuación, se describe el proceso de búsqueda y negociación con los proveedores de prendas a comercializar por nuestro canal digital.

Figura 25. Flujograma del proceso de compra

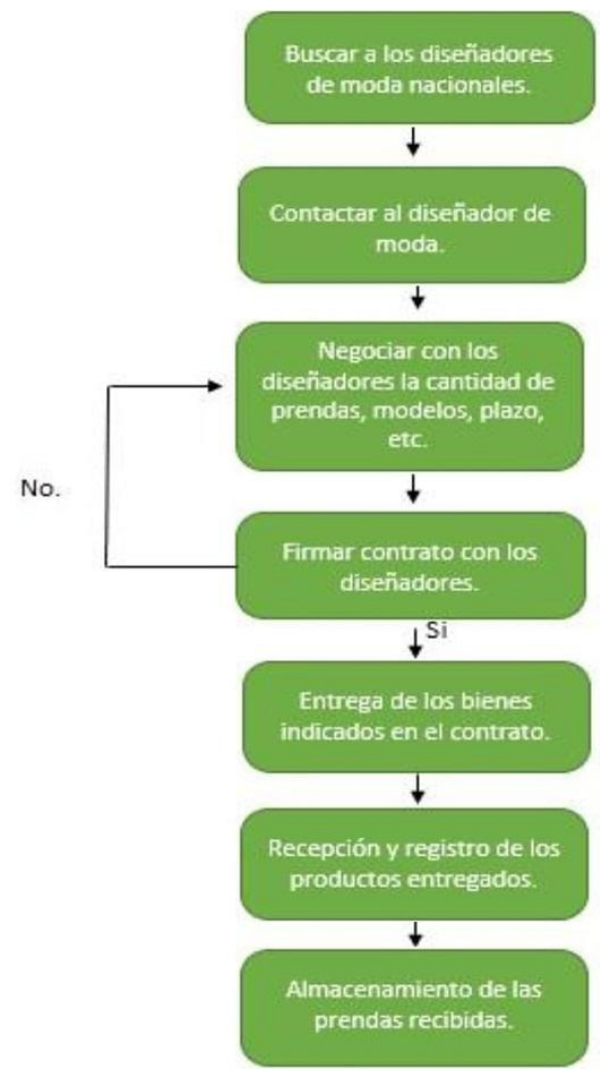


Pasos:

1. Buscar a los diseñadores de moda nacionales.

2. Contactar al diseñador de moda.

3. Negociar con los diseñadores la cantidad de prendas, modelos, plazo, etc.

4. Firmar contrato con los diseñadores.

5. Entrega de los bienes indicados en el contrato en el momento que se le solicite.

6. Recepción y descargo de las prendas vendidas (a través del app).

7. Realizar cronogramas de visitas al proveedor para corroborar la calidad de las prendas que se han diseñado tanto en materia prima como en diseño.

Asimismo, cabe resaltar que cada proceso que se identifique pasará por una evaluación para hacerlo más eficiente, para determinar que este se encuentra relacionado a nuestra estrategia, determinar cuál de los pasos es el más importante y se establecerá indicadores para medirlos.

\subsubsection{Planificación}

Sabemos que la planificación es muy importante para el cimiento de una empresa ya que permite reducir los riesgos, la incertidumbre y alcanzar las metas trazadas. Nuestras políticas de planificación se centran en :

- Analizar nuestro entorno y la situación actual

- Establecer objetivos

- Formular estrategias

- Diseñar plan de acción

La políticas y principios de Kallpa Textil están orientadas al logro de nuestros objetivos para ser más eficientes y eficaces como empresa, implementaremos planes de acción centrados a la mejora continua de los servicios que ofrecemos, mejorando de esta manera los procesos internos.

El precio que ofrecemos será competitivo en el mercado, Kallpa Textil se diferencia de las demás empresas por brindar un servicio personalizado a través de un app donde se ofrecen prendas de vestir exclusivas y de alta calidad. 
Por otro lado para que nuestro servicio sea fiable, haremos seguimiento de las prendas de vestir a través de un dispositivo de gps, hasta llegar a su destino y corroborar la conformidad del cliente, de esta manera minimizamos riesgos de posibles robos.

\subsubsection{Inventarios}

Kallpa Textil no cuenta con inventarios de prendas de vestir, pues somos intermediarios de los diseñadores y los usuarios finales. Sin embargo a través de nuestra app en un módulo independiente de la plataforma virtual, descargaremos las prendas que están vendidas para bajar el stock que el diseñador tiene de dichas prendas, ya que nuestros proveedores son los encargados de ingresar la cantidad de prendas de vestir por cada modelo que realicen así como detallar las tallas que hayan diseñado.

\subsection{Diseño de Instalaciones}

\subsubsection{Localización de las instalaciones}

Kallpa Textil no contará con instalaciones físicas para venta o atención al público, todos estos procedimientos se realizarán por medio de nuestra app virtual, página web o de lo contrario por nuestras redes sociales. Sin embargo, es necesario contar con un local que sirva de oficina administrativa, para que se pueda realizar las ventas online, y el mantenimiento de nuestro software.

Para ello, se necesitará un local que se esté en un distrito céntrico, con el fin de llegar a todos los distritos de una forma rápida, asimismo, se buscará un local con un precio económico y no mayor a 30m2.

Este local se encontrara en el distrito de Lince, debido a que es un distrito con un costo de $\mathrm{m} 2$ bajo y por su cercanía con otros distritos. Asimismo, el local tendrá $30 \mathrm{~m} 2$ y su costo mensual es de S/. 300.00 (trescientos soles con 00/100). Asimismo, aprovecharemos los espacios del local para utilizarlos de forma eficiente. 
Figura 26: Mapa de Ubicación

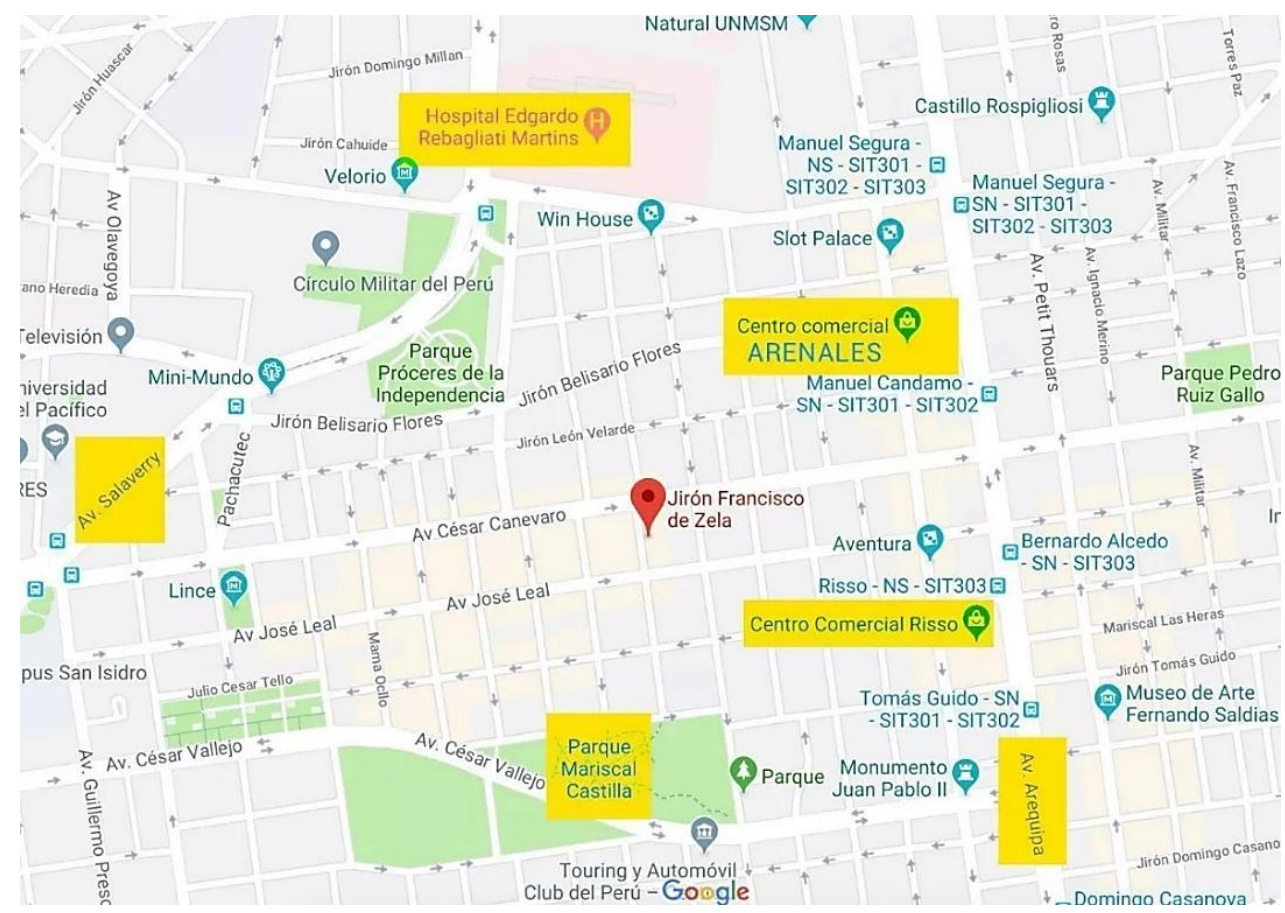

\subsubsection{Capacidad de las instalaciones}

Las instalaciones de Kallpa Textil S.A.C. servirán en la empresa para reuniones y coordinaciones de los accionistas para la toma decisiones en relación al negocio y para el desarrollo de las actividades del dia a dia. Dentro de él, se encontrara 1 personas a cargo de los pedidos de clientes; asimismo, se encontrarán las personas que trabajarán en cada una de las áreas para el funcionamiento de la empresa (5 personas aproximadamente) Personal requerido para realizar las actividades dentro de las instalaciones:

- Community Manager para el manejo de redes que además se encarga de diseñar las publicaciones en redes y analista de Tecnología de la Información.

- Asistente de Contabilidad y Finanzas (Externo por recibos por honorarios)

- Asistente de logistica

Kallpa Textil S.A.C. no elabora ni diseña las prendas que se venden en su página y aplicación móvil, por lo que no es necesario contar con personal designado a la producción de algún bien, lo que si es necesario para el funcionamiento del negocio es contar con personas encargadas en el área de marketing, finanzas, logística y sistemas. El horario de atención para realizar una compra: 
- Será de 24 horas ininterrumpidas. El cliente podrá conectarse desde la comidad de su casa o lugar en donde se encuentre las 24 horas del dia de Lunes a Domingo con la excepción de los días en que se realice mantenimiento a los servidores.

- Tiempo estimado de selección y compra: 30m

El horario de trabajo en las instalaciones:

- De Lunes a Viernes de 9:00am a 6:00pm.

\subsubsection{Distribución de las instalaciones}

El local seleccionado por Kallpa Textil es de $30 \mathrm{~m} 2$ y se distribuye en:

- Cocina

- Sala de Reuniones

- Centro de Trabajo

- Baño

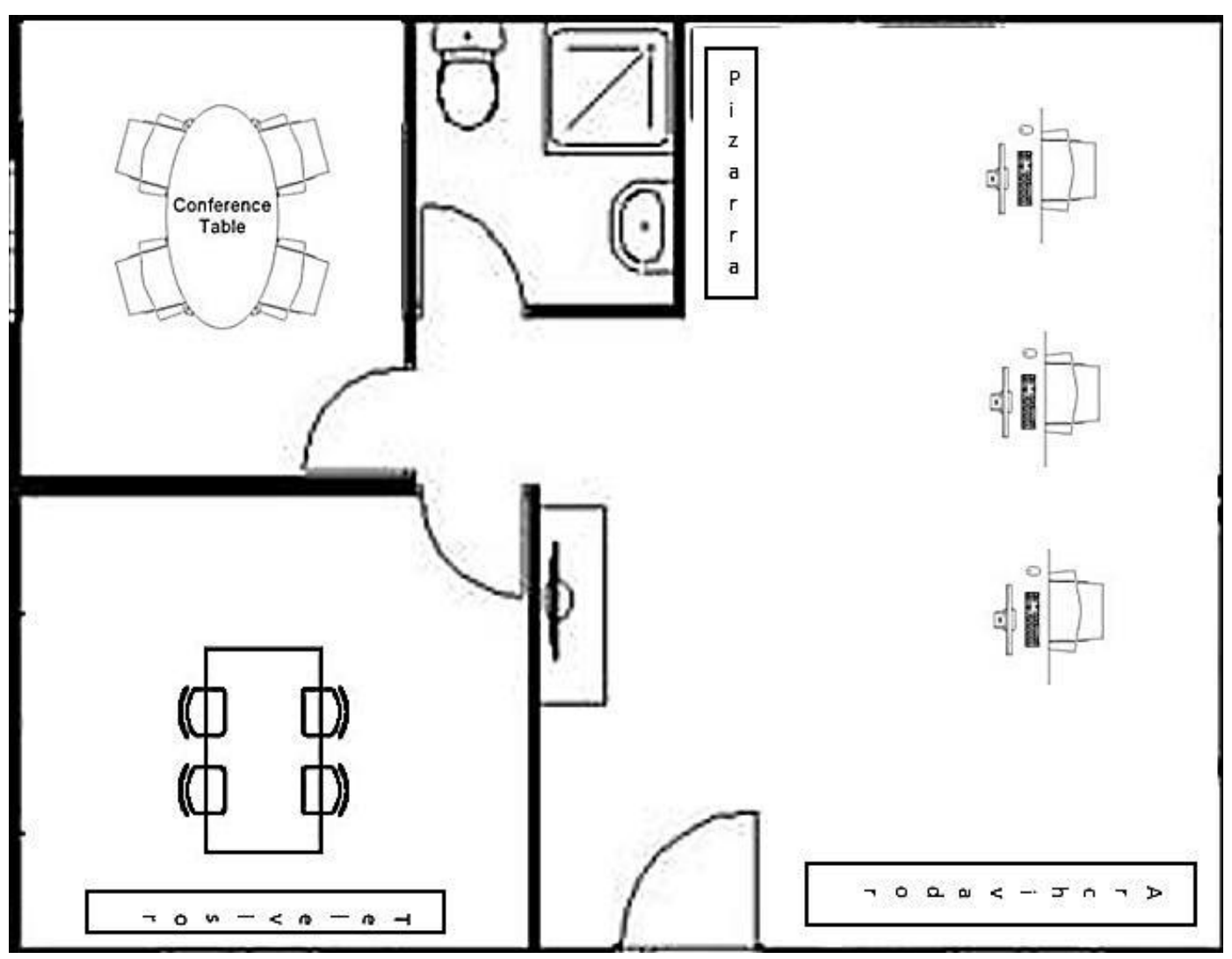




\subsection{Especificaciones Técnicas del Producto / servicio}

Con respecto a las especificaciones técnicas del producto, se contará con la aplicación anteriormente mencionada disponible para android e IOS, asimismo sera posible ingresar desde una PC.

Esta aplicación podrá ser instalada en cualquier dispositivo que cuente con la suficiente memoria y capacidad para poder manejar redes sociales.

La elaboración de la plataforma y aplicación cuesta:

Características generales:

La plataforma se encontrará disponible en una gran cantidad de idiomas, así mismo, se podrá utilizar en cualquier dispositivo PC, tablet, smartphone, entre otros.

Se tendrá la capacidad de buscar productos personalizados, a preferencia del cliente.

Se integrará con todas las redes sociales que puedan ser alcanzadas.

Características comerciales:

Permite gestionar el precio de los productos dependiendo de las características que estos puedan llegar a tener.

Se generará la configuración de las distintas formas de pago, envío y el transporte que será utilizado para realizar éste.

Se permitirá generar la creación de distintos productos especializados teniendo estos las características que sean de la preferencia del cliente.

\subsection{Planeamiento de la Producción}

\subsubsection{Gestión de compras y stock}

La empresa no contará precisamente con un stock específico, por otro lado, lo que realizará será realizar un acuerdo con los proveedores, es decir, los diseñadores, en el cual se brindará una gama de productos para que serán vendidos por la vía web, sin embargo, estos también podrán ser vendidos de la forma en que los diseñadores decidan hacerla, pero todo este proceso será registrado en un sistema para poder saber cual es el stock real de cada una de las prendas en todo el lugar donde se venda sincronizadamente.Es así que, por medio de un contrato el proveedor se verá obligado a declarar el stock que queda de cada uno de sus productos para que así nunca se genere un malestar al cliente. Con este audaz sistema, lo que se logrará será que no exista ningún error en el stock de la empresa 
y así mismo tener una relación más estrecha con el proveedor, lo cual sea el modo el cual sea, será beneficioso para la empresa.

\subsubsection{Proveedores}

Nuestros proveedores son los diseñadores que hemos seleccionado cuidadosamente de acuerdo al perfil que solicitamos para la venta de prendas de ropa de vestir de modelos exclusivos y de alta calidad, dichos proveedores se encuentran ubicados en Lima Metropolitana y son egresados de las mejores escuelas de moda de Lima.

- CEAM

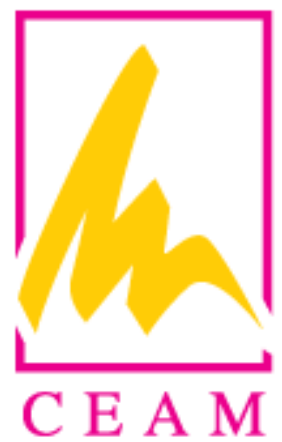

- Chio Lecca

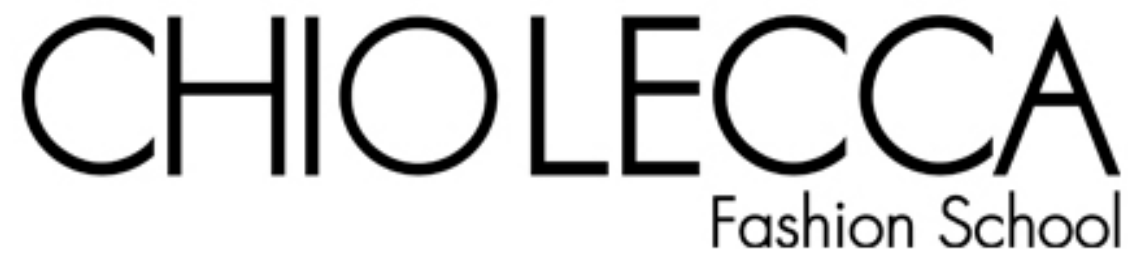

- Toulouse Lautrec

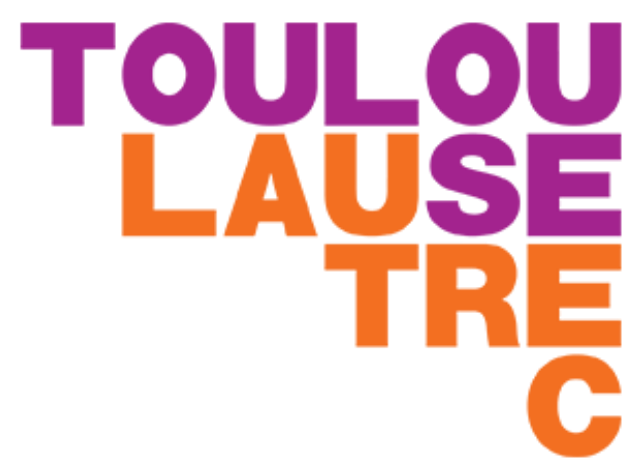


- Universidad Peruana de Ciencas Aplicadas

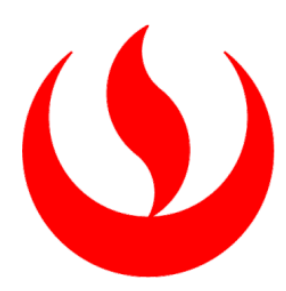

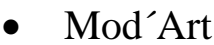

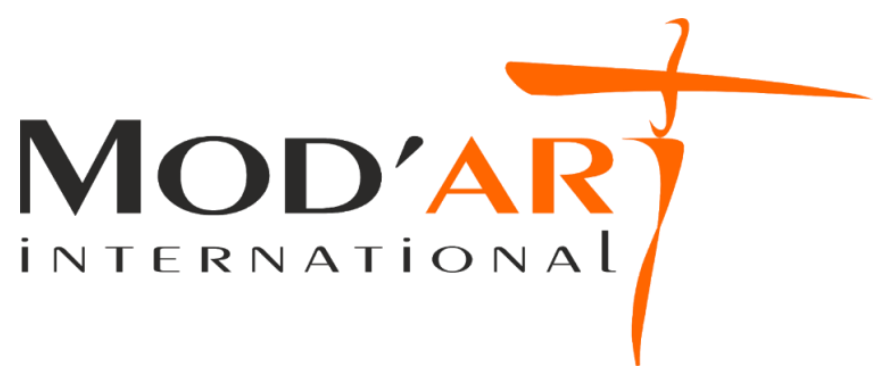

- Instituto Continental

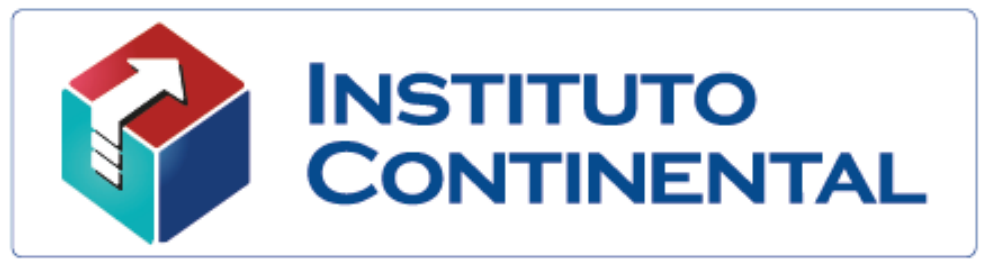

\subsubsection{Inversión en activos fijos vinculados al proceso productivo}

Contamos con los siguientes activos fijos sujetos a depreciación:

Activos Fijos:

Bienes Inmuebles: Local alquilado

Bienes Muebles: Tenemos los siguientes:

\begin{tabular}{|l|c|c|r|r|r|r|}
\hline MUEBLES Y ENSERES & CANTIDAD & UNID DE MEDIDA & PRECIO SIN IGV & TOTAL SIN IGV & AÑOS & DEPRECIACIÓN \\
\hline Escritorios & 3 & unidades & 300.00 & 900.00 & 10 & 90.00 \\
Sillas & 3 & unidades & 80.00 & 240.00 & 10 & 24.00 \\
Mueble de Archivadc & 3 & unidades & 850.00 & $2,550.00$ & 10 & 255.00 \\
Botiquin & 1 & unidades & 15.00 & 15.00 & 10 & 1.50 \\
\cline { 3 - 6 } TOTAL & & & $\mathbf{1 , 2 4 5 . 0 0}$ & $\mathbf{3 , 7 0 5 . 0 0}$ & & $\mathbf{3 7 0 . 5 0}$ \\
\cline { 3 - 6 } & & & & & &
\end{tabular}

\begin{tabular}{|c|c|c|c|c|c|c|}
\hline EQUIPOS COMPUTO & CANTIDAD & UNID DE MEDIDA & PRECIO SIN IGV & TOTAL SIN IGV & AÑ̃OS & DEPRECIACIÓN \\
\hline Laptop láser Hp & 3 & unidades & $1,800.00$ & $5,400.00$ & 4 & $1,350.00$ \\
\hline Impresora láser $\mathrm{Hp}$ & 1 & unidades & 850.00 & 850.00 & 4 & 212.50 \\
\hline TOTAL & & & $2,650.00$ & $6,250.00$ & & $1,562.50$ \\
\hline
\end{tabular}




\begin{tabular}{|c|c|c|c|c|c|c|}
\hline INTANGIBLE & CANTIDAD & UNID DE MEDIDA & PRECIO SIN IGV & TOTAL SIN IGV & AÑOS & DEPRECIACIÓN \\
\hline Software & 1 & unidades & $12,000.00$ & $12,000.00$ & 10 & $1,200.00$ \\
\hline TOTAL & & & $12,000.00$ & $12,000.00$ & & $1,200.00$ \\
\hline
\end{tabular}

\subsubsection{Estructura de costos de producción y gastos operativos}

Consideramos pagar S/ 300.00 soles por el concepto del alquiler de un departamento ubicado en el distrito de Lince con un espacio de $30 \mathrm{~m} 2$, el cual será utilizado como centro de operaciones.

En la planilla se está considerando a tres personas que son: El Gerente general, Atención al cliente el Community Management ) El soporte de sistema y el área de contabilidad serán personal externos los cuales emitirán sus recibos por honorarios.

A continuación se encuentran detallados los salarios de planilla así como otros gastos mensuales y anuales.

PLANILLA

\begin{tabular}{|l|c|r|r|r|r|r|}
\hline NOMBRE DEL PUESTO & N $^{\circ}$ DE PERSONAS & SUELDO MENSUAL (S/) & $\begin{array}{c}\text { SUELDO BRUTO ANUAL } \\
\text { (S/)+ GRATIFI. }\end{array}$ & SUB TOTAL (S/) & ESSALUD & TOTAL ANUAL (S/) \\
\hline Gerente General & 1 & $2,500.00$ & $35,000.00$ & $35,000.00$ & $3,150.00$ & $38,150.00$ \\
\hline Atención al cliente & 1 & $2,000.00$ & $28,000.00$ & $28,000.00$ & $2,520.00$ & $30,520.00$ \\
\hline Community Manager & 1 & $1,200.00$ & $16,800.00$ & $16,800.00$ & $1,512.00$ & $18,312.00$ \\
\hline TOTAL & 3 & $5,700.00$ & $79,800.00$ & $79,800.00$ & $7,182.00$ & $86,982.00$ \\
\hline
\end{tabular}

\begin{tabular}{|l|r|r|}
\hline \multicolumn{1}{|c|}{ GASTOS OPERATIVOS } & MENSUAL (S/) & \multicolumn{1}{c|}{ ANUAL } \\
\hline Alquiler de oficina & 300.00 & $3,600.00$ \\
\hline Agua & 50.00 & 600.00 \\
\hline Luz & 100.00 & $1,200.00$ \\
\hline Paquete telef. (trio) & 239.00 & $2,868.00$ \\
\hline Telefono movil & 49.00 & 588.00 \\
\hline Constitución de empresa & & $2,200.00$ \\
\hline TOTAL & $\mathbf{7 3 8 . 0 0}$ & $\mathbf{1 1 , 0 5 6 . 0 0}$ \\
\hline
\end{tabular}

\subsubsection{Mapa de Procesos y PERT}

A continuación, se detalla un flujograma de cómo se realiza la venta de los productos ofrecidos por la aplicación móvil; en él, se detallan los pasos a seguir tanto del usuario o cliente que adquiere la prenda y de la empresa Kallpa Textil. Es un proceso simple, amigable y muy rápido de realizar, lo cual se alinea a la estrategia planteada por la organización. 
Figura 27: Mapas de procesos y PERT

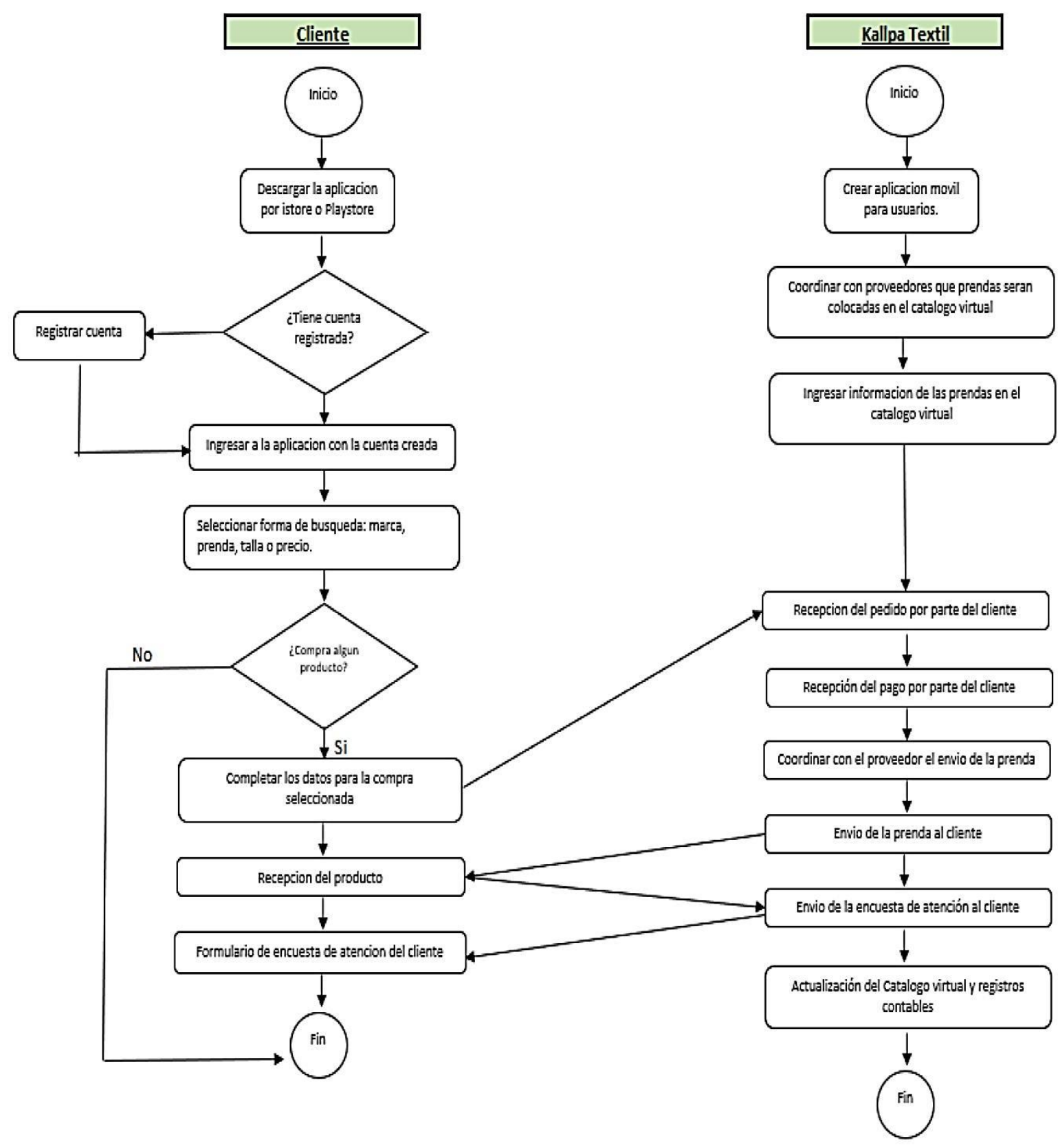




\section{DETALLE DE LOS PASOS:}

- Paso 1:

El cliente descarga la aplicación móvil ingresando desde su smartphone al Appstore o Playstore dependiendo del equipo que tenga.

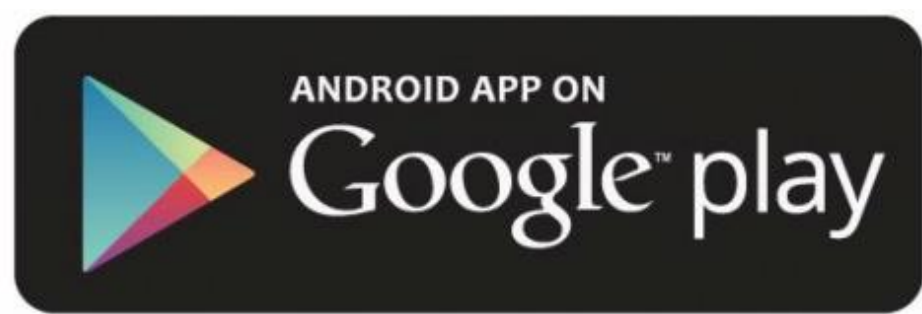

\section{Available on the}

- Paso 2:

Una vez descargada la aplicación desde cualquier plataforma con la que trabaje el equipo del cliente, se deberá ingresar.

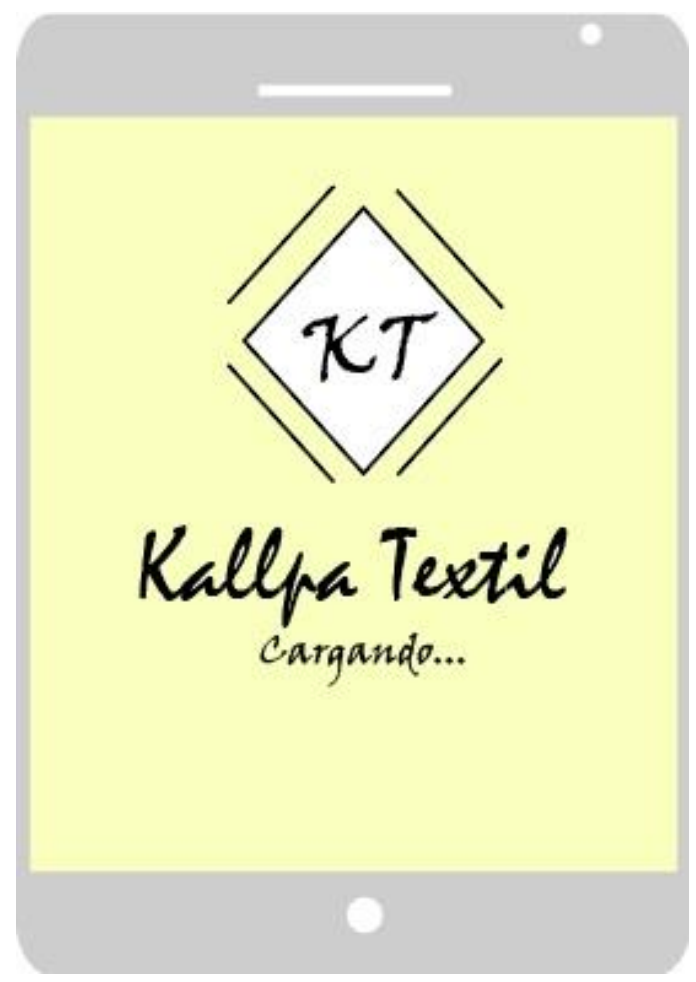




\section{- Paso 3:}

Una vez que cargue la aplicación, se deberá registrar el usuario y contraseña para con ello poder visualizar el catálogo de productos que ofrece la empresa.

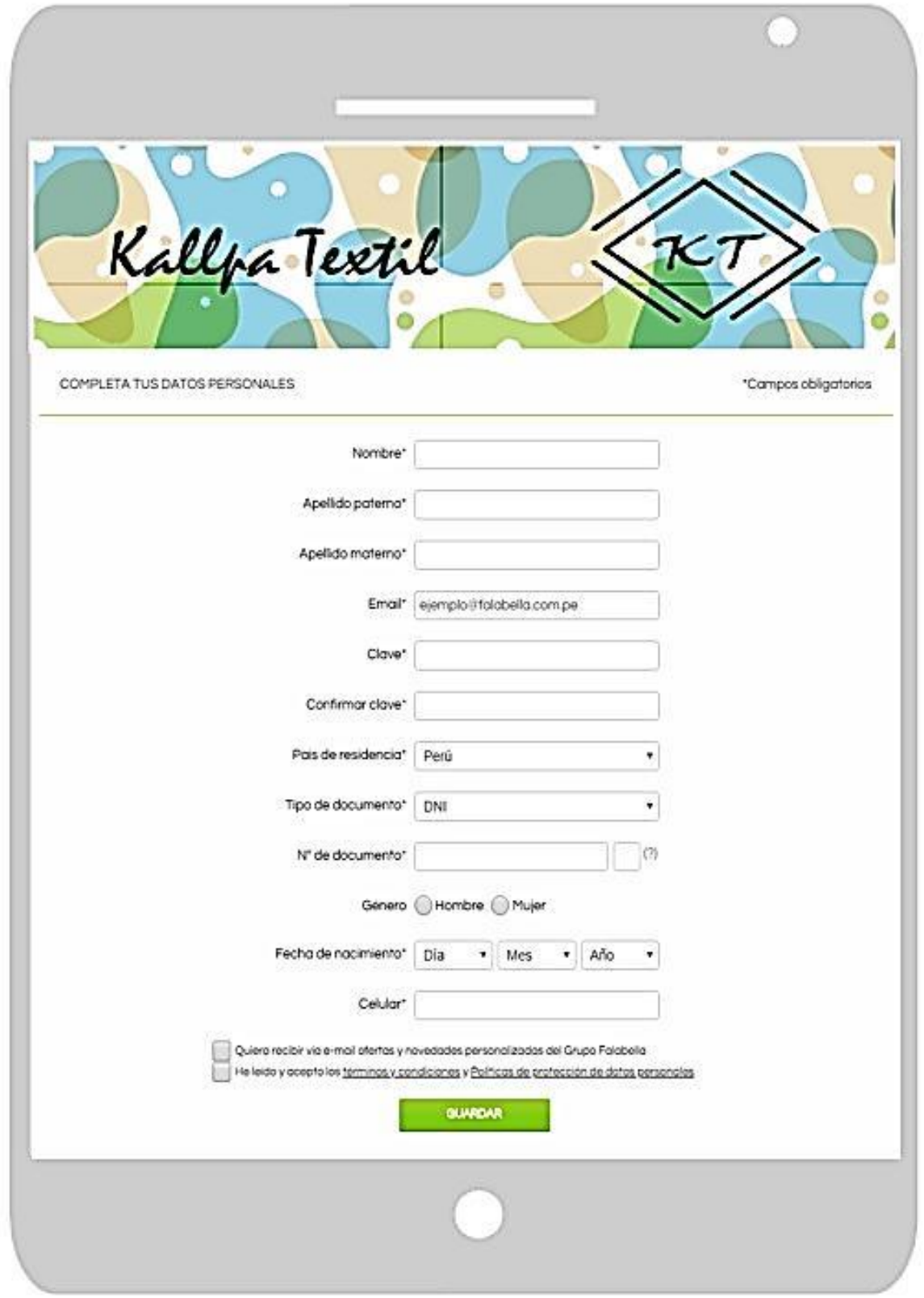




\section{- Paso 4:}

Una vez dentro de la aplicacion, podras realizar busquedas de acuerdo al tipo de prenda, marca, precios y tallas. Este paso facilitará la búsqueda personalizada del usuario.

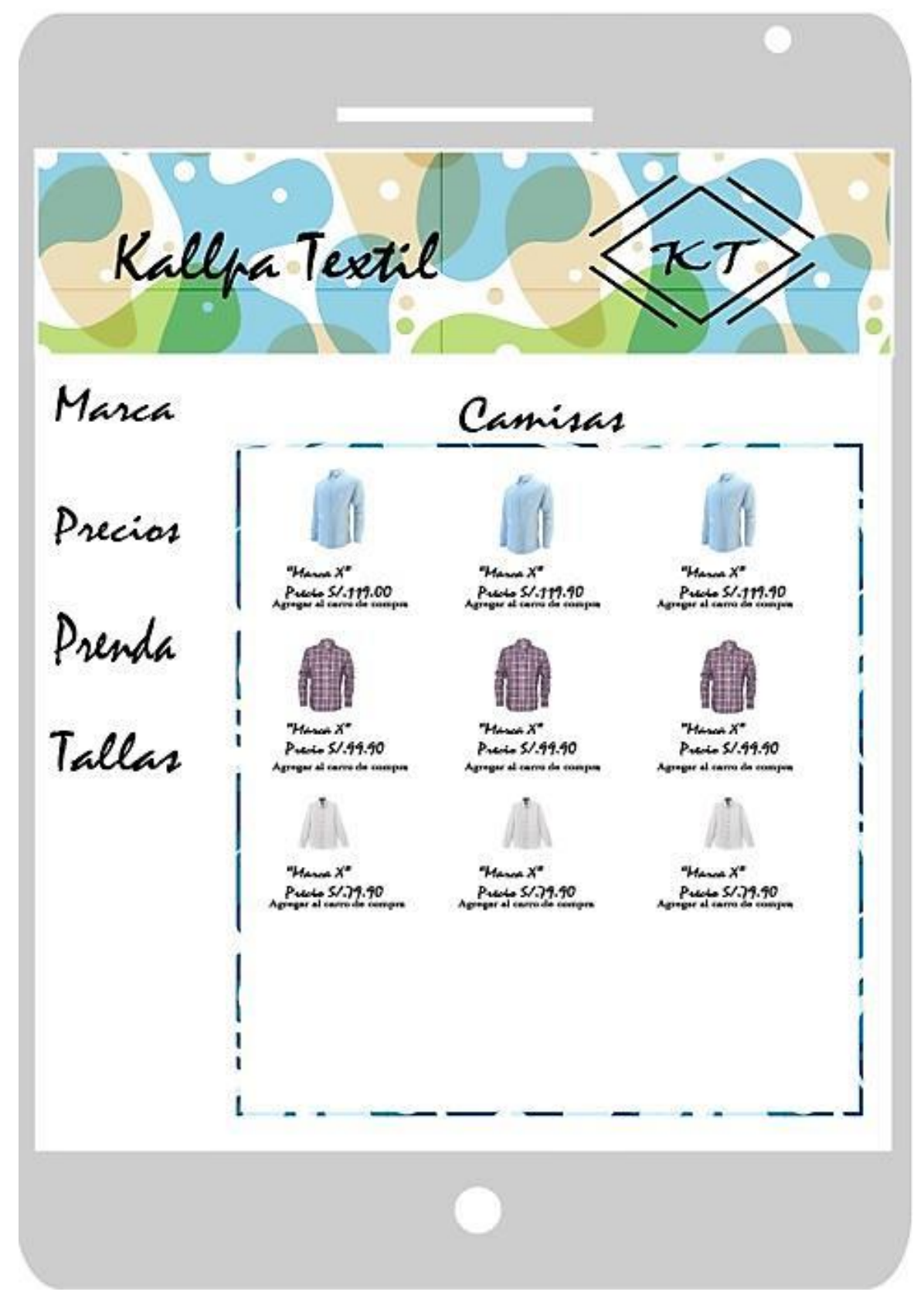




\section{- Paso 5}

Una vez que el cliente encuentre la prenda que desea comprar, tendra que darle click a "Agregar al carrito de compras", este botón se encuentra debajo del precio de cada prenda.

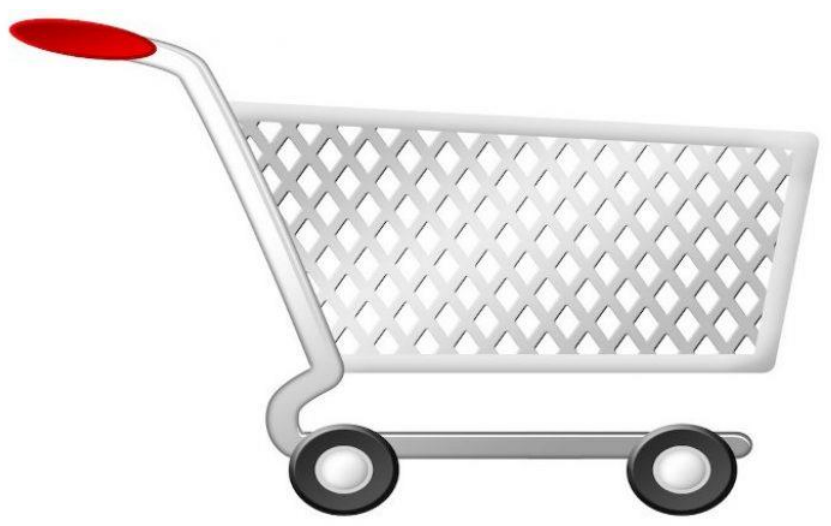

\section{- Paso 6}

Cuando el cliente haya seleccionado la(s) prendas que desea, tendrá que dirigirse al carrito de compras y completar la información de envio y forma de pago. Este paso confirma la operación.

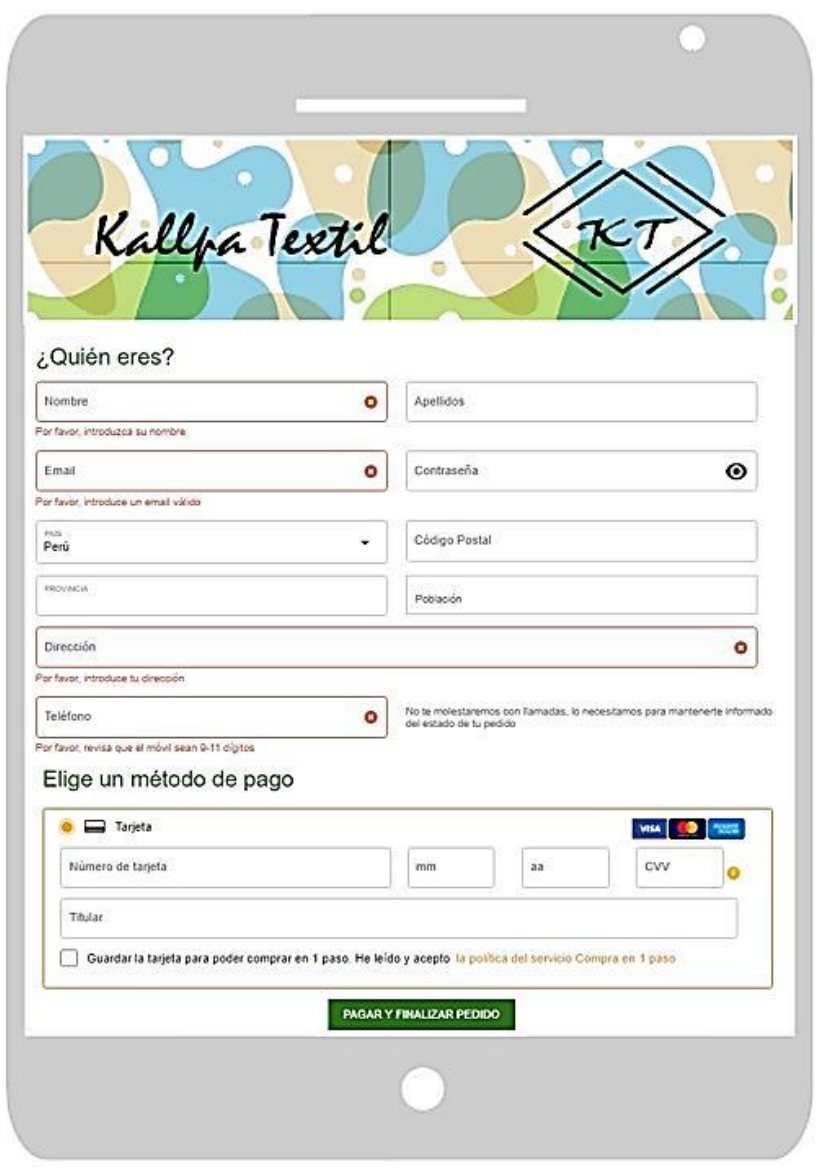




\section{- $\quad$ Paso 7}

Se enviará una constancia de la compra al correo electrónico indicado por el cliente, en el, se detallará los datos como nombre, correo, hora de compra, número de pedido, prenda seleccionada y monto cancelado.

\section{- Paso 8}

Una vez que la empresa haya recibido el pago por las prendas seleccionadas por el cliente, se comunicara con el proveedor de las prendas para que este haga entrega del producto. Asimismo, se contactara a los proveedores de envio para que entreguen el producto al cliente.
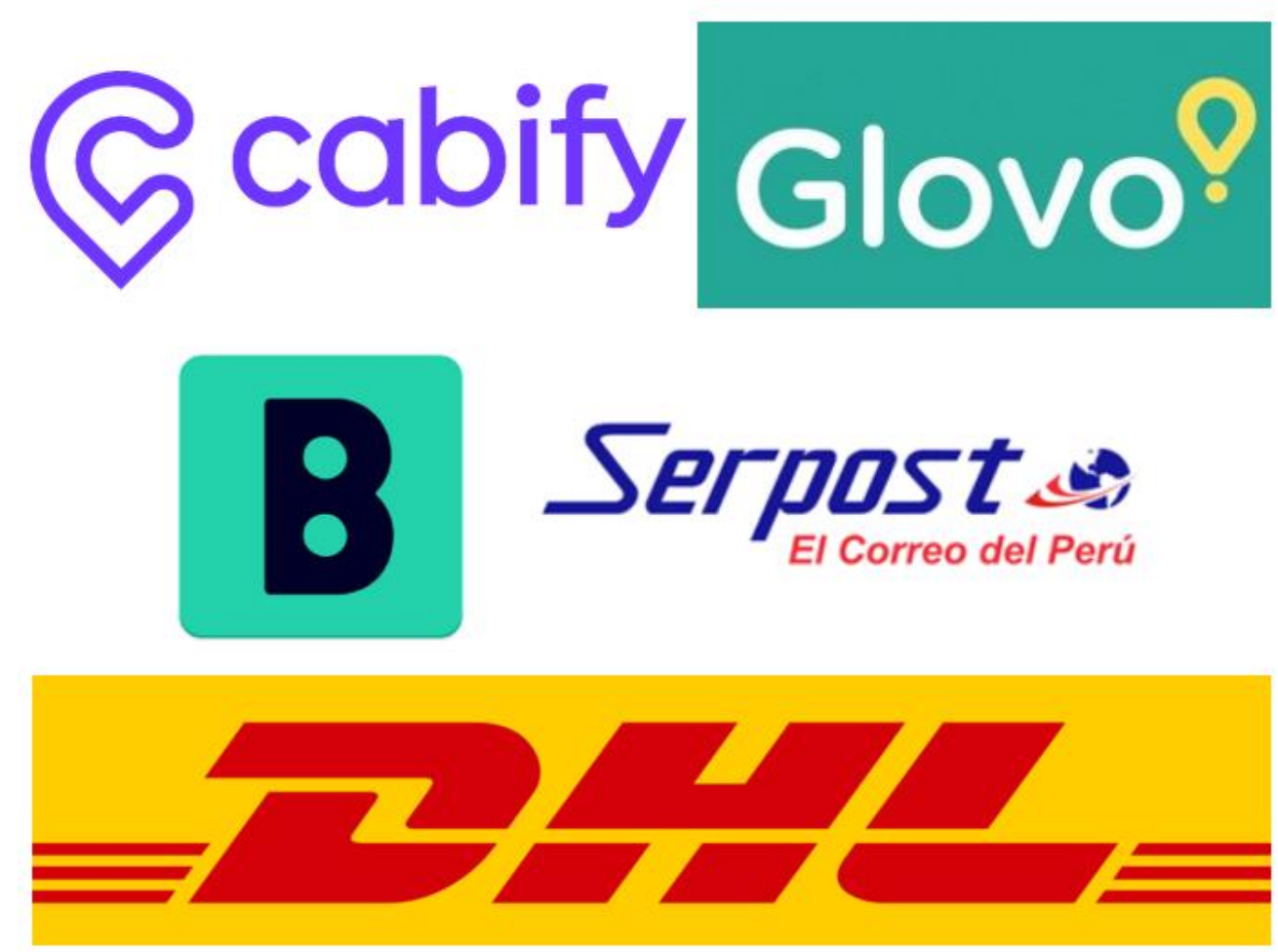

\section{- Paso 9}

Cliente recepciona el pedido por parte de Kallpa Textil. 


\section{- Paso 10}

Se procede a enviar la encuesta de satisfacción para que el cliente pueda completarla y brindarnos una retroalimentación del servicio que estamos brindando.

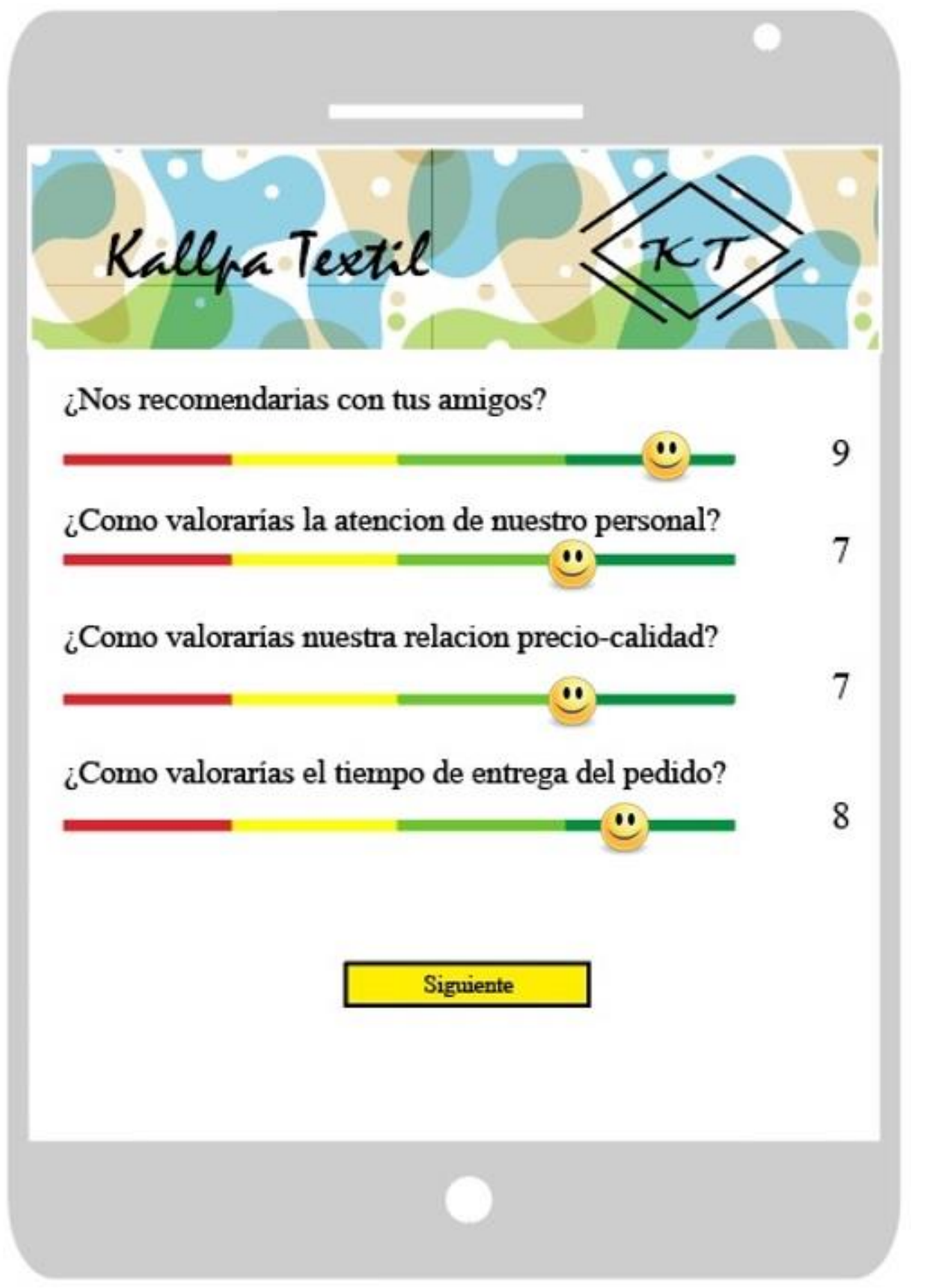


A continuación se muestra el diagrama Pert, el cual permite entender los tiempos y orden de los procesos para poner Kallpa Textil en marcha.

\begin{tabular}{|c|c|c|c|}
\hline Codigo & Precedente & Actividad & Tiempo de Ejecución \\
\hline A & Inicio & Planificación y Proyeccion & 40 dias \\
\hline B & Inicio & Creacion de Aplicación & 90 días \\
\hline C & A & Constitucion de la empresa & 7 días \\
\hline D & A & Instalación de la oficina & 5 días \\
\hline E & C & Instalacion de sistemas y redes & 25 días \\
\hline F & C & Instalacion de la plataforma de Pagos & 25 días \\
\hline G & D,E, F & Licencia de funcionamiento & 5 días \\
\hline H & G & Reclutamiento & 15 días \\
\hline I & H & Capacitación & 5 días \\
\hline J & G & Inicio de Plan de Marketing (Redes) & 10 días \\
\hline K & $\mathrm{B}, \mathrm{J}, \mathrm{I}$ & Periodos de Prueba & 15 días \\
\hline
\end{tabular}

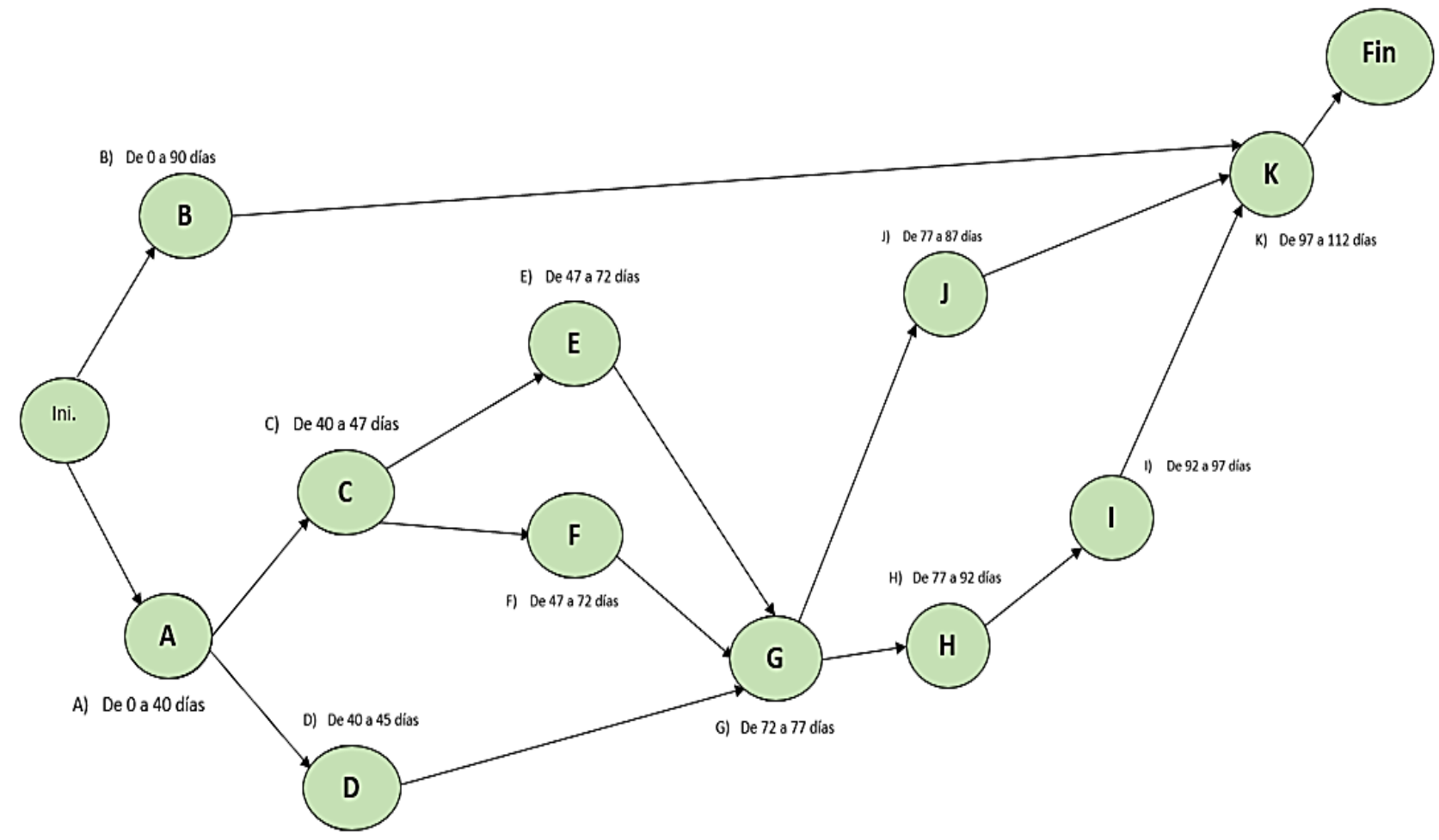




\section{Capítulo 6. Estructura organizacional y recursos humanos}

\subsection{Objetivos Organizacionales}

Los objetivos organizacionales de nuestra empresa se encuentran alineados en nuestra misión "Ser la empresa líder del mercado en la comercialización de prendas a nivel nacional” y visión "Generar bienestar a los consumidores por medio de un canal rápido, atractivo y moderno; en donde encontrarán prendas de alta calidad y elaboradas por talentosos diseñadores a nivel nacional”. Para ello contamos con objetivos como:

- Buscar a los diseñadores más destacados de cada uno de los institutos que se dedican a este rubro.

- Generar alianzas estratégicas con los proveedores (diseñadores)

- Le daremos la confianza de compra al cliente mediante la opción de que podrá ir el diseñador a su realizar los ajustes de sus prendas si es que lo requieren.

- Realizar campañas publicitarias en diferentes medios accesibles para que la empresa sea reconocida por el público.

- Realizar estudios de mercado donde se pueda ver más claro el gusto de nuestros clientes para de alguna forma orientar a los diseñadores.

- Realizar contratos con los proveedores para que las prendas que brinden para la empresa solo puedan ser vendidas mediante la página.

Procuramos que nuestros objetivos organizacionales se conviertan en una realidad empresarial, ya que buscamos como toda empresa, permanecer en el tiempo obteniendo rentabilidad y posicionarnos en el mercado como una marca reconocida.

\subsection{Naturaleza de la Organización}

Kallpa Textil es una pequeña empresa con fines de lucro y capital (que estará repartido en participaciones sociales aportadas por los socios), contará con un máximo de cinco colaboradores, tres de ellos estarán en planilla, los otros dos serán externos. 
Nuestra empresa es de tipo horizontal, pues la gestión es colaborativa, solo hay un gerente general que las áreas le reportarán todo. Lo que busca la organización es el compromiso de los trabajadores y calidad en el servicio que ofrecemos.

\subsubsection{Organigrama}

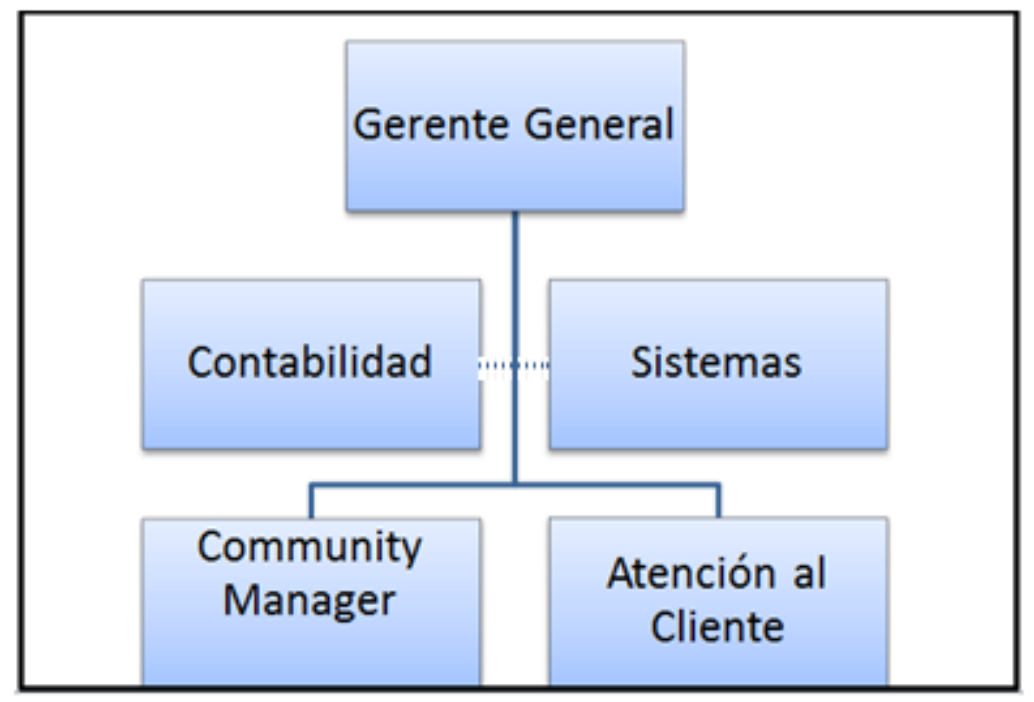

\section{Gerencia General}

- Representante legal de la empresa

- Medir las metas trazadas de las ventas

- Planificar las metas a corto y largo plazo

- Administración del personal

\section{Community manager}

- Responsable de la promoción de la empresa a través de las redes sociales

- Elaborar estrategias para el incremento de ventas

\section{Servicio al Cliente}

- Atención de las órdenes que el cliente solicite

- Realizar el seguimiento de la entrega del pedido

- Cumpliento de la meta de calidad de atención 
- Atender la postventa y reclamos

\section{Contabilidad y Finanzas (Externo - Recibos por honorarios)}

- Elaborar los EEFF de la empresa

- Conciliaciones bancarias.

- Declaraciones de las DJ mensuales y anuales

- Medición de las ventas

\section{Sistemas (Externo - Recibos por honorarios)}

- Soporte de la plataforma virtual

\subsubsection{Diseño de puestos y Funciones}

Perfil del puesto: Gerente General

\begin{tabular}{|l|l|l|}
\hline A: Datos del puesto & & \\
\hline Nombre del puesto: & Gerente general & \\
\hline Gerencia: & Administración & \\
\hline Área & Jerárquicamente & Funcionalmente \\
\hline Jefe Inmediato & Ninguno & Ninguno \\
\hline Supervisa a: & Jerárquicamente & Funcionalmente \\
\hline & $\begin{array}{l}\text { Community manager, } \\
\text { contabilidad, sistemas, atención al al } \\
\text { cliente }\end{array}$ & $\begin{array}{l}\text { Community manager, } \\
\text { contabilidad, sistemas, } \\
\text { atención al cliente }\end{array}$ \\
\hline
\end{tabular}

\begin{tabular}{|l|}
\hline B. Misión \\
\hline El gerente general es responsable de velar por la rentabilidad de la empresa. \\
\hline C. Responsabilidades principales del puesto \\
\hline Administrar de una forma óptima los recursos de la empresa \\
Toma de decisiones ante las situaciones que se presentes en los procesos de la empresa \\
\hline D. Funciones específicas del puesto \\
\hline Responsable de firmar documentos como representante legal de la empresa \\
Representar a la empresa \\
Dirigir las funciones que realizaran los trabajadores de la empresa \\
Realizar la debida inspección de las funciones que se realizan en cada área de la \\
empresa \\
Definir las metas de corto y largo plazo para la empresa \\
Verificar mensualmente el cumplimientos de las metas propuestas para la empresa \\
\hline
\end{tabular}




\begin{tabular}{|l|l|}
\hline E. Formación \\
\hline Profesión/ocupación: & Administrador de empresas \\
\hline Grado de instrucción: & Universitario completo \\
\hline Otros: & Deseable \\
\hline
\end{tabular}

F. Conocimientos

\begin{tabular}{|l|l}
\hline Conocimiento de idiomas: & Ingles avanzado
\end{tabular}

\begin{tabular}{ll}
\hline Conocimiento de informática: & Windows, Office, Gmail.
\end{tabular}

G. Experiencia

Entre 1 y 2 años

Entre 2 y 3 años

Entre 3 y 5 años

Entre 5 y 10 años

Más de 10 años

\begin{tabular}{|l|c|}
\hline H. Ubicación y condiciones \\
\hline Lima: \\
\hline Provincia: \\
\hline Extranjero: \\
\hline $\begin{array}{l}\text { ¿El puesto realiza viajes por motivos de } \\
\text { trabajo? }\end{array}$ \\
\hline $\begin{array}{l}\text { ¿El puesto requiere movilizarse de su } \\
\text { puesto de trabajo cotidiano? }\end{array}$ \\
\hline $\begin{array}{l}\text { Autonomía del puesto (Intensidad de la } \\
\text { supervisión recibida) }\end{array}$ \\
\hline
\end{tabular}

\begin{tabular}{|l|l|}
\hline I. Competencias & \\
\hline Competencias organizacionales: & $\begin{array}{l}\text { Liderazgo personal y grupal } \\
\text { Trabajo en equipo } \\
\text { Responsabilidad }\end{array}$ \\
\hline Competencias funcionales: & Trabajo bajo presión \\
& Respuesta rápida y de calidad \\
& Tolerancia al estrés \\
& Capacidad de mejorar constantemente \\
\hline
\end{tabular}

\section{Perfil del puesto: Contabilidad}

\begin{tabular}{|l|l|l|}
\hline A: Datos del puesto & & \\
\hline Nombre del puesto: & Contador & \\
\hline Gerencia: & & \\
\hline Área & Contabilidad & \\
\hline Jefe Inmediato & Jerárquicamente & Funcionalmente \\
\hline & Gerente general & Gerente general \\
\hline Supervisa a: & Jerárquicamente & Funcionalmente \\
\hline & Ninguno & Ninguno \\
\hline
\end{tabular}




\section{B. Misión}

El Contador es responsable de brindar la información contable de la empresa, así como de realizar la debida declaración de impuestos de ésta.

C. Responsabilidades principales del puesto

Programar y procesar los pagos de la empresa

Realizar los estados financieros de la empresa

D. Funciones específicas del puesto

Llevar la contabilidad de la empresa

Realizar y analizar los estados financieros

Medir las ventas y cumplimiento de metas

Administrar la salud financiera de la empresa.

\begin{tabular}{|l|l|}
\hline E. Formación & \\
\hline Profesión/ocupación: & Contador \\
\hline Grado de instrucción: & Universitario completo \\
\hline Otros: & Deseable \\
\hline
\end{tabular}

F. Conocimientos

\begin{tabular}{l|l}
\hline Conocimiento de idiomas: & Ingles intermedio
\end{tabular}

\begin{tabular}{l|l}
\hline Conocimiento de informática: & Windows, Office, Gmail \\
\hline
\end{tabular}

\begin{tabular}{|l|l|}
\hline G. Experiencia & \\
\hline Entre 1 y 2 años & \\
\hline Entre 2 y 3 años & \\
\hline Entre 3 y 5 años & \\
\hline Entre 5 y 10 años & \\
\hline Más de 10 años & \\
\hline
\end{tabular}

\begin{tabular}{|l|c|}
\hline H. Ubicación y condiciones \\
\hline Lima: \\
\hline Provincia: \\
\hline Extranjero: \\
\hline $\begin{array}{l}\text { ¿El puesto realiza viajes por motivos de } \\
\text { trabajo? }\end{array}$ \\
\hline $\begin{array}{l}\text { ¿El puesto requiere movilizarse de su } \\
\text { puesto de trabajo cotidiano? }\end{array}$ \\
\hline $\begin{array}{l}\text { Autonomía del puesto (Intensidad de la } \\
\text { supervisión recibida) }\end{array}$ \\
\hline
\end{tabular}

\begin{tabular}{|l|l|}
\hline I. Competencias & \\
\hline Competencias organizacionales: & Orientación a resultados \\
& Vocación de servicio \\
\hline Competencias funcionales: & Manejo de tecnologías \\
& Trabajo bajo presión \\
& Mejora continua \\
\hline
\end{tabular}


Perfil del puesto: Community Manager

\begin{tabular}{|l|l|l|}
\hline A: Datos del puesto & & \\
\hline Nombre del puesto: & Community manager & \\
\hline Gerencia: & & \\
\hline Área & Marketing & \\
\hline Jefe Inmediato & Jerárquicamente & Funcionalmente \\
\hline & Gerente general & Gerente general \\
\hline Supervisa a: & Jerárquicamente & Funcionalmente \\
\hline & Ninguno & Ninguno \\
\hline
\end{tabular}

B. Misión

El Community manager es el responsable del marketing de la empresa.

C. Responsabilidades principales del puesto

Es el responsable de planificar y realizar las actividades de marketing de la empresa

D. Funciones específicas del puesto

Realizar estrategias y publicaciones que ayuden a la rentabilidad de la empresa

Realizar los costos por las actividades que se realizarán

E. Formación

Profesión/ocupación:

Administración y marketing

Grado de instrucción:

Otros: Universitario completo

Deseable

\section{F. Conocimientos}

Conocimiento de idiomas:

Conocimiento de informática:

Ingles avanzado

Windows, Office, Gmail, VSCO CAM, ILUSTRATOR

\begin{tabular}{|l|l|}
\hline G. Experiencia & \\
\hline Entre 1 y 2 años & \\
\hline Entre 2 y 3 años & \\
\hline Entre 3 y 5 años & \\
\hline Entre 5 y 10 años & \\
\hline Más de 10 años & \\
\hline
\end{tabular}

\begin{tabular}{|l|c|}
\hline H. Ubicación y condiciones \\
\hline Lima: \\
\hline Provincia: \\
\hline Extranjero: \\
\hline $\begin{array}{l}\text { ¿El puesto realiza viajes por motivos de } \\
\text { trabajo? }\end{array}$ \\
\hline $\begin{array}{l}\text { ¿El puesto requiere movilizarse de su } \\
\text { puesto de trabajo cotidiano? }\end{array}$ \\
\hline $\begin{array}{l}\text { Autonomía del puesto (Intensidad de la } \\
\text { supervisión recibida) }\end{array}$ \\
\hline
\end{tabular}




\begin{tabular}{|l|l|}
\hline I. Competencias & \\
\hline Competencias organizacionales: & Responsabilidad \\
& Dirección y liderazgo \\
& Habilidades comunicativas óptimas \\
\hline Competencias funcionales: & $\begin{array}{l}\text { Manejo de tecnologías } \\
\text { Mejora continua }\end{array}$ \\
\hline
\end{tabular}

\section{Perfil del puesto: Sistemas}

\begin{tabular}{|l|l|l|}
\hline A: Datos del puesto & & \\
\hline Nombre del puesto: & Sistemas & \\
\hline Gerencia: & & \\
\hline Área & Sistemas & \\
\hline Jefe Inmediato & Jerárquicamente & Funcionalmente \\
\hline & Gerente general & Gerente general \\
\hline Supervisa a: & Jerárquicamente & Funcionalmente \\
\hline & Ninguno & Ninguno \\
\hline
\end{tabular}

\begin{tabular}{|l|}
\hline B. Misión \\
\hline $\begin{array}{l}\text { La persona encargada del área de sistemas realizará todo lo que respecta a la aplicación } \\
\text { de la página }\end{array}$ \\
\hline C. Responsabilidades principales del puesto \\
\hline Soporte de la plataforma virtual \\
\hline D. Funciones específicas del puesto \\
\hline $\begin{array}{l}\text { Realizar la plataforma virtual } \\
\text { Analizar las mejoras que se necesitan a partir de las experiencias de la empresa } \\
\text { Realizar las mejoras necesarias para la satisfacción del cliente }\end{array}$ \\
\hline
\end{tabular}

\begin{tabular}{|l|l|}
\hline E. Formación \\
\hline Profesión/ocupación: & Ingeniería de sistemas \\
\hline Grado de instrucción: & Universitario completo \\
\hline Otros: & Deseable \\
\hline
\end{tabular}

\begin{tabular}{|l|l|}
\hline F. Conocimientos \\
\hline Conocimiento de idiomas: & Ingles Avanzado \\
\hline Conocimiento de informática: & $\begin{array}{l}\text { Windows, office, Gmail, Realización de } \\
\text { aplicaciones }\end{array}$ \\
\hline
\end{tabular}

\begin{tabular}{|l|l|}
\hline G. Experiencia & \\
\hline Entre 1 y 2 años & \\
\hline Entre 2 y 3 años & X \\
\hline Entre 3 y 5 años & \\
\hline Entre 5 y 10 años & \\
\hline Más de 10 años & \\
\hline
\end{tabular}




\begin{tabular}{|l|c|}
\hline H. Ubicación y condiciones \\
\hline Lima: \\
\hline Provincia: \\
\hline Extranjero: \\
\hline $\begin{array}{l}\text { ¿El puesto realiza viajes por motivos de } \\
\text { trabajo? }\end{array}$ \\
\hline $\begin{array}{l}\text { ¿El puesto requiere movilizarse de su } \\
\text { puesto de trabajo cotidiano? }\end{array}$ \\
\hline $\begin{array}{l}\text { Autonomía del puesto (Intensidad de la } \\
\text { supervisión recibida) }\end{array}$ \\
\hline
\end{tabular}

\begin{tabular}{|l|l|}
\hline I. Competencias & \\
\hline Competencias organizacionales: & $\begin{array}{l}\text { Trabajo en equipo } \\
\text { Responsabilidad } \\
\text { Orientación a resultados }\end{array}$ \\
\hline Competencias funcionales: & $\begin{array}{l}\text { Manejo de tecnologías } \\
\text { Trabajo bajo presión } \\
\text { Mejora continua }\end{array}$ \\
\hline
\end{tabular}

\section{Perfil del puesto: Atención al cliente}

\begin{tabular}{|l|l|l|}
\hline A: Datos del puesto & & \\
\hline Nombre del puesto: & Atención al cliente & \\
\hline Gerencia: & & \\
\hline Área & Atención al cliente & \\
\hline Jefe Inmediato & Jerárquicamente & Funcionalmente \\
\hline & Gerente general & Gerente general \\
\hline Supervisa a: & Jerárquicamente & Funcionalmente \\
\hline & Ninguno & Ninguno \\
\hline
\end{tabular}

\section{B. Misión}

La persona encargada de la atención al cliente es el encargado de verificar la conformidad del cliente al comprar uno de los productos de la empresa, así mismo debe estar atento en lo que respecta a reclamos o consultas de estos.

C. Responsabilidades principales del puesto

Asegurarse de la conformidad del cliente

Atender a las consultas o reclamos de los clientes

D. Funciones específicas del puesto

Constante supervisión en lo que respecta al servicio postventa

Realizar los pasos a seguir en lo que respecta a la atención al cliente

Atender el servicio postventa y reclamos

\begin{tabular}{|l|l|}
\hline E. Formación & $\begin{array}{l}\text { Administración de empresas, marketing, } \\
\text { hotelería }\end{array}$ \\
\hline Profesión/ocupación: & Universitario completo \\
\hline Grado de instrucción: & Deseable \\
\hline Otros: &
\end{tabular}




\begin{tabular}{|l|l|}
\hline F. Conocimientos \\
\hline Conocimiento de idiomas: & Ingles intermedio \\
\hline Conocimiento de informática: & Office, Gmail, Redes sociales \\
\hline
\end{tabular}

\begin{tabular}{|l|l|}
\hline G. Experiencia & \\
\hline Entre 1 y 2 años & \\
\hline Entre 2 y 3 años & \\
\hline Entre 3 y 5 años & \\
\hline Entre 5 y 10 años & \\
\hline Más de 10 años & \\
\hline
\end{tabular}

\begin{tabular}{|l|c|}
\hline H. Ubicación y condiciones \\
\hline Lima: \\
\hline Provincia: \\
\hline Extranjero: \\
\hline $\begin{array}{l}\text { ¿El puesto realiza viajes por motivos de } \\
\text { trabajo? }\end{array}$ \\
\hline $\begin{array}{l}\text { ¿El puesto requiere movilizarse de su } \\
\text { puesto de trabajo cotidiano? }\end{array}$ \\
\hline $\begin{array}{l}\text { Autonomía del puesto (Intensidad de la } \\
\text { supervisión recibida) }\end{array}$ & Si \\
\hline
\end{tabular}

\begin{tabular}{|l|l|}
\hline I. Competencias & \\
\hline Competencias organizacionales: & $\begin{array}{l}\text { Trabajo orientado a resultados } \\
\text { Responsabilidad }\end{array}$ \\
& Contar con habilidades comunicativas \\
& óptimas \\
\hline Competencias funcionales: & $\begin{array}{l}\text { Manejo de tecnologías } \\
\text { Trabajo bajo presión } \\
\\
\text { Tolerancia al estrés }\end{array}$ \\
\hline
\end{tabular}

\subsection{Políticas Organizacionales}

Las políticas organizacionales de la empresa se centran en el bienestar y conformidad para todos los clientes que esta llegue a tener.

Enfoque en el producto: Ser especialistas en la venta y comercio de ropa, tomando en cuenta todas las necesidades del cliente y constantemente mejorando nuestra forma de realizar las actividades.

Enfoque en el mercado: Ya que la empresa no manejara directamente una gran cantidad de stock, tendrá una forma más fácil de adaptarse a los cambios en la demanda. 
Enfoque en la investigación y tecnología: Se verá lo que respecta a la actualización de la aplicación realizando constantes cambios para la comodidad del cliente.

Evaluación del capital: Se analizará todos los estados financieros de la empresa, así mismo, se tendrá una constante evaluación de los costos de la empresa.

La red asociada de Kallpa: Se realizarán actividades de capacitación en nuestra forma de actuar con respecto a situaciones que puedan presentarse a los diseñadores. Así mismo, se realizarán actividades para motivar a estos y a toda la red de asociados que pueda llegar a tener la empresa.

\subsection{Gestión Humana}

La gestión humana jugará un papel clave para nuestra organización, se debe tratar de contar con los mejores perfiles ya que de ello dependerá de que logremos tener una estructura sólida. Por otro lado debido a los cambios continuos que se dan en este aspecto necesitamos perfiles que se adapten rápidamente a los cambios.

\subsubsection{Reclutamiento}

El proceso de reclutamiento se basará en captar el mejor talento para las posiciones disponibles, nuestro objetivo principal será atraer candidatos capaces.

Para dar a conocer nuestras ofertas de trabajo estamos considerando utilizar nuestra app y las principales redes sociales por otro lado utilizaremos las páginas webs especializadas para la búsqueda de trabajo como computrabajo, aptitus entre otros.

Los candidatos que cuenten con los requisitos mínimos para el puesto pasaran una fase de evaluación la cual consistirá en una entrevista preliminar, prueba de conocimiento, prueba psicológica y entrevista final.

\subsubsection{Selección, contratación e inducción}

Tan pronto se termine el proceso de evaluación de los candidatos se procede a seleccionar al que tenga los puntajes más elevados y comenzamos con el proceso de contratación, firma de contratos y se le dan las condiciones del trabajo sueldo horarios entre otros. 
En lo que respecta a la inducción pasará por un proceso previo en cual se le brinda feedback necesario para que pueda realizar una buena gestión.

\subsubsection{Capacitación, desarrollo y evaluación del desempeño}

En toda organización es necesario que los empleados pasen por un proceso de capacitación en el cual se le brindara toda la información que ellos necesitan acerca del core de la empresa sus productos ya que no necesariamente vienen de una empresa del mismo rubro, en nuestro caso realizaremos capacitaciones constantes a nuestros empleados en colaboración con el desarrollador de nuestra app y los diseñadores.

Líneas abajo un check list con el cual podremos evaluar el desempeño de nuestros empleados.

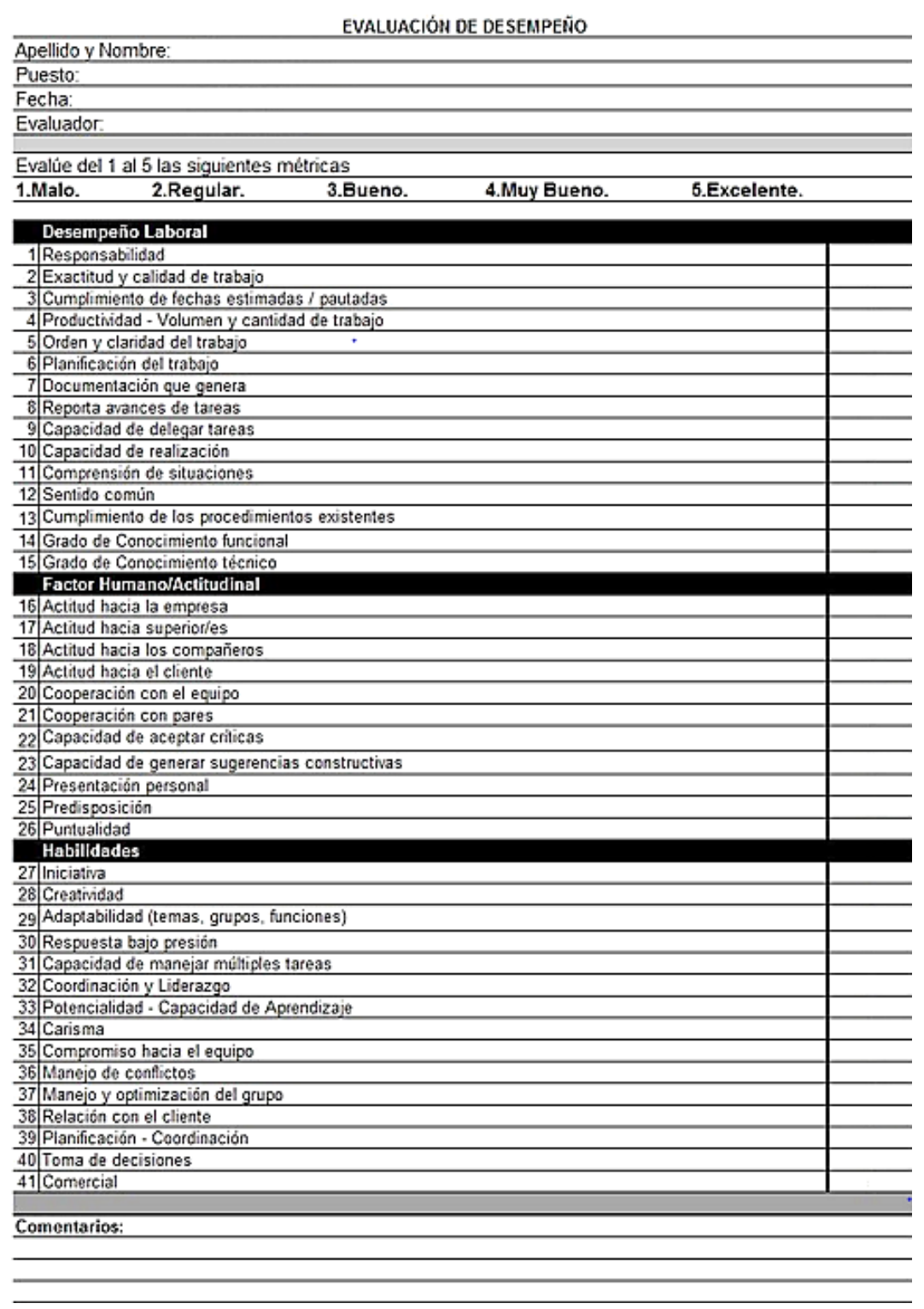




\subsubsection{Motivación}

La motivación para nuestra empresa es importante por lo cual nos queremos enfocar en el desarrollo personal y profesional de nuestros trabajadores, ofreciéndoles un buen ambiente de trabajo, flexibilidad y buenas condiciones de trabajo.

Por otro lado, tenemos pensado que conforme la demanda aumente brindar bonos para nuestros trabajadores ya que somos conscientes que el tema remunerativo es importante también queremos que se sigan especializando y buscaremos alianzas con instituciones educativos, consideramos que la cámara de comercio de lima sería una buena opción.

\subsubsection{Sistema de remuneración}

Kallpa textil cuenta con 3 colaboradores registrados en planilla a quienes se les reconoce todos los beneficios de ley como es salud y gratificaciones en julio y diciembre. Existen otros dos departamentos que son sistemas y contabilidad que son colaboradores externos el cual nos emitirán por sus servicios recibos por honorarios para ello deben contar con RUC

El pago de planilla de los colaboradores se realizará de manera quincenal y fin de mes en sus cuentas corrientes. En el caso de los servicios prestados por terceros el pago será a 30 días de prestado el servicio.

\subsubsection{Estructura de gastos de RRHH}

La planilla de Kallpa textil está compuesta por tres posiciones contratadas por tiempo determinado el cual será renovado semestralmente, pues de esta manera evitaremos futuros pagos por indemnizaciones por despido arbitrario, si es que el colaborador no va acorde al perfil del puesto o por el tiempo de trabajo baja su rendimiento.

PLANILLA MENSUAL

\begin{tabular}{|l|c|r|r|r|r|}
\hline \multicolumn{1}{|c|}{ NOMBRE DEL PUESTO } & N $^{\circ}$ DE PERSONAS & SUELDO MENSUAL (S/) & \multicolumn{1}{c|}{ GRATIFI. Y BONIF } & \multicolumn{1}{c|}{ CTS } & \multicolumn{1}{c|}{ ESSALUD } \\
\hline Gerente General & 1 & $1,500.00$ & $1,635.00$ & 886.25 & 135.00 \\
\hline Community Manager & 1 & $1,500.00$ & $1,635.00$ & 886.25 & 135.00 \\
\hline Atención al cliente & 1 & 930.00 & $1,013.70$ & 549.48 & 83.70 \\
\hline TOTAL & 3 & $3,930.00$ & $4,283.70$ & $2,321.98$ & 353.70 \\
\hline
\end{tabular}




\begin{tabular}{|l|r|r|r|r|r|r|r|}
\hline \multicolumn{1}{|c|}{ CONCEPTO } & \multicolumn{1}{c|}{ ENERO } & \multicolumn{1}{c|}{ FEBRERO } & \multicolumn{1}{c|}{ MARZO } & \multicolumn{1}{c|}{ ABRIL } & \multicolumn{1}{c|}{ MAYO } & \multicolumn{1}{c}{ JUNIO } & TOTAL SEMESTRAL \\
\hline SUELDOS DE EMPLEADOS & $3,930.00$ & $3,930.00$ & $3,930.00$ & $3,930.00$ & $3,930.00$ & $3,930.00$ & $23,580.00$ \\
\hline ESSALUD & 353.70 & 353.70 & 353.70 & 353.70 & 353.70 & 353.70 & $2,122.20$ \\
\hline GRATIFICACION & 0.00 & 0.00 & 0.00 & 0.00 & 0.00 & 0.00 & 0.00 \\
\hline CTS & 0.00 & 0.00 & 0.00 & 0.00 & $2,321.98$ & 0.00 & $2,321.98$ \\
\hline TOTAL & $4,283.70$ & $4,283.70$ & $4,283.70$ & $4,283.70$ & $6,605.68$ & $4,283.70$ & $28,024.18$ \\
\hline
\end{tabular}

\begin{tabular}{|l|r|r|r|r|r|r|r|r|}
\hline \multicolumn{1}{|c|}{ CONCEPTO } & \multicolumn{1}{c|}{ JULIO } & \multicolumn{1}{c|}{ AGOSTO } & \multicolumn{1}{c|}{ SETIEMBRE } & \multicolumn{1}{c|}{ OCTUBRE } & NOVIEMBRE & DICIEMBRE & TOTAL SEMESTRAL & TOTAL ANUAL \\
\hline SUELDOS DE EMPLEADOS & $3,930.00$ & $3,930.00$ & $3,930.00$ & $3,930.00$ & $3,930.00$ & $3,930.00$ & $23,580.00$ & $47,160.00$ \\
\hline ESSALUD & 0.00 & 353.70 & 353.70 & 353.70 & 353.70 & 353.70 & $1,768.50$ & $3,890.70$ \\
\hline GRATIFICACION & $4,283.70$ & 0.00 & 0.00 & 0.00 & 0.00 & $4,283.70$ & $8,567.40$ & $8,567.40$ \\
\hline CTS & 0.00 & 0.00 & 0.00 & 0.00 & $2,321.98$ & 0.00 & $2,321.98$ & $4,643.95$ \\
\hline TOTAL & $8,213.70$ & $4,283.70$ & $4,283.70$ & $4,283.70$ & $6,605.68$ & $8,567.40$ & $36,237.88$ & $64,262.05$ \\
\hline
\end{tabular}

\section{PROYECCIÓN ANUAL}

\begin{tabular}{|l|r|r|r|}
\hline \multicolumn{1}{|c|}{ CONCEPTO } & \multicolumn{1}{c|}{2019} & \multicolumn{1}{c|}{2020} & \multicolumn{1}{c|}{2021} \\
\hline SUELDOS DE EMPLEADOS & $47,160.00$ & $47,160.00$ & $47,160.00$ \\
\hline ESSALUD & $3,890.70$ & $3,890.70$ & $3,890.70$ \\
\hline GRATIFICACION & $8,567.40$ & $8,567.40$ & $8,567.40$ \\
\hline CTS & $4,643.95$ & $4,643.95$ & $4,643.95$ \\
\hline TOTAL & $64,262.05$ & $64,262.05$ & $64,262.05$ \\
\hline
\end{tabular}




\section{Capítulo 7. Plan económico-financiero}

\subsection{Supuestos}

Se utilizará los siguientes supuestos en la empresa Kallpa Textil:

- El presupuesto se elaborará en la moneda local (soles), de esta forma buscamos disminuir el riesgo por tipo de cambio y porque nuestras actividades de compra y venta se realizaran en el mercado local.

- La inversión está comprendida por la implementación de la oficina donde se desarrollará nuestro negocio, el cual es un local alquilado de $30 \mathrm{~m} 2$

- La depreciación de los activos fijos de acuerdo a su naturaleza y a lo que la administración unitaria estipula es para muebles y enseres 10 años y para computadoras e impresora 4 años de vida útil

- La tasa que se aplicará para IGV es de $18 \%$; Impuesto a la Renta $29.5 \%$

- El Costo de venta comprenderá los gastos de servicio terciarizado (Courier), depreciación de los activos fijos, alquiler de local, y la planilla (community manager, atención al cliente).

- Consideramos un incremento de $5 \%$ anual en nuestras ventas

- Costo de personal se incluye toda la carga laboral de un empleado en planilla bajo el régimen general. Sus beneficios sociales se prorratean a fin de provisionar de forma mensual es costo del empleado.

- Gastos de Administración incluye planilla de personal (gerente general), servicios terciariarizados (honorarios sistemas, contables, otros), gastos de personal

- Gastos de Ventas, incluye los gastos de Marketing y publicidad, gastos logísticos y otros gastos de ventas. 


\subsection{Inversión en activos (fijos e intangibles) y depreciación}

\section{ESTRUCTURA DE LA INVERSIÓN EN ACTIVOS FIJOS}

\begin{tabular}{|c|c|c|c|c|c|c|}
\hline MUEBLES Y ENSERES & CANTIDAD & UNID DE MEDIDA & A PRECIO SIN IGV & TOTAL SIN IGV & AÑOS & DEPRECIACIÓN \\
\hline Escritorios & 3 & unidades & 300.00 & 900.00 & 10 & 90.00 \\
\hline Sillas & 3 & unidades & 80.00 & 240.00 & 10 & 24.00 \\
\hline Mueble de Archivadc & 3 & unidades & 850.00 & $2,550.00$ & 10 & 255.00 \\
\hline Botiquin & 1 & unidades & 15.00 & 15.00 & 10 & 1.50 \\
\hline TOTAL & & & $1,245.00$ & $3,705.00$ & & 370.50 \\
\hline
\end{tabular}

\begin{tabular}{|l|l|l|l|l|l|l|}
\hline EQUIPOS COMPUTO & CANTIDAD & UNID DE MEDIDA & PRECIO SIN IGV & TOTAL SIN IGV & AÑOS & DEPRECIACIÓN \\
\hline
\end{tabular}

\begin{tabular}{|c|c|c|c|c|c|c|}
\hline Laptop láser Hp & 3 & unidades & $1,800.00$ & $5,400.00$ & 4 & $1,350.00$ \\
\hline Impresora láser $\mathrm{Hp}$ & 1 & unidades & 850.00 & 850.00 & 4 & 212.50 \\
\hline TOTAL & & & $2,650.00$ & $6,250.00$ & & $1,562.50$ \\
\hline
\end{tabular}

\begin{tabular}{|l|l|l|l|l|l|l|}
\hline INTANGIBLE & CANTIDAD & UNID DE MEDIDA & PRECIO SIN IGV & TOTAL SIN IGV & AÑOS & DEPRECIACIÓN \\
\hline
\end{tabular}

\begin{tabular}{|c|c|c|c|c|c|c|}
\hline \multirow[t]{2}{*}{ Software } & \multirow[t]{2}{*}{1} & \multirow[t]{2}{*}{ unidades } & $8,000.00$ & $8,000.00$ & \multirow[t]{2}{*}{10} & 800.00 \\
\hline & & & $8,000.00$ & $8,000.00$ & & 800.00 \\
\hline
\end{tabular}

\subsection{Proyección de ventas}

A continuación, se presentarán los cuadros elaborados para las proyecciones de ventas. En ellas se han detallado el número de unidades que se planea vender mensualmente, considerando fechas en donde las compras disminuyen y aumentan. Asimismo, se ha tomado el supuesto de crecimiento de $5 \%$ anual. 

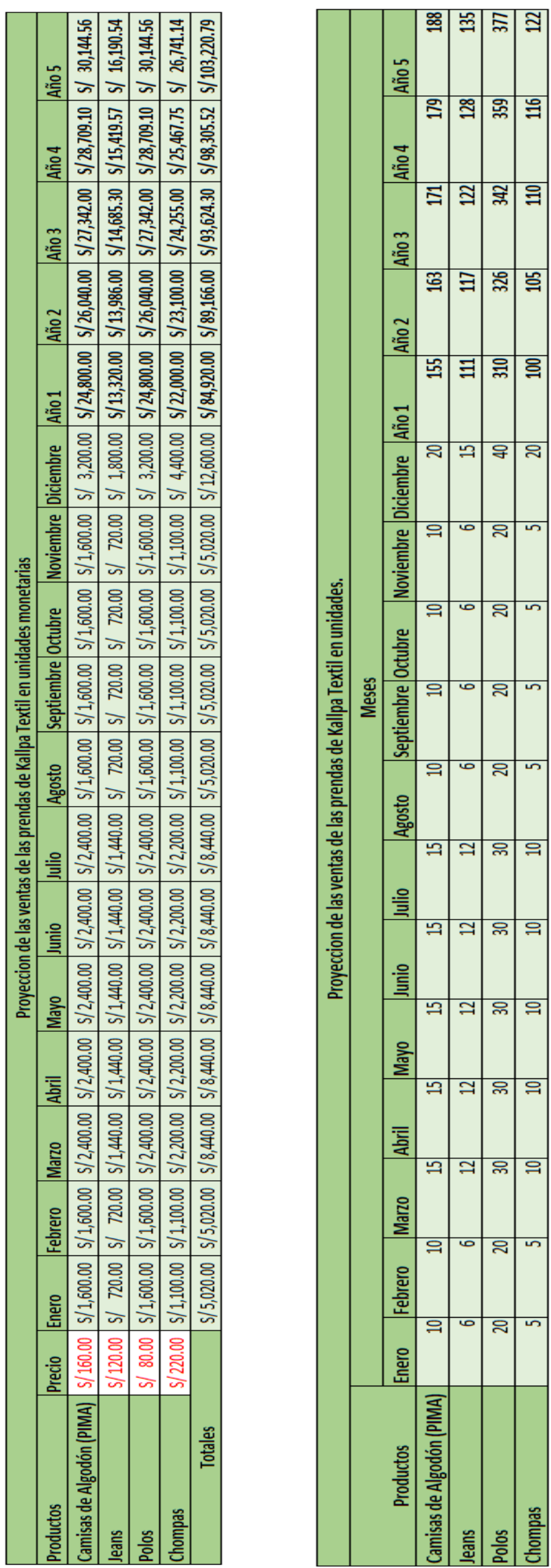


\subsection{Cálculo del capital de trabajo}

Se ha considerado los siguientes puntos para determinar el capital de trabajo necesario anualmente. Con respecto al efectivo que tendrá la empresa, se ha determinado que se tendrá en caja S/. 700 mensuales. Asimismo, se han considerado en los costos de producción, la compra de las prendas, los insumos energéticos utilizados en las actividades diarias y el pago del dominio anual; en los gastos administrativos se están considerando los sueldos de nuestros 3 empleados; y por último, en los gastos de ventas hemos determinado el costo mensual de la publicidad y el pago a los couriers, quienes enviaran las prendas al consumidor final.

\begin{tabular}{|c|c|c|}
\hline Costos de Producción & \multicolumn{2}{|c|}{ Mensual. } \\
\hline 1) Compra de Prendas ( $40 \%$ del valor de venta) & S/ & 232.00 \\
\hline Camisas de Algodón (PIMA) & s/ & 64.00 \\
\hline Jeans & $\mathrm{s} /$ & 48.00 \\
\hline Polos & s/ & 32.00 \\
\hline Chompas & s/ & 88.00 \\
\hline 2) Insumos energeticos & S/ & 100.00 \\
\hline 3) Pago de Dominio & S/ & 4.167 \\
\hline Total Costo de Producción & S/ & 336.17 \\
\hline Efectivo en Caja & S/ & 600.00 \\
\hline Caja Chica & S/ & 100.00 \\
\hline Total Efectivo & S/ & 700.00 \\
\hline
\end{tabular}

\begin{tabular}{|c|c|c|}
\hline Gastos de Administración & S/ & $3,930.00$ \\
\hline 1) Sueldos de Gerente General & S/ & $1,500.00$ \\
\hline 2) Sueldo de CM & S/ & $1,500.00$ \\
\hline 3) Sueldo de Atencion al Cliente & S/ & 930.00 \\
\hline Gasto de Ventas & S/ & 798.00 \\
\hline 1) Publicidad & S/ & 350.00 \\
\hline 2) Pago al Courier & S/ & 448.00 \\
\hline
\end{tabular}

Una vez determinado los costos asociados al capital de trabajo, se anualizan los costos para determinar el costo de capital de trabajo requerido anualmente.

\begin{tabular}{|c|c|c|c|c|c|c|c|c|}
\hline \multicolumn{9}{|c|}{ Capital de Trabajo Requerido } \\
\hline Concepto & Veces al Año & Año1 & Año 2 & & Año 3 & Año 4 & Año & \\
\hline Total Efectivo & 12 & s/ $8,400.00$ & S/ & $8,400.00$ & S/ $8,400.00$ & S/ $8,400.00$ & s/ & $8,400.00$ \\
\hline Costos de Producción & 12 & S/ $4,034.00$ & $\mathrm{~s} /$ & $4,034.00$ & S/ $4,034.00$ & S/ $4,034.00$ & s/ & $4,034.00$ \\
\hline Gastos Administrativos & 12 & S/ $47,160.00$ & $\mathrm{~s} /$ & $47,160.00$ & $\mathrm{~s} / 47,160.00$ & S/ $47,160.00$ & S/ & $47,160.00$ \\
\hline Gastos de Ventas & 12 & S/ $9,576.00$ & $\mathrm{~s} /$ & $9,576.00$ & S/ $9,576.00$ & S/ $9,576.00$ & s/ & $9,576.00$ \\
\hline \multicolumn{2}{|c|}{ Total Capital de Trabajo } & S/ $69,170.00$ & S/ & $69,170.00$ & S/ $69,170.00$ & S/ $69,170.00$ & s/ & $69,170.00$ \\
\hline
\end{tabular}

Cabe resaltar que este monto S/. 69,170 no será utilizado como inversión en el flujo de caja presentado más adelante.

\subsection{Estructura de financiamiento: Tradicional y no tradicional}

Nuestra estructura de financiamiento es netamente tradicional (Banco BBVA) que conforma un $70 \%$ del total de inversión y un $30 \%$ con capital propio. 


\begin{tabular}{|l|r|r|}
\hline \multicolumn{3}{|c|}{ Estructura de Capital } \\
\hline Datos & Particip $\%$ & Tasa (costo) \\
\hline Capital propio & $30.00 \%$ & $13.8994 \%$ \\
\hline Deuda (BANCOS) & $70.00 \%$ & $6.4500 \%$ \\
\hline Total & $100.00 \%$ & \\
\hline
\end{tabular}

WACC

$7.3529 \%$

Cronograma de pago que se le debe al banco BBVA por el préstamo para el financiamiento del proyecto.

\begin{tabular}{|c|c|c|c|c|}
\hline \multicolumn{5}{|c|}{ Cromograma de Pagos. } \\
\hline Años & Prestamo & Amortización & Interes & Cuota \\
\hline 1 & $-27,828$ & $-4,893$ & $-1,795$ & $-6,687$ \\
\hline 2 & $-22,936$ & $-5,208$ & $-1,479$ & $-6,687$ \\
\hline 3 & $-17,728$ & $-5,544$ & $-1,143$ & $-6,687$ \\
\hline 4 & $-12,184$ & $-5,902$ & -786 & $-6,687$ \\
\hline 5 & $-6,282$ & $-6,282$ & -405 & $-6,687$ \\
\hline
\end{tabular}

\subsection{Estados Financieros (Balance General, Estado de GGPP, Flujo de Caja)}

\begin{tabular}{|c|c|c|c|c|c|}
\hline \multicolumn{6}{|c|}{ Estados Financieros Anuales [En nuevos soles] } \\
\hline \multicolumn{6}{|c|}{ KALLPA TEXTIL S.A.C. } \\
\hline ESTADO DE SITUACIÓN FINANCIERA & Año 1 & Año 2 & Año 3 & Año 4 & Año 5 \\
\hline \multicolumn{6}{|l|}{$\begin{array}{l}\text { Actiyos } \\
\text { Actiyos Corrientes }\end{array}$} \\
\hline Efectivo y Equivalentes al Efectivo & 29,231 & 36,907 & 47,846 & 64,084 & 86,812 \\
\hline Cuentas por cobrar comerciales por cobrar & - & - & - & - & - \\
\hline Inventarios & - & - & - & - & - \\
\hline $\begin{array}{l}\text { Total Actiwos Corrientes } \\
\text { Activos No Corrientes }\end{array}$ & 29,231 & 36,907 & 47,846 & 64,084 & 86,812 \\
\hline Propiedades, Planta y Equipo (neto) & 18,822 & 15,689 & 12,556 & 9,423 & 7,853 \\
\hline Total Actiwos ho Corrientes & 18,822 & 15,689 & 12,556 & 9,423 & 7.853 \\
\hline TDTAL DE ACTWOS & 48,053 & 52,596 & $60,4,02$ & 73,507 & 94,665 \\
\hline \multicolumn{6}{|l|}{$\begin{array}{l}\text { Pasiwos y Patrimonio } \\
\text { Pasiwos Corrientes }\end{array}$} \\
\hline Dbligaciones financieras -Corto Plazo & 26,750 & & & & \\
\hline \multicolumn{6}{|l|}{ Cuentas por Pagar Comerciales } \\
\hline \multicolumn{6}{|l|}{ Dtras Cuentas por Pagar } \\
\hline \multicolumn{6}{|l|}{ Cuentas por pagar a los Empleados } \\
\hline renta por pagar & 2,766 & 4,129 & 5,494 & 7.459 & 10,415 \\
\hline $\begin{array}{l}\text { Total Pasivos Corrientes } \\
\text { Pasivos No Corrientes }\end{array}$ & 29,516 & 4,129 & 5,494 & 7,459 & 10,415 \\
\hline Obligaciones Financieras - Largo Plazo & & 20,062 & 13,375 & 6.687 & \\
\hline Total Pasiyos ho Corrientes & - & 20,062 & 13,375 & 6,687 & \\
\hline Total Pasiyos & 29,516 & 24,192 & 18,869 & 14,147 & 10,415 \\
\hline \multicolumn{6}{|l|}{ Patrimonio } \\
\hline Capital & 11,926 & 11,926 & 11,926 & 11,926 & 11,926 \\
\hline Resultados del Ejercicio & 6,610 & 9,868 & 13,129 & 17,826 & 24,890 \\
\hline Resultados de Acumulado & & 6,610 & 16,478 & 29,607 & 47,434 \\
\hline Total Patrimonio & 18,537 & 28,405 & 41,534 & 59,360 & 84.250 \\
\hline TOTAL PASIVOY PATRIMONO & 48,053 & 52.596 & 60,402 & 73,507 & 94,665 \\
\hline
\end{tabular}


KALLPA TEXTIL S.A.C.

\begin{tabular}{|c|c|c|c|c|c|}
\hline ESTADO DE RESULTADOS & Año 1 & Año 2 & Año 3 & Año 4 & Año 5 \\
\hline Ingresos por Ventas & 138,480 & 145,404 & 152,674 & 163,361 & 179,698 \\
\hline Costo de Ventas & -89.435 & $-92,205$ & -95.113 & -99.388 & -105.922 \\
\hline Ganancia (Pérdida) Bruta & 49.045 & 53.199 & 57.561 & 63.974 & 73.775 \\
\hline Gastos de Ventas y Distribución & $-1,735$ & $-1,804$ & $-1,877$ & $-1,984$ & $-2,147$ \\
\hline Gastos de marketing & -350 & -350 & -350 & -350 & -350 \\
\hline Gastos de logistica / transporte (OLVA COURIER) & $-1,385$ & $-1,454$ & $-1,527$ & $-1,634$ & $-1,797$ \\
\hline Gastos de Administración & -36.139 & $-35,919$ & -35.919 & -35.919 & -35.919 \\
\hline Gasto de personal & $-24,663$ & $-24,663$ & $-24,663$ & $-24,663$ & $-24,663$ \\
\hline Gastos servicios tercerizados & $-2,400$ & $-2,400$ & $-2,400$ & $-2,400$ & $-2,400$ \\
\hline Gastos de servicios públicos y otros & $-9,076$ & $-8,856$ & $-8,856$ & $-8,856$ & $-8,856$ \\
\hline Ganancia (Pérdida) por actividades de operación & 11,171 & 15,477 & 19,766 & 26,071 & 35,710 \\
\hline Ingresos Financieros & & & & & 0 \\
\hline Gastos Financieros & $-1,795$ & $-1,479$ & $-1,143$ & -786 & -405 \\
\hline Resultado antes de Impuesto a las Ganancias & 9,376 & 13,997 & 18,622 & 25,286 & 35,305 \\
\hline Impuesto a la renta & $-2,766$ & $-4,129$ & $-5,494$ & $-7,459$ & -10.415 \\
\hline Ganancia (Pérdida) Neta del Ejercicio & 6,610 & 9,868 & 13,129 & 17,826 & 24,890 \\
\hline
\end{tabular}

\section{Análisis Vertical}

\begin{tabular}{|c|c|c|c|c|c|}
\hline ESTADO DE RESULTADOS & Año 1 & Año 2 & Año 3 & Año 4 & Aïo 5 \\
\hline Ingresos por Ventas & $100 \%$ & $100 \%$ & $100 \%$ & $100 \%$ & $100 \%$ \\
\hline Costo de Ventas & $.65 \%$ & $-63 \%$ & $.62 \%$ & $.61 \%$ & $.59 \%$ \\
\hline Ganancia (Pérdida) Bruta & $35 \%$ & $37 \%$ & $38 \%$ & $39 \%$ & $41 \%$ \\
\hline Gastos de Ventas y Distribución & $.1 \%$ & $.1 \%$ & $.1 \%$ & $.1 \%$ & $.1 \%$ \\
\hline Gastos de marketing & $0 \%$ & $0 \%$ & $0 \%$ & $0 \%$ & $0 \%$ \\
\hline Gastos de logistica / transporte & $-1 \%$ & $-1 \%$ & $-1 \%$ & $-1 \%$ & $-1 \%$ \\
\hline Otros gasstos de Ventas & $0 \%$ & $0 \%$ & $0 \%$ & $0 \%$ & $0 \%$ \\
\hline Gastos de Administración & $.28 \%$ & $.25 \%$ & $.24 \%$ & $.22 \%$ & $.20 \%$ \\
\hline Gasto de personal & $-18 \%$ & $-17 \%$ & $-16 \%$ & $-15 \%$ & $-14 \%$ \\
\hline Gastos servicios tercerizados & $-2 \%$ & $-2 \%$ & $-2 \%$ & $-1 \%$ & $-1 \%$ \\
\hline Otros gastos de Ventas & $-8 \%$ & $-6 \%$ & $-6 \%$ & $-5 \%$ & $-5 \%$ \\
\hline Otros gastos del personal & $0 \%$ & $0 \%$ & $0 \%$ & $0 \%$ & $0 \%$ \\
\hline Ganancia (Pérdida) por actividades de & $6 \%$ & $11 \%$ & $13 \%$ & $16 \%$ & $20 \%$ \\
\hline Inaresos Financieros & $0 \%$ & $0 \%$ & $0 \%$ & $0 \%$ & $0 \%$ \\
\hline Gastos Financieros & $1 \%$ & $1 \%$ & $0 \%$ & $0 \%$ & $0 \%$ \\
\hline Resultado antes de Impuesto a las & $7 \%$ & $11 \%$ & $13 \%$ & $16 \%$ & $20 \%$ \\
\hline Impuesto a la renta & $-2 \%$ & $-3 \%$ & $-4 \%$ & $.5 \%$ & $-6 \%$ \\
\hline Ganancia (Pérdida) Neta del Ejercicio & $5 \%$ & $8 \%$ & $9 \%$ & $11 \%$ & $14 \%$ \\
\hline
\end{tabular}

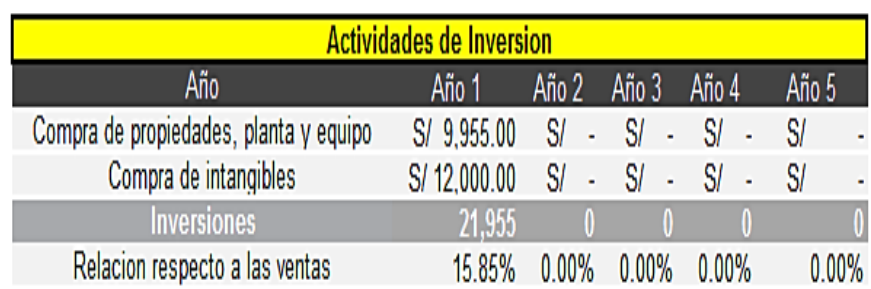

\section{Análisis Horizonta}

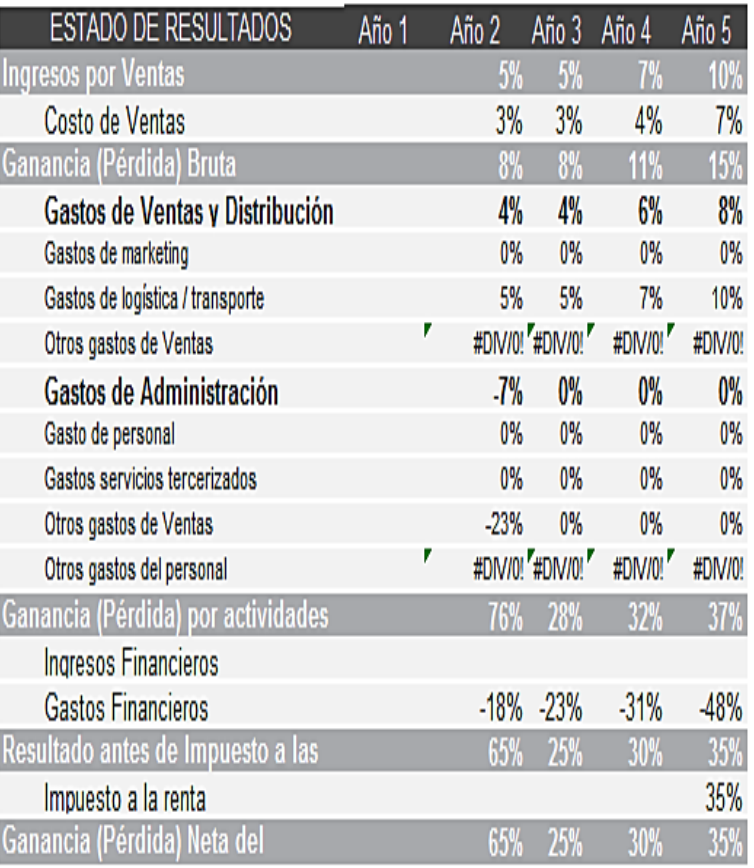




\subsection{Flujo Financiero}

FLUJO DE CAJA

\begin{tabular}{|c|c|c|c|c|c|c|}
\hline & Año 0 & Año 1 & Año 2 & Año 3 & Año 4 & Año 5 \\
\hline VENTAS & & 138,480 & 144,158 & 150,068 & 156,221 & 162,626 \\
\hline Incremento de Ventas & & & $4.1 \%$ & $4.1 \%$ & $4.1 \%$ & $4.1 \%$ \\
\hline COSTOS DE VENTAS & & $-89,435$ & $-92,205$ & $-95,113$ & $-99,388$ & $-105,922$ \\
\hline Incremento de Costos & & & $3 \%$ & $3 \%$ & $4 \%$ & $7 \%$ \\
\hline GASTOS OPERATIVOS & & $-37,873$ & $-37,723$ & $-37,795$ & $-37,902$ & $-38,065$ \\
\hline Crecimiento de Gastos Operativos & & & $-0.40 \%$ & $0.19 \%$ & $0.28 \%$ & $0.43 \%$ \\
\hline Margen bruto & & $35.42 \%$ & $36.04 \%$ & $36.62 \%$ & $36.38 \%$ & $34.87 \%$ \\
\hline Margen operativo & & $8.0671 \%$ & $9.8713 \%$ & $11.4347 \%$ & $12.1181 \%$ & $11.4608 \%$ \\
\hline
\end{tabular}

\begin{tabular}{|l|c|c|c|}
\hline \multicolumn{1}{|c|}{ Activos de inversion } & Inversión & Inversión (sin IGV) & Vida util (Añ̃os) \\
\cline { 2 - 4 } Escritorios & 1,062 & 900 & 10 \\
\cline { 2 - 4 } \multirow{3}{*}{$\begin{array}{l}\text { Sillas } \\
\text { Mueble de Archivadores }\end{array}$} & 283 & 240 & 10 \\
\cline { 2 - 4 } $\begin{array}{l}\text { Botiquin } \\
\text { Laptop láser Hp }\end{array}$ & 3,009 & 2,550 & 10 \\
\cline { 2 - 4 } $\begin{array}{l}\text { Impresora láser Hp } \\
\text { Software }\end{array}$ & 18 & 15 & 10 \\
\cline { 2 - 4 } & 6,372 & 5,400 & 4 \\
\hline Total Inversion & 1,003 & 850 & 4 \\
\cline { 2 - 4 } & 14,160 & 12,000 & 10 \\
\hline
\end{tabular}

\begin{tabular}{|l|c|}
\hline Capital de trabajo & 13,848 \\
\hline
\end{tabular}

\begin{tabular}{|l|l|}
\hline Impuesto a la renta & $29.5 \%$ \\
\hline
\end{tabular}

\begin{tabular}{|c|c|c|c|c|c|}
\hline Calculo de la Depreciacion & Depreciacion Anual & Dep Acum 5 Años & Valor Libro año 5 & $\mathbb{I R}$ & $\begin{array}{l}\text { Valor de } \\
\text { rescate }\end{array}$ \\
\hline Escritorios & \begin{tabular}{|c|}
90 \\
\end{tabular} & 450 & 450 & 133 & 317 \\
\hline Mueble de Archivadores & 255 & 1,275 & 1,275 & 376 & 899 \\
\hline Botiquin & 2 & 8 & 8 & 2 & 5 \\
\hline Laptop láser Hp & 1,350 & 5,400 & 0 & 0 & 0 \\
\hline \multirow[t]{2}{*}{ Software } & 1,200 & 6,000 & 6,000 & 1,770 & 4,230 \\
\hline & 3,133 & 14,103 & 7,853 & 2,316 & 5,536 \\
\hline
\end{tabular}

\begin{tabular}{|c|c|c|c|c|c|}
\hline \multicolumn{6}{|c|}{ FLUJO DE CAJA } \\
\hline & Año 1 & Año 2 & Año 3 & Año 4 & Año 5 \\
\hline SALDO INICIAL (CAPITAL + PRESTAMO) & 39,755 & 29,231 & 36,907 & 47,846 & 64,084 \\
\hline \multicolumn{6}{|l|}{ INGRESOS } \\
\hline Ingreso Por Ventas & 163,406 & 171,577 & 180,156 & 192,766 & 212,043 \\
\hline \multicolumn{6}{|l|}{ GASTOS } \\
\hline COMPRA DE ACTIVO FIJO C/IGV & $-25,907$ & & & & \\
\hline PLANILLA & $-51,922$ & $-51,922$ & $-51,922$ & $-51,922$ & $-51,922$ \\
\hline ESSALUD & $-3,346$ & $-3,650$ & $-3,650$ & $-3,650$ & $-3,650$ \\
\hline GASTOS OPERATIVOS & $-11,476$ & $-11,256$ & $-11,256$ & $-11,256$ & $-11,256$ \\
\hline GASTOS DE MKT Y LOGISTICA & $-1,735$ & $-1,804^{\prime}$ & $-1,877^{\prime}$ & $-1,984^{\prime}$ & $-2,147$ \\
\hline PAGO PRESTAMO & $-6,687$ & $-6,687$ & $-6,687$ & $-6,687$ & $-6,687$ \\
\hline IMPUESTO A LA RENTA & & $-2,766$ & $-4,129$ & $-5,494$ & $-7,459$ \\
\hline PAGO IGV SUNAT & $-19,624$ & $-24,822$ & $-26,130$ & $-28,054$ & $-30,995$ \\
\hline PAGO A LOS DISEÑADORES & $-62,316$ & $-65,432$ & $-68,703$ & $-73,513$ & $-80,864$ \\
\hline Saldo Final & 29,231 & 36,907 & 47,846 & 64,084 & 86,812 \\
\hline
\end{tabular}


7.8. Tasa de descuento accionistas y wacc

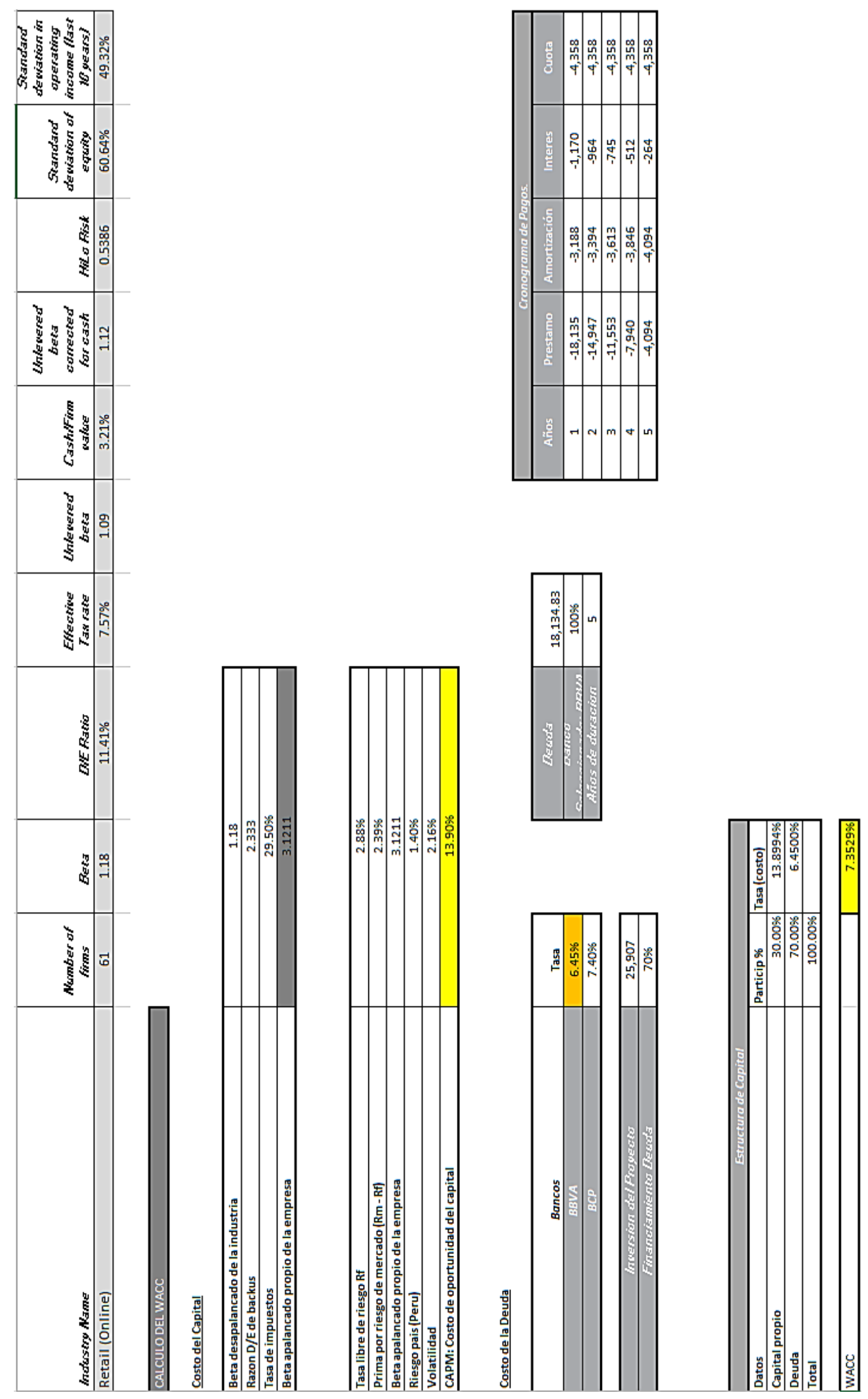




\begin{tabular}{l|l}
\hline Tasa libre de riesgo ff & Fuente: \\
\hline Prima por riesgo de mercado ( $\mathrm{Rm}-\mathbf{R}$ ) & Fuente: \\
\hline Beta apalancado propio de la empresa & Fuente: \\
\hline Fiesgo pais (Peru) & Fuente: \\
\hline Volatilidad &
\end{tabular}

https://ww.datosmacro.com/bono/usa

https://ww.datosmacro.com/prima-riesgo/usa

https://gestion.pe/economia/riesgo-pais-peru-subio-dos-puntos-basicos-1-40-puntos-porcentuales-236852

Promedio en la volatilidad de nuestra moneda en el ultimo mes. http $/ /$ mww.ambito.com $/$ economia $/ \mathrm{mercados} / \mathrm{riesgo-pais/info/?id=13}$ Rendimiento minimo requerido por los accionistas con su composición Deuda/Capital

De acuerdo a la estructura de financiamiento (70/30) se determina que el wacc es de $7.3529 \%$ y el cok es de $13.90 \%$

\subsection{Indicadores de rentabilidad}

\section{Análisis Vertical}

\begin{tabular}{|c|c|c|c|c|c|}
\hline ESTADO DE RESULTADOS & Año 1 & Año 2 & Año 3 & Año 4 & Año 5 \\
\hline Ingresos por Ventas & $100 \%$ & $100 \%$ & $100 \%$ & $100 \%$ & $100 \%$ \\
\hline Costo de Ventas & $-65 \%$ & $-63 \%$ & $-62 \%$ & $-61 \%$ & $-59 \%$ \\
\hline Ganancia (Pérdida) Bruta & $35 \%$ & $37 \%$ & $38 \%$ & $39 \%$ & $41 \%$ \\
\hline Gastos de Ventas v Distribución & $-1 \%$ & $-1 \%$ & $-1 \%$ & $-1 \%$ & $-1 \%$ \\
\hline Gastos de marketing & $0 \%$ & $0 \%$ & $0 \%$ & $0 \%$ & $0 \%$ \\
\hline Gastos de logistica / transporte & $-1 \%$ & $-1 \%$ & $-1 \%$ & $-1 \%$ & $-1 \%$ \\
\hline Gastos de Administración & $-26 \%$ & $-25 \%$ & $-24 \%$ & $-22 \%$ & $-20 \%$ \\
\hline Gasto de personal & $-18 \%$ & $-17 \%$ & $-16 \%$ & $-15 \%$ & $-14 \%$ \\
\hline Gastos servicios tercerizados & $-2 \%$ & $-2 \%$ & $-2 \%$ & $-1 \%$ & $-1 \%$ \\
\hline Gastos de servicios públicos y otros & $-7 \%$ & $-6 \%$ & $-6 \%$ & $-5 \%$ & $-5 \%$ \\
\hline Ganancia (Pérdida) por actividades de & $8 \%$ & $11 \%$ & $13 \%$ & $16 \%$ & $20 \%$ \\
\hline Ingresos Financieros & $0 \%$ & $0 \%$ & $0 \%$ & $0 \%$ & $0 \%$ \\
\hline Gastos Financieros & $-1 \%$ & $-1 \%$ & $-1 \%$ & $0 \%$ & $0 \%$ \\
\hline Resultado antes de Impuesto a las & $7 \%$ & $10 \%$ & $12 \%$ & $15 \%$ & $20 \%$ \\
\hline Impuesto a la renta & $-2 \%$ & $-3 \%$ & $-4 \%$ & $-5 \%$ & $-6 \%$ \\
\hline Ganancia (Pérdida) Neta del Ejercicio & $5 \%$ & $7 \%$ & $9 \%$ & $11 \%$ & $14 \%$ \\
\hline
\end{tabular}

Podemos apreciar en el análisis vertical el componente que más destaca es el costo de venta el cual va disminuyendo en el transcurso de los años, ya que tenemos una proyección de $5 \%$ de crecimiento anual en nuestras ventas obteniendo una mejora continua en nuestros costos de venta. Asimismo el segundo componente más destacado el gasto administrativo que está compuesto en su mayor parte por el sueldo del gerente. Los gastos financieros no son tan significativos con respecto a las ventas, podemos apreciar que desde el primer año tenemos utilidad en el ejercicio. 
Análisis Horizontal

\begin{tabular}{|c|c|c|c|c|c|}
\hline ESTADO DE RESULTADOS & Añ́o 1 & Año 2 & Año 3 & Año 4 & Año 5 \\
\hline Ingresos por Ventas & & $5 \%$ & $5 \%$ & $7 \%$ & $10 \%$ \\
\hline Costo de Ventas & & $3 \%$ & $3 \%$ & $4 \%$ & $7 \%$ \\
\hline Ganancia (Pérdida) Bruta & & $8 \%$ & $8 \%$ & $11 \%$ & $15 \%$ \\
\hline Gastos de Ventas v & & $4 \%$ & $4 \%$ & $6 \%$ & $8 \%$ \\
\hline Gastos de marketing & & $0 \%$ & $0 \%$ & $0 \%$ & $0 \%$ \\
\hline Gastos de logistica / transporte & & $5 \%$ & $5 \%$ & $7 \%$ & $10 \%$ \\
\hline Gastos de Administración & & $-1 \%$ & $0 \%$ & $0 \%$ & $0 \%$ \\
\hline Gasto de personal & & $0 \%$ & $0 \%$ & $0 \%$ & $0 \%$ \\
\hline \multirow{2}{*}{ 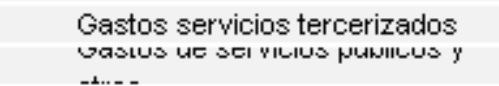 } & & $0 \%$ & $0 \%$ & $0 \%$ & $0 \%$ \\
\hline & & $-2 \%$ & $0 \%$ & $0 \%$ & $0 \%$ \\
\hline Ganancia (Pérdida) por & & $39 \%$ & $28 \%$ & $32 \%$ & $37 \%$ \\
\hline \multicolumn{6}{|l|}{ Ingresos Financieros } \\
\hline Gastos Financieros & & $-18 \%$ & $-23 \%$ & $-31 \%$ & $-48 \%$ \\
\hline Resultado antes de Impuesto & & $49 \%$ & $33 \%$ & $36 \%$ & $40 \%$ \\
\hline Impuesto a la renta & & $49 \%$ & $33 \%$ & $36 \%$ & $40 \%$ \\
\hline $\begin{array}{l}\text { Ganancia (Pérdida) Neta del } \\
\text { Ejercicio }\end{array}$ & & $49 \%$ & $33 \%$ & $36 \%$ & $40 \%$ \\
\hline
\end{tabular}

En el análisis horizontal nos muestra un crecimiento constante en nuestras ventas en el año 2 y 3 el cual irá incrementándose en los años siguientes, ya que seríamos una plataforma más conocida, al incrementar nuestras ventas por ende aumentará los gastos de transporte (Courier).

\begin{tabular}{|c|c|c|c|c|c|}
\hline & Año 1 & Año 2 & Año 3 & Año 4 & Año 5 \\
\hline \multicolumn{6}{|l|}{ Ratio de liquidez } \\
\hline Ratio corriente & 0.99 & 8.94 & 8.71 & 8.59 & 8.34 \\
\hline Prueba ácida & 1.0 & 8.9 & 8.7 & 8.6 & 8.3 \\
\hline \multicolumn{6}{|c|}{ Ratio de solvencia } \\
\hline Ratio de patrimonio & $39 \%$ & $54 \%$ & $69 \%$ & $81 \%$ & $89 \%$ \\
\hline \multicolumn{6}{|c|}{ Ratios de rentabilidad } \\
\hline $\mathrm{ROE}$ & $36 \%$ & $35 \%$ & $32 \%$ & $30 \%$ & $30 \%$ \\
\hline RDA & $14 \%$ & $19 \%$ & $22 \%$ & $24 \%$ & $26 \%$ \\
\hline \multicolumn{6}{|c|}{ Ratio de endeudamiento } \\
\hline Deuda/EBITDA & 2.39 & 1.41 & 0.78 & 0.35 & 0.00 \\
\hline
\end{tabular}

Nuestra empresa presenta un ratio de liquidez aceptable, aunque en el primer año podemos cubrir nuestras deudas corrientes casi a 1, en los años siguientes nuestra liquidez es mucho más a una razón de 8 a 1 e incluso la prueba ácida es mayor a 1.

Los indicadores de rentabilidad son positivos a partir del primer año, luego de superar el punto de equilibrio y obtener resultados financieros positivos

El nivel de endeudamiento respecto al Ebitda es considerable en el año 1, debido a que se pide el préstamo, pero en los años 3 y 4 alcanza niveles bastante prudentes $<1$. 


\subsection{Análisis de riesgo}

\subsubsection{Análisis de Sensibilidad}

En el análisis de sensibilidad se toma diferentes factores el cual influyen en el desempeño económico de la empresa debida a la estrecha relación con los factores macroeconómicos (aumento o disminución en el PBI, inflación, tipo de cambio, etc). En el primer trimestre del 2018 el Pbi alcanzó un crecimiento de 3.2\% con referencia al año anterior y se proyecta cerrar con un crecimiento del $4.1 \%$ según estadísticas de INEI1. Asimismo según el ministro de la producción Pedro Olaechea, estima que las prendas de vestir creció en un $4 \%$ este año2.

Según los datos obtenidos se plantean los siguientes escenarios:

Tabla 8: Análsis de riesgo : Base

\begin{tabular}{|c|c|c|c|c|c|c|}
\hline & \multicolumn{2}{|c|}{1} & \multicolumn{2}{|c|}{2} & \multicolumn{2}{|c|}{4} \\
\hline & Año 0 & Año 1 & Año 2 & Año 3 & Año 4 & Año 5 \\
\hline Ingresos & & 138,480 & 144,158 & 150,068 & 156,221 & 162,626 \\
\hline Costo de venta & & $-89,435$ & $-92,205$ & $-95,113$ & $-99,388$ & $-105,922$ \\
\hline Utilidad Bruta & & 49,045 & 51,953 & 54,955 & 56,833 & 56,704 \\
\hline Margen Bruto & & $35.42 \%$ & $36.04 \%$ & $36.62 \%$ & $36.38 \%$ & $34.87 \%$ \\
\hline GASTOS OPERATNOS & & $-37,873$ & $-37,723$ & $-37,795$ & $-37,902$ & $-38,065$ \\
\hline EBITDA & & 11,171 & 14,230 & 17,160 & 18,931 & 18,638 \\
\hline Depreciación y Amortización & & $-3,133$ & $-3,133$ & $-3,133$ & $-3,133$ & $-3,133$ \\
\hline EBIT & & 8,038 & 11,097 & 14,027 & 15,798 & 15,505 \\
\hline Impuestos (-) & & 2,371 & 3,274 & 4,138 & 4,660 & 4,574 \\
\hline NOPAD & & 5,667 & 7,824 & 9,889 & 11,138 & 10,931 \\
\hline Depreciación (+) & & 3,133 & 3,133 & 3,133 & 3,133 & 3,133 \\
\hline Activo Fijos & $-25,907$ & & & & & \\
\hline CTN & $-13,848$ & & & & & 13,848 \\
\hline FCLD & $-39,755$ & 8,800 & 10,957 & 13,022 & 14,271 & 27,912 \\
\hline Financiamiento & 27,828 & & & & & \\
\hline Amortizacion de capital & & 4,893 & 5,208 & 5,544 & 5,902 & 6,282 \\
\hline Intereses & & 1,795 & 1,479 & 1,143 & 786 & 405 \\
\hline Escudo fiscal de los intereses & & -530 & -436 & -337 & -232 & -120 \\
\hline FCNI & $-11,926$ & 2,642 & 4,705 & 6,672 & 7,815 & 21,344 \\
\hline
\end{tabular}

Incremento en las ventas anua de $4.1 \%$ de acuerdo a las proyecciones del PBI y del sector.

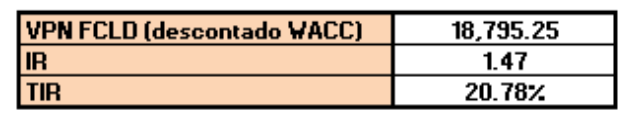

\begin{tabular}{|l|c|}
\hline UPN FCNI (descontado COK) & $31,252.12$ \\
\hline IR & 3.62 \\
\hline TIR & $42.79 \%$ \\
\hline
\end{tabular}


Tabla 9: Análsis de riesgo : Escenario pesimista

\section{Escenario pesimista}

Incremento de las ventas por debajo de las proyecciones de crecimiento

\begin{tabular}{|c|c|c|c|c|c|c|}
\hline & Año 0 & Año 1 & Año 2 & Año 3 & Año 4 & Año 5 \\
\hline Ingresos & & 142,634 & 148,482 & 154,570 & 160,908 & 167,505 \\
\hline Costo de venta & & $-92,118$ & $-94,971$ & $-97,966$ & $-102,370$ & $-109,100$ \\
\hline Utilidad Bruta & & 50,516 & 53,511 & 56,604 & 58,538 & 58,405 \\
\hline Margen Bruto & & $35.42 \%$ & $36.04 \%$ & $36.62 \%$ & $36.38 \%$ & $34.87 \%$ \\
\hline Gastos Operativos & & $-37,873$ & $-37,723$ & $-37,795$ & $-37,902$ & $-38,065$ \\
\hline EBITDA & & 12,643 & 15,789 & 18,809 & 20,636 & 20,339 \\
\hline Depreciación y Amortización & & $-3,133$ & $-3,133$ & $-3,133$ & $-3,133$ & $-3,133$ \\
\hline EBIT & & 9,510 & 12,656 & 15,676 & 17,503 & 17,206 \\
\hline Impuestos (-) & & 2,805 & 3,733 & 4,624 & 5,163 & 5,076 \\
\hline NOPAD & & 6,704 & 8,922 & 11,051 & 12,340 & 12,130 \\
\hline Depreciación (+) & & 3,133 & 3,133 & 3,133 & 3,133 & 3,133 \\
\hline $\begin{array}{l}\text { Activo Fijos } \\
\text { CTN }\end{array}$ & $\begin{array}{l}-25,907 \\
-13,848\end{array}$ & & & & & 13,848 \\
\hline FCLD & $-39,755$ & 9,837 & 12,055 & 14,184 & 15,473 & 29,111 \\
\hline Financiamiento & 27,828 & & & & & \\
\hline Amortizacion de capital & & 4,893 & 5,208 & 5,544 & 5,902 & 6,282 \\
\hline Intereses & & 1,795 & 1,479 & 1,143 & 786 & 405 \\
\hline Escudo fiscal de los intereses & & -530 & -436 & -337 & -232 & -120 \\
\hline $\mathrm{FCNI}$ & $-11,926$ & 3,679 & 5,804 & 7,834 & 9,017 & 22,544 \\
\hline
\end{tabular}

\begin{tabular}{|l|c|}
\hline UPN FCLD (descontado HACC) & $27,828.43$ \\
\hline
\end{tabular}

IR

\begin{tabular}{ll} 
TIR \\
\hline TIR
\end{tabular}

1.70

23.93\%

\begin{tabular}{|l|c|}
\hline UPN FCNI (descontado COK) & $36,951.82$ \\
\hline IR & 4.10 \\
\hline TIR & $50.74 \%$ \\
\hline
\end{tabular}

Tabla 10: Análsis de riesgo : Escenario optimista

\section{Escenario Optimista}

Incremento de los ingresos por ventas de $7 \%$

Incremento de los costos de ventas de

\begin{tabular}{|c|c|c|c|c|c|c|}
\hline & Año 0 & Año 1 & Año 2 & Año 3 & Año 4 & Año 5 \\
\hline Ingresos & & 148,174 & 154,249 & 160,573 & 167,156 & 174,010 \\
\hline Costo de venta & & $-95,696$ & $-98,659$ & $-101,771$ & $-106,345$ & $-113,337$ \\
\hline Utilidad Bruta & & 52,478 & 55,589 & 58,802 & 60,811 & 60,673 \\
\hline Margen Bruto & & $35.42 \%$ & $36.04 \%$ & $36.62 \%$ & $36.38 \%$ & $34.87 \%$ \\
\hline Gastos Operativos & & $-37,873$ & $-37,723$ & $-37,795$ & $-37,902$ & $-38,065$ \\
\hline EBITDA & & 14,604 & 17,867 & 21,007 & 22,909 & 22,607 \\
\hline Depreciación y Amortización & & $-3,133$ & $-3,133$ & $-3,133$ & $-3,133$ & $-3,133$ \\
\hline EBIT & & 11,471 & 14,734 & 17,874 & 19,776 & 19,474 \\
\hline Impuestos (-) & & 2,384 & 4,347 & 5,273 & 5,834 & 5,745 \\
\hline NOPAD & & 9,088 & 10,387 & 12,601 & 13,942 & 13,729 \\
\hline $\begin{array}{l}\text { Depreciación (+) } \\
\text { Activo Fijos }\end{array}$ & $-25,907$ & 3,133 & 3,133 & 3,133 & 3,133 & 3,133 \\
\hline CTN & $-13,848$ & & & & & 13,848 \\
\hline FCLD & $-39,755$ & 12,221 & 13,520 & 15,734 & 17,075 & 30,710 \\
\hline Financiamiento & 27,828 & & & & & \\
\hline Amortizacion de capital & & 4,893 & 5,208 & 5,544 & 5,902 & 6,282 \\
\hline Intereses & & 1,795 & 1,479 & 1,143 & 786 & 405 \\
\hline Escudo fiscal de los intereses & & -530 & -436 & -337 & -232 & -120 \\
\hline FCNI & $-11,926$ & 6,063 & 7,269 & 9,384 & 10,620 & 24,143 \\
\hline
\end{tabular}

\begin{tabular}{|l|c|}
\hline VPN FCLD (descontado WACC) & $49,506.12$ \\
\hline IR & 2.25 \\
\hline TIR & $28.93 \%$ \\
\hline
\end{tabular}

\begin{tabular}{|l|c|}
\hline UPN FCNI (descontado COK) & $45,551.91$ \\
\hline IR & 4.82 \\
\hline TIR & $64.54 \%$ \\
\hline
\end{tabular}




\begin{tabular}{|c|c|c|c|c|c|}
\hline Escenario del FCLD & 2018 & 2019 & 2020 & 2021 & 2022 \\
\hline & 1 & 2 & 3 & 4 & 5 \\
\hline Pesimista & $9,837.34$ & $12,055.33$ & $14,184.26$ & $15,472.56$ & $29,111.43$ \\
\hline Base & $8,800.05$ & $10,956.53$ & $13,021.96$ & $14,270.54$ & $27,912.15$ \\
\hline Optimista & $12,220.90$ & $13,520.40$ & $15,733.99$ & $17,075.25$ & $30,710.47$ \\
\hline Probabilidad & 1 & 2 & 3 & 4 & 5 \\
\hline Pesimista & $18 \%$ & $20 \%$ & $19 \%$ & $20 \%$ & $23 \%$ \\
\hline Base & $21 \%$ & $21 \%$ & $19 \%$ & $21 \%$ & $18 \%$ \\
\hline Optimista & $13 \%$ & $9 \%$ & $26 \%$ & $25 \%$ & $27 \%$ \\
\hline
\end{tabular}

\begin{tabular}{|l|c|c|c|c|c|}
\hline Valor esperado & $\mathbf{2 0 1 8}$ & $\mathbf{2 0 1 9}$ & $\mathbf{2 0 2 0}$ & $\mathbf{2 0 2 1}$ & $\mathbf{2 0 2 2}$ \\
\hline E(fcjd) & $5,207.45$ & $5,928.77$ & $9,260.02$ & $10,360.14$ & $20,011.64$ \\
\hline
\end{tabular}

\begin{tabular}{|l|l|}
\hline$E(\mathrm{VPN})=$ & -439.73 \\
\hline
\end{tabular}

\begin{tabular}{|c|c|c|c|c|c|}
\hline \multirow[t]{2}{*}{ HALLAR LA VARIABILIDAD DEL FCLD } & \multirow[b]{2}{*}{2018} & 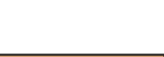 & \multirow{2}{*}{2020} & \multirow[b]{2}{*}{2021} & \multirow[b]{2}{*}{2022} \\
\hline & & 2019 & & & \\
\hline$V(F C t)=$ & $12,963,395.60$ & $18,002,343.09$ & $18,193,266.32$ & $19,711,724.96$ & $61,186,184.55$ \\
\hline & $3,600.47$ & $4,242.92$ & $4,265.36$ & $4,439.79$ & $7,822.16$ \\
\hline$\sigma(\mathrm{VPN})=$ & $19,311.84$ & & & & \\
\hline
\end{tabular}

HALLAR LA PROBABILIDAD

Basados en el análisis de escenarios, hallar la probabilidad de que el proyecto sea rentable.

$$
Z=\frac{V P N-E(V P N}{\sigma(V P N)}
$$

PROB. VPN $(\mathrm{fcdl})<0 \quad \mathrm{Z}(0)=\quad 0.02$

SEGÚN TABLA DE VALORES DE PROBABILIDAD ACUMULADA PARA LA DISTRIBUCION NORMAL ESTANDAR =

PROB. VPN(fcdl) $>0 \quad 49.2000 \%$

La probabilidad que el proyecto sea rentable es de $49.20 \%$
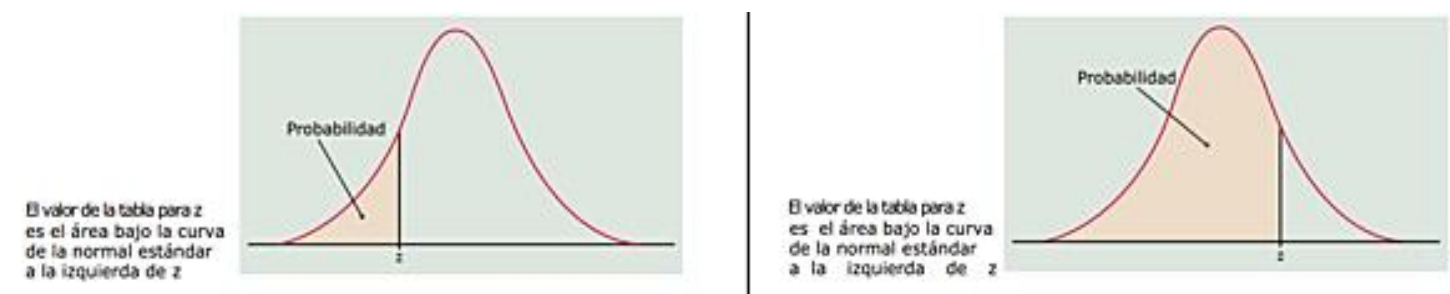

TABLA A: Probabilidades de la normal estándar

\begin{tabular}{|c|c|c|c|c|c|c|c|c|c|c|}
\hline 2 & $\infty$ & ot & $n z$ & as & st & es & $\omega$ & .07 & .as & $n$ \\
\hline 0.0 & 5000 & 5040 & 5 & 5520 & 516 & 5199 & 5239 & 5279 & 5319 & 53599 \\
\hline & s:s & $\begin{array}{l}3018 \\
5818\end{array}$ & (ST) & $\frac{5917}{3997}$ & 3597 & $\begin{array}{l}5506 \\
5987\end{array}$ & 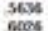 & 567 & 5714 & \\
\hline $\begin{array}{l}a_{02} \\
0.3\end{array}$ & 8179 & 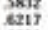 & cons & 6 & WHA & $\begin{array}{l}53887 \\
6506\end{array}$ & 6405 & 44 & test & 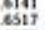 \\
\hline & 455 & 6 & 6028 & 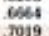 & $\begin{array}{l}6700 \\
704\end{array}$ & 5736 & 677 & 6500 & 6 & $\begin{array}{l}68797 \\
727\end{array}$ \\
\hline & .725 & $\frac{6950}{729}$ & Thes & .01937 & $\begin{array}{ll}7045 \\
7389\end{array}$ & 742 & 7 & 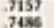 & $\begin{array}{l}7590 \\
7\end{array}$ & 7224 \\
\hline & 7850 & 7611 & .3642 & .797 & 7778 & $m 3$ & $7 \mathrm{~mA}$ & $m{ }^{2}$ & 7823 & 7852 \\
\hline$a x$ & 78 & 790 & 793 & T.756 & 723 & $\$ 23$ & Rodi & 8078 & 8106 & 813 \\
\hline & & & & & & & & & & 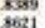 \\
\hline I & 8643 & sests & 8656 & 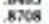 & 8789 & 870 & 870 & ; & $\$$ & 8010 \\
\hline & 8849 & 8589 & 8888 & $8 \times 07$ & 8925 & 894 & 8562 & 8980 & 8997 & Sols \\
\hline & & & sing & 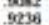 & 925 & 985 & 929 & $x_{90 \%}$ & 3,926 & $\begin{array}{r}1,77 \\
3_{319}\end{array}$ \\
\hline & 9302 & .9345 & 9357 & 9300 & 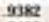 & 994 & 9406 & MAIS & 920 & SWA \\
\hline & 9428 & & & & & & & & 953 & 9515 \\
\hline & 36 & 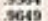 & 9656 & S & 9 & vin & 9 & 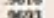 & 9 & 36 \\
\hline 1.9 & 9nis & 919 & 9786 & 972 & 978 & 974 & 9750 & 980 & 9र⿵冂卄 & $\xi_{N T H}$ \\
\hline 21 & 9772 & 9778 & 9783 & $978 x$ & 9798 & 9798 & gsems & 900 & 9812 & 9817 \\
\hline & & & & & & & & & & 380 \\
\hline 23 & 5871 & 5026 & sex & mol & not & mor & 9800 & का1 & 9013 & 2916 \\
\hline & & & 9022 & mins & & & & Sinz & 3034 & \\
\hline 8 & 9353 & 9955 & S9AS & 9957 & 9 & 9 & 9961 & $\$$ & 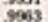 & . \\
\hline & 9095 & .9066 & .967 & 9088 & 9969 & 9 & 9971 & 9972 & 9973 & 927 \\
\hline 8 & 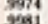 & 390 & 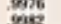 & $m_{m \rightarrow 3}$ & 997 & mit & 957 & $m$ & 8 & vas \\
\hline 10 & $9 \times 87$ & 5287 & $\operatorname{sas}$ & mas & mat & mo & 900 & 9 & $9 m 0$ & $m o$ \\
\hline & 983 & $9 m 3$ & .994 & . & 998 & 999 & 9984 & $m$ & toms & soms \\
\hline $\begin{array}{l}33 \\
34\end{array}$ & & m & 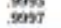 & $m$ & & $m$ & 9 & $m m$ & 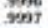 & $\begin{array}{l}m^{m} \\
y^{2}\end{array}$ \\
\hline
\end{tabular}




\subsubsection{Análisis de punto de equilibro}

\begin{tabular}{|c|c|c|c|c|c|}
\hline \multicolumn{6}{|c|}{ ANÁLISIS PUNTO DE EQUILIBRIO } \\
\hline Ingresos por Ventas & 112,005 & 107,147 & 103,281 & 98,793 & 93,706 \\
\hline Ganancia (Pérdida) Bruta & 39,668 & 39,202 & 38,939 & 38,688 & 38,471 \\
\hline Gastos de Ventas y Distribución & $-1,735$ & $-1,804$ & $-1,877$ & $-1,984$ & $-2,147$ \\
\hline Gastos de Administración & $-36,139$ & $-35,919$ & $-35,919$ & $-35,919$ & $-35,919$ \\
\hline Gasto de personal & $-24,663$ & $-24,663$ & $-24,663$ & $-24,663$ & $-24,663$ \\
\hline Gastos servicios tercerizados & $-2,400$ & $-2,400$ & $-2,400$ & $-2,400$ & $-2,400$ \\
\hline Otros gastos de Ventas & $-9,076$ & $-8,856$ & $-8,856$ & $-8,856$ & $-8,856$ \\
\hline Resultado antes de Impuesto a las Ganancias & 0 & 0 & 0 & 0 & 0 \\
\hline Utilidades al personal & - & - & - & - & - \\
\hline Impuesto a la renta & - & - & - & - & - \\
\hline Ganancia (Pérdida) Neta del Ejercicio & 0 & 0 & 0 & 0 & 0 \\
\hline
\end{tabular}

El punto de equilibrio en los primeros cinco años de nuestra empresa estará con un promedio de ventas anuales de S/.102 mil anuales, significativamente por debajo de las proyecciones de ventas.

\subsubsection{Principales riesgos del proyecto (cualitativos)}

De acuerdo al tipo de negocio en el que nos vamos a desenvolver, podemos afirmar que existe

\section{$\underline{\text { Riesgo de Mercado }}$}

Un riesgo relacionado al ingreso percibido por los consumidores. Cuando las condiciones económicas no son favorables, se refleja en menos consumo por parte de la población lo que conlleva a una reducción de nuestros ingresos.

\section{$\underline{\text { Riesgo Operacional }}$}

Nuestras operaciones comerciales se realizaran vía internet, por lo que todos nuestros procesos deben estar bien controlados. Una falla en nuestros sistemas nos puede generar pérdidas económicas.

Riesgo Reputacional:

Al trabajar con un canal digital, este debe operar de forma continua, las 24 horas del día, ya que, una falla ocasionara que nuestros clientes se lleven una mala imagen de nuestro negocio y puedan no confiar en nuestra página web para colocar sus datos y comprar. La sensibilidad de un proyecto por internet es alta. 


\section{Capítulo 8. Conclusiones}

\subsection{Conclusiones Generales}

- Kallpa textil es un modelo de negocio creativo e innovador se diferencia de la competencia, por su atención personalizada en la calidad de prendas y el servicio que ofrece.

La facilidad de contar con una app en una plataforma virtual ayudará a nuestros clientes minimizar el tiempo de compra de las prendas de vestir que necesitan, de esta manera desde la comodidad de su hogar podrán visualizar los modelos exclusivos que más le guste, además se le brinda el detalle de las tallas en un cuadro referencial con las medidas exactas, para que de esta manera no se equivoquen en pedir la talla que mejor le quede.

Se contará con los mejores diseñadores de ropa del mercado peruano creando una alianza estratégica con ellos, el cual hemos seleccionado cuidadosamente de acuerdo al perfil que solicitamos para la venta de prendas de ropa de vestir de modelos exclusivos y de alta calidad, dichos proveedores se encuentran ubicados en Lima Metropolitana y son egresados de las mejores escuelas de moda de Lima.

Nuestro modelo de negocio se enfocará en mantener a nuestros clientes totalmente satisfechos con un servicio de postventa, además de contar con una adecuada estrategia de marketing.

- Podemos concluir que nuestra hipótesis planteada en valida, ya que se han realizado y analizado distintas herramientas que comprueban que el proyecto empresarial cumple con los criterios de viabilidad tanto técnica como económica.

A través del Experiment Board comprobamos que las personas aprueban nuestra idea de negocio y una vez en el mercado ingresaran y realizaran compras validando la propuesta de valor que ofrece Kallpa Textil.

Asimismo, podemos afirmar que a través de las herramientas e indicadores financieros utilizados, nuestro proyecto es atractivo para los posibles inversionitas ya que nuestro COK es de $13.90 \%$ y la empresa tendría un VAN de 31,252 y una rentabilidad (TIR) de $42.79 \%$. 
Las barreras de entrada para este negocio no son altas, por ello, la empresa debe mantener siempre una adecuada gestión tanto en su plataforma virtual como en las alianzas estratégicas que tiene con los distintos diseñadores nacionales.

Nuestro proyecto resulta atractivo debido a que ofrecemos una plataforma en donde nuestros clientes podrán adquirir prendas de calidad desde la comodidad de su casa, tiempo que puede ser utilizado para otras actividades. Asimismo, nuestro proyecto impulsa un sector que ha sido desatendido y que hoy pasa por una crisis, queremos impulsar el sector, con herramientas acordes a los tiempos modernos, realizando alianzas estratégicas para dar a conocer los diseños de talentosos peruanos y eliminando costos que han reducido la rentabilidad de las empresas que operan en el sector.

\subsection{Conclusiones Individuales}

\section{PEDRO LUIS MERCADO ALVARADO - ADMINISTRACIÓN DE EMPRESAS}

Considero que los pilares mas importantes para poder lograr el exito de un negocio se basan en la calidad de servicio y producto que se ofrece en el caso de Kallpa Textil nos enfocamos en brindar un servicio personalizado y un producto novedoso que es elaborado por diseñadores peruanos lo cual vendria a ser parte de nuestro producto aumentado, entrando de esta forma mucho mas al detalle de la venta lo cual potencia nuestra interaccion con los clientes generando vinculos de confianza y fidelizacion algo que nuestra competencia no ofrece.

Otro aspecto positivo es que la denominacion como marca Kallpa Textil se encuentra en quechua y significa fuerza lo cual influye de cierta manera en la mente del consumidor objetivo, esta informacion sera fortalecida durante la puesta marcha del plan de marketing de la misma forma que nuestro fuerte servicio de post venta.

En lo que refiere a temas de rentabilidad y viabilidad de proyecto lo hemos evaluado bajos 3 escenarios pesimo, base y optimista en los cuales se ha podido encontrar que Kallpa Textil es viable inclusive situandose bajo su peor escenario brindandonos retorno al tercer año ademas la inversion de los accionistas es de un $30 \%$ la cual no es excesiva y un $70 \%$ financiado por el banco en este caso BBVA despues de realizar el respectivo analisis. Los flujos positivos son positivos mas no 
elevados generan de una manera adecuada disponibilidad de efectivo para cubrir gastos, tenemos ratios de liquidez en crecimiento desde el primer año todo esto debido a los bajos costos de nuestra propuesta. 


\section{BIBLIOGRAFIA}

Diario Gestión (2018) Perú Sector prendas de vestir se recuperará en el 2018 y crecería alrededor de 4\%. En Diario Gestión, 08 de enero, consultado junio, 18,2018. https://gestion.pe/economia/produce-sector-prendas-vestir-recuperara-2018creceria-alrededor-4-224404

Diario Gestión (2018) Riesgo país de Perú subió dos puntos básicos a 1.40 puntos porcentuales. En Diario Gestión, 25 de junio, consultado junio, 30,2018. https://gestion.pe/economia/riesgo-pais-peru-subio-dos-puntos-basicos-1-40puntos-porcentuales-236852

Emprendices (sf) "Ejemplo de un manual de organización de una empresa" consultado junio, 17, 2018, de https://www.emprendices.co/ejemplo-manual-organizacionuna-empresa/

Arellano Marketing Investigación y Consultoría (2017) Consultado mayo, 20, 2018, de http://www.arellanomarketing.com/inicio/

APEIM, (2016) Niveles Socioeconómicos 2016, Tomado enero, 18, 2017 de http://www.apeim.com.pe/wp-content/themes/apeim/docs/nse/APEIM-NSE2016.pdf

MEF, (2018) Principales calificaciones de riesgo soberano consultado mayo 20,2018 https://www.mef.gob.pe/es/principales-calificaciones-de-riesgo-soberano

Instituto Nacional de Estadística e Informática (2018). Menu recursivo de informe técnico $\mathrm{n}^{\circ} 2$ de PBI trimestral 2018. Consultado el 16 de mayo de 2018. Recuperado de https://www.inei.gob.pe/media/MenuRecursivo/boletines/02-informe-tecnicon02_pbi-trimestral_-itrim2018.

Datos Macro (2018) Bono de EEUU a 10 años. Consultado el 27 de mayo de 2018 de https://www.datosmacro.com/bono/usa

Diario Gestión (2018) Produce indica que el sector de prendas se recuperará en el 2018. En Diario Gestión, 08 de Enero, consultado junio, 30,2018. https://gestion.pe/economia/produce-sector-prendas-vestir-recuperara-2018creceria-alrededor-4-224404 